\title{
Erich Meuthen
}

\section{Charakter und Tendenzen des deutschen Humanismus*}

Gemeinsame Überlegungen zum Thema Renaissance-,Humanismus"1 haben immer noch eine vorgängige Verständigung über diesen Begriff nötig². Die intensive Klärung, die in den letzten Jahrzehnten vor allem Paul Oskar Kristeller herbeigeführt hat, ist weithin, wenngleich nicht kritiklos, anerkannt worden ${ }^{3}$. In Übereinstimmung mit dem Selbstverständnis des 15. und 16. Jahrhunderts ist demnach ein Humanist, wer den studia humanitatis obliegt, den fünf Wissenschaften der Grammatik, der Rhetorik, der Poetik ${ }^{4}$, der Geschichte und der Moralphilosophie ${ }^{5}$. Als Humaniora gelten sie, weil sie, wie z.B. Leonardo Bruni definierte, „den Menschen vervollkommnen und

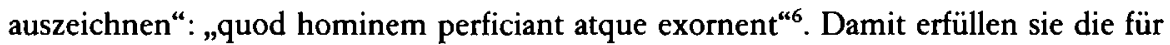
das Selbstverständnis des Humanismus grundlegende Bildungsaufgabe ${ }^{7}$. Sie sind in der Antike gepflegt worden, später aber untergegangen. Petrarca, so wiederum Bruni 1405 in seinem zweiten Dialog, habe sie als erster „erneuert“: „reparavit" ${ }^{\text {“8 }}$

Bekanntlich hat man im 19. und 20.Jahrhundert im weiteren Sinne unter Humanismus die Prägung des Menschen durch Übernahme antiker, als „klassisch“ aufgefaßter Idealität schlechthin verstehen wollen, die in neuer Form lebendig gemacht werden sollte; doch ist nach Kristeller ihr „Hauptanliegen in dem Studium und der Nachahmung der klassischen griechischen und lateinischen Literatur" innerhalb der genannten Fächer zu sehen'. Ich möchte Humanismus im folgenden als enge Verbindung dieser beiden Sachverhalte verstehen, als Rezeption der Antike ${ }^{10}$ im Rahmen der Humaniora, „Moralphilosophie“11 dabei aber recht weit gefaßt wissen als allgemeine (auch sozial wichtige) Lebensgestaltung ${ }^{12}$. Noch umfassendere, wenngleich oft sehr verschwommene „Humanismus“-Definitionen, die sich an den unterschiedlichsten Gesichtspunkten orientieren, darf unser Überblick allerdings nicht außer Betracht lassen, wenn er dem Gang der Forschung Rechnung tragen soll ${ }^{13}$.

Der Kreis der fünf studia humanitatis ist dabei in der Regel mehr oder weniger weit überschritten worden. Als Äußerung des deutschen Hochhumanismus ${ }^{14}$ am Ende des 15. und in den ersten Jahrzehnten des 16 . Jahrhunderts ${ }^{15}$ ist bisweilen jederart wissenschaftliche Bemühung, so vor allem auch "natur"wissenschaftliche (weithin eigentlich: naturphilosophische) mitbegriffen worden ${ }^{16}$ (Paracelsus, Agrippa von Nettesheim, Kopernikus). Obschon sie für das wissenschaftliche Gesamtbild gerade in Deutschland sehr charakteristisch war ${ }^{17}$, muß das „Human“ismusthema selbst doch in mancherlei

* Die Anmerkungen zu diesem Beitrag befinden sich auf S. $231 \mathrm{ff}$. 
Weise verunklärt werden, wenn man diesen Komplex so undifferenziert dem „Humanismus“ zuschlägt. Offenkundig fällt die damals überaus breitgestreute Neuerschließung antiker Quellen zur Naturlehre thematisch weitgehend aus dem Rahmen der studia humanitatis im soeben bestimmten Sinne ${ }^{18}$. Man könnte sich dahin verständigen, daß die Erschließung antiker Quellen jedweder Art, also auch naturwissenschaftlicher Schriften, vor allem als philologische Aufgabe, in der Tat „Humanismus“ ist ${ }^{19}$. Humanistisch gelebt zu werden nach den üblichen Anforderungen brauchte das Ergebnis dieser Quellenstudien demnach noch nicht, wozu sie auch nicht viel hergegeben hätten ${ }^{20}$. Allerdings sei generell betont, daß sich mit dem allgemeinen Vordringen des Humanismus eine entsprechende Ausweitung humanistischen Interesses verband, die nicht nur die Naturforschung, sondern auch andere Disziplinen wie die Jurisprudenz ergriff, ohne daß diese damit schon humanistische Disziplinen als solche geworden wären ${ }^{21}$.

Im Zusammenhang unseres Themas treten bei den naturinteressierten Bestrebungen zur Zeit des deutschen Hochhumanismus jedoch zwei für das damalige geistige Klima in ganz anderer Weise wichtige Sachverhalte hervor: Einerseits das Interesse am Dunklen, am Abyssus, am Dämonischen in der Natur; das ist eine weit verbreitete Tendenz der Renaissance-Naturwissenschaft ${ }^{22}$, die vielleicht auch mit dem Erlösungsdruck im religiösen Bereich ${ }^{23}$ zusammengebracht werden muß ${ }^{24}$. Andererseits die Tatsache wissenschaftlicher Aktivität und Vitalität überhaupt, die, wie auch im übrigen deutschen Hochhumanismus, so unterschiedlich die Zielsetzungen im einzelnen waren, in ihrer allgemein stimulierenden Wirkung eine gerade für Deutschland kaum abschätzbare Bedeutung gewann: Zum erstenmal seit langer Zeit gab es in Deutschland Wissenschaft in einer auf solche Weise unbekannten Ballung und im europäischen Vergleich durchaus führenden Bedeutung ${ }^{25}$, aber auch mit einer äußerst gesteigerten und oft überzogenen Selbsteinschātzung und Anspruchsforderung.

Diese Entwicklung erreichte ihre am meisten herausragenden, eigentlich „humanistischen" Ergebnisse wohl in der Geschichtswissenschaft; Namen wie Celtis, Wimpfeling, Beatus Rhenanus und Aventin sind hier nur anzutönen ${ }^{26}$, und man tut gut, gerade im Hinblick darauf soweit wie möglich am engeren Humanismusbegriff festzuhalten. Jedenfalls spielte aus dem „humanistischen“ Fächerkreis im besonderen die Geschichte $^{27}$ für die Aktivierung des deutschen Selbstbewußtseins eine nationalpsychologisch offenkundige, wenngleich im einzelnen nur schwer meßbare Rolle ${ }^{28}$.

Die begriffsdefinitorische Statuierung eines „hochhumanistischen“ Zeitabschnitts, wie er für die genannten Jahrzehnte des 15. und 16. Jahrhunderts in Anspruch genommen wird, lenkt zugleich auf ein anderes Grenzgebiet des Humanismus im eigentlichen Sinne, das für Deutschland in einem Maße wie sonst nirgendwo zum Problemfeld wurde: den Überschneidungs- und Deckungsbereich von Humanismus und Religion. Dieses Problemfeld hat zwei Aspekte, den chronologischen und den thematischen.

Zum ersten ${ }^{29}$. Dem Humanismus gehören ohne Zweifel dominierend jene Jahrzehnte deutscher Geistesgeschichte um 1500. Wohl sämtliche Darstellungen über diese Zeit suggerieren, daß nach 1520 die Epoche des Humanismus von der Reformation als dem für die deutsche Geschichte schlechthin bestimmenden Vorgang abgelöst wird: Humanismus und Reformation stellen demnach zwei einander folgende Ab- 
schnitte der deutschen Geschichte dar. Das - noch näher zu untersuchende - Verhältnis von Humanismus und Reformation ${ }^{30}$ ist in der Regel Thema der Reformations-, nicht der Humanismusgeschichte.

Der zweite Aspekt betrifft das innere Verhältnis von Humanismus und Reformation: Sind sie verwandt, etwa partiell identisch, oder haben sie nicht nur nichts miteinander gemein, sondern schließen sich gar einander aus? Sind zwischen diesen ÄuBerstpunkten vielleicht vermittelnde Interpretationen möglich? Die Verwandtschaft von Humanismus und Reformation hat man im wesentlichen in zweierlei Weise gesehen. Einerseits sind beide als Parallelentwicklungen auf dem Wege von mittelalterlicher Scholastik zu modernem Idealismus und Individualismus erschienen; ich nenne nur Wilhelm Dilthey ${ }^{31}$. Andererseits sollen die deutschen Humanisten insgesamt bereits eine „religiöse Renaissance“ repräsentieren, die der evangelischen Erneuerung voranging, wie es etwa der Titel des einschlägigen Buches von Lewis W. Spitz formuliert ${ }^{32}$, wenngleich er mit großem Nachdruck auf den tiefen Gegensatz dieser Religiosität zu Luthers Glaubensverständnis hinweist. Man kann es in diesem Zusammenhang mit einem "gespaltenen“ deutschen Humanismus versuchen, wie Paul Joachimsen, der in dem (anders als in Italien) grundsätzlich religiös-moralisch ausgerichteten deutschen Humanismus zwischen „romantischem“ und „aufklärerischem“ Humanismus unterschied ${ }^{33}$. Diese Interpretationen arbeiten allerdings oft unversehens mit einem weiteren Humanismusbegriff als dem vorhin definierten, wie es im Problemfeld Humanismus-Religion überhaupt recht regelmäßig der Fall ist ${ }^{34}$. Picos Philosophie der "hominis dignitas“ bietet ihm einen gern benutzten Definitionshintergrund ${ }^{35}$.

Doch gerade dann und um so mehr muß das Verhältnis von Humanismus und Reformation als problematisch erscheinen. Diese Problematik wurde von Gerhard Ritter, im übrigen nicht von ungefähr mit einem engeren Humanismusverständnis, in eine Art historischer Finalität gewendet, indem er das „Dazwischentreten“ der Reformation als entscheidende Fruchtbarmachung des Humanismus für die deutsche $\mathrm{Ge}$ schichte wertete ${ }^{36} .1959$ formulierte dann Bernd Moeller, und so wird es seither fast stereotyp wiederholt: „Ohne Humanismus keine Reformation" ${ }^{\text {"37 }}$. Aber auch diese griffige Formulierung besagt keine Identität der beiden Sachverhalte, wenngleich sie oft in dieser Weise mißverstanden worden ist. Sie bezeichnet eindeutig das erste nur als Bedingung des zweiten und betont, geschichtlich gesehen, vor allem das Situationale des Zusammentreffens von Humanismus und Reformation 1517/18, dem das substantiell Wesensgegensätzliche von lutherischer Theologie und humanistischer Lebenswelt gegenübersteht. Wir werden daran anknüpfen, müssen aber zunächst einen Bogen über die Entwicklung des Humanismus insgesamt zurückschlagen. Dies aus folgendem Grunde:

Den Interpretationen des Themas Humanismus-Reformation, die hier genannt wurden, ist gemeinsam, daß der Humanismus für die deutsche Geschichte nur sekundäre Bedeutung hat und, etwa in seinem Bedingungscharakter, dem eigentlich Wichtigen, nämlich der Reformation unterzuordnen ist. Dieser Bedeutungsunterschied dürfte im Rahmen der deutschen Geschichte unbestreitbar sein. Gleichwohl ist auch die deutsche Geschichte nur Teil der europäischen, und die deutsche Geschichtswissenschaft tut gut daran, die deutsche Entwicklung in den europäischen Rahmen zu 
stellen. Indem ich mir diese Forderung zu eigen mache, versuche ich, das „deutsche“ Thema in seinen größeren Zusammenhängen aufzuschließen.

Abgesehen von Randerscheinungen wie Pomponius Laetus kennt Italien, das Mutterland des Humanismus, zunächst (das heißt: vor dem Ausbruch des konfessionellen Zeitalters) kein Problemfeld Humanismus-Religion ${ }^{38}$. Problematisch entwickeln sich hier gerade die nicht-humanistischen Disziplinen, etwa der naturphilosophische Averroismus $^{39}$. Und im besonderen italienische Kirchenkritiker sind voller Lob für die humanistischen, künstlerischen und allgemein kulturellen Interessen im kirchlichen Bereich $^{40}$.

Der Renaissance-Humanismus war seinem Wesen nach religiös indifferent ${ }^{41}$. Da die von ihm wiederentdeckte Antike sowohl heidnische als auch christliche Autoren umschloß, bestand natürlich eine gewisse Ambivalenz $z^{42}$; doch entscheidend war, daß es primär um die Freilegung der antiken Literatur und ihrer Vorbildlichkeit als solcher ging. So läßt sich das heidnische Element in der Antikerezeption gewiß nicht übersehen. Die je nach Standort beeindruckende oder schockierende Offenheit gerade italienischer Christlichkeit hat es aber vermocht, in einer regelrecht eleganten Weise die neuerschlossene Antikität zu assimilieren - gewiß, nicht in theologischer Auseinandersetzung, dafür aber in äußerlicher, stilvoller und anschauungskräftiger Gestaltgebung $^{43}$.

Wenn man deshalb sagen kann, dies geschah im Vergleich zur Aristotelesbewältigung der hochmittelalterlichen Scholastik in vielleicht oberflächlicherer Aneignung, so ergibt sich daraus zugleich, daß der Humanismus für das Renaissance-Christentum viel disparater, viel weniger provokativ wirkte (wenn überhaupt) als im Hochmittelalter der arabisierte Aristotelismus. Es wäre dann aber auch von der Gegenseite aus prinzipiell falsch, über Pastors und Janssens gute und schlechte, lies: christliche und heidnische Humanisten ${ }^{44}$ hinaus Giuseppe Toffanin auf der Einbahnstraße einer rein religiösen Humanismusinterpretation $\mathrm{zu}_{\text {folgen }}{ }^{45}$ : Seinem Selbstverständnis nach hatte der Humanismus allenfalls virtuell mit dem Christentum zu tun ${ }^{46}$, doch mußte er sich bei seiner Realisierung (und vor allem in der dadurch mitbestimmten Zielsetzung) der geschichtlichen Umwelt einordnen, die christlich war. Jedenfalls haben mehr als 100 Jahre fruchtbarer italienischer studia humanitatis weder zu einer wesentlichen Aktualisierung theologischer Fragen noch zu ernsthafter kritischer Bedrängung der kirchlichen Institutionen geführt ${ }^{47}$. Gerade dieses zweite bildet bekanntlich ein Charakteristikum des deutschen Humanismus.

Der Begriff "christlicher Humanismus“ bezeichnet indessen wohl etwas Bestimmteres als die Assimilierung, von der soeben die Rede war. Die Definitionsschwierigkeit ist als solche nicht geringer als beim Humanismusbegriff, wenn man einmal Revue passieren läßt, was alles mit dem Etikett „christlicher Humanismus“ versehen worden ist. Oft hat man den Eindruck, er besage nicht mehr als ein gutes und wahres Christentum. Greifen wir auf unsere einleitende Begriffsbestimmung zurück, so bedeutet „christlicher Humanismus“ die Gestaltung christlichen Lebens aus einer von der antik-christlichen Literatur gebotenen Vorbildlichkeit heraus ${ }^{48}$, wenn man es nicht gar bei der entsprechenden literarisch-intellektuellen Bildung bewenden lassen will. Die von IJsewijn eingeführte Unterscheidung von christlichen Humanisten und humani- 
stischen Christen scheint mir da recht hilfreich zu sein ${ }^{49}$. Man spricht recht gängig auch von „biblischen Humanisten“; doch fürchte ich, daß die Formulierung den Humanismusbegriff problematisch macht, wenn er in diesem Zusammenhang nicht ganz genau bestimmt wird ${ }^{50}$.

Der christliche Humanismus ist eine gesamteuropäische Erscheinung ${ }^{51}$, wenngleich Schwerpunkte deutlich sind, wie der französische ${ }^{52}$ und der niederländische ${ }^{53}$; Lefèvre d'Étaples $^{54}$ und Erasmus ${ }^{55}$ sind die herausragenden Vertreter. Der niederländische Humanismus lenkt direkt zu unserem Thema hin: Man wird den oberdeutschen Humanismus wohl nicht in derart selbstverständlicher Weise als „christlichen Humanismus" bezeichnen wollen, ohne natürlich seine auch hier recht starke Verwurzelung im kirchlichen Bereich zu übersehen ${ }^{56}$.

Zwei Gestaltungskräfte vereinigen sich im christlichen Humanismus der Niederlande: die philologisch fundierte Gelehrsamkeit ${ }^{57}$ und eine an der Vita evangelica ausgerichtete religiöse Praxis. Eben diese hatte hier als Devotio moderna eine schon über 100jährige Tradition hinter sich, die in Oberdeutschland fehlte. Eine Differenzierung solcher Art erscheint mir nicht unwichtig ${ }^{58}$. Das von Spitz gezeichnete Gesamtbild des "religiösen“ deutschen Humanismus führt zwanglos in eben diese Richtung, wenngleich die Differenzierung in seinem Schlußergebnis dann nicht mehr hervortritt ${ }^{59}$. Möglicherweise wirkt sich auch zu Beginn des 16.Jahrhunderts der frömmigkeitsgeschichtliche Vorsprung der Niederlande immer noch aus.

Die Devotio moderna als solche hatte mit den Humaniora nichts zu tun. Es ist das Verdienst von Post, den zunächst ganz und gar religiösen Charakter dieser Bewegung herausgearbeitet zu haben, wenngleich dann bei ihrer Weiterentwicklung auch Bildung und Schule immer kennzeichnender wurden ${ }^{60}$. Die Devoten lebten vor allem im Protest gegen die Überintellektualisierung der Spätscholastik, der sie Verdunkelung der eigentlichen und einfachen Schriftoffenbarung zum Vorwurf machten. Eine Periode höchster interpretativer Abstraktion, wie sie der scholastische Lehrbetrieb gezüchtet hatte, schlug um in den direkten Rückgriff auf den Text: Tolle, lege! Auf diese Weise bestand allerdings grundlegende Affinität zur humanistischen Textwissenschaft. Mit dieser verband sich nun eine Lebensform, die ihrerseits 100 Jahre auf solche wissenschaftliche Prägung hatte warten müssen. Wie intensiv die Verbindung dann war, bleibe offen. Daß von den Spannungen, aus denen die deutsche Reformation emporschoß, hier vieles evolutionär entschärft war, ist aber unbestreitbar. Nicht zuletzt standen sich Devotio moderna und Humanismus in ihrer Betonung der Praxis und ihrer au fond pädagogischen Ausrichtung nahe, wenngleich sie sich nach Herkunft und Zielsetzung wesentlich unterschieden, da der Humanismus nicht die christliche Grundsätzlichkeit kannte, die für die Devoten substantiell war.

Im Unterschied zu Deutschland hatte die Anti-Scholastik in Italien einen zusätzlichen nationalen Akzent; sie galt in starkem Maße als Sache der Ultramontanen ${ }^{61}$, der allgemein verhaßten fremden Barbaren, der „Goten“. Im übrigen hatte eine lange mittelalterliche Traditionslinie die humanistischen Fächer an den italienischen Universitäten organischer zur Entfaltung kommen lassen ${ }^{62}$, als dies in Deutschland der Fall war. Daß der Humanismus dabei stets auch der scholastischen Tradition verpflichtet blieb, ist in der heutigen Forschung unbestritten ${ }^{63}$. Ein wichtiger Unterschied zu 
Deutschland bestand darin, daß die Universitätstheologie in Italien nur eine geringe Rolle spielte. Das Artes-Studium lenkte, wenn man schon weiterstudierte, nicht so sehr zur Theologie hin. Viele Humanisten wandten sich der Medizin $z^{63 a}{ }^{63}$. Damit entfielen konfliktreiche Konsequenzen, die sich aus der Ablehnung der Scholastik für den Theologen zwangsläufig ergeben mußten.

Wie in Deutschland gab es freilich auch in Italien vor allem den außeruniversitären Humanismus. Die maßgeblichen Anstöße kamen nicht so sehr aus der Welt der Fachgelehrsamkeit. Die entsprechenden Trivialfächer boten jedoch ein gutes organisatorisches Auffangbecken. Der Humanismus füllte in einer methodisch neuen und von einem ebenso neuen Stoffinteresse bestimmten Weise ein für Italien damals offenkundiges Bildungsvakuum. Wie in nicht unähnlicher Dynamik die Bildende Kunst, drang der Humanismus in einen Leerraum ein und bot der wirtschaftlich erfolgreichen Stadtstaatgesellschaft das Äquivalent geistiger Entfaltung.

Diese organische Entwicklung fehlte dem nördlichen Humanismus. Davon abgesehen, daß er importiert wurde, stieß er im religiösen Bereich in eine durch Spannungen problematisierte Situation hinein, die seine antischolastischen Tendenzen auch emotional noch weiter aufluden. Man hat die Bedeutung dieser Spannungen als üblichen Streit der Disziplinen bagatellisieren wollen, auf die auch dem Humanismus immanenten scholastischen Elemente hingewiesen ${ }^{64}$. Der Wechsel von scholastischen zu neuen humanistischen Lehrbüchern auf den deutschen Universitäten ${ }^{65}$ zeigt jedoch eine Auseinandersetzung an, die eindeutig tiefer reichte ${ }^{66}$. Viel stärker als in Italien war der Humanismus hier auf Kampf eingestellt, forderte er programmatisch und engagiert, die Bildungssituation zu wenden, fühlte er sich als elitäre Minorität, während sich die italienischen Humanisten in ihrer historischen Reflexion stärker als Teil einer gleichsam naturhaften Entwicklung verstanden ${ }^{67}$.

Eine nicht unwichtige differenzierende Bedingung dürfte in Deutschland, im besonderen in Oberdeutschland hinzugekommen sein. Mit einer Verspätung von zwei bis drei Jahrhunderten holte Deutschland den Versuch bodenständiger, nicht in Paris oder in Bologna und Padua einzukaufender Wissenschaftlichkeit nach. Gleichwohl blieb Oberdeutschland, abgesehen von dem Sonderfall Heidelberg, bis zur zweiten Hälfte des 15. Jahrhunderts ein universitätsleerer Raum. Hier wie überall in Mitteleuropa nahm die Breitenbildung, nun auch die Laien ergreifend, immer mehr zu. Lebten die süddeutschen Reichsstädte ${ }^{68}$ mit ihrer spektakulären wirtschaftlichen Entwicklung ${ }^{69}$ nicht in einer bildungsgeschichtlichen Anspruchssituation ${ }^{70}$, die der älteren italienischen vergleichbar war $^{71}$ und gerade auch Mitglieder der politischen Führungsschichten wissenschaftlich interessiert oder gar ambitioniert werden lie $\beta^{72}$ ?

Bezeichnenderweise drängte sich über die Hälfte der Universitätsneugründungen zwischen 1450 und 1500 in dichter zeitlicher Folge und räumlicher Konzentration in Oberdeutschland. Sehen wir von Mitteldeutschland $\mathrm{ab}^{73}$, so war es gerade hier, wo sich mit dem Humanismus in einem schon ohnehin immer breiteren Bildungsinteresse nun ein ganz neues Bildungsideal Bahn brach ${ }^{74}$, das den Vorzug hatte, anders als die traditionelle Schulbildung zu sein, und ein Selbstbewußtsein gab ${ }^{75}$, das gerade Neugebildeten eigen ist. Mit den Universitätsgründungen war aber auch das fürstliche Bildungsinteresse und (vielleicht viel wichtiger:) Bildungsprestige verbunden ${ }^{76}$. Der 
Hofhumanismus konzentrierte sich ebenfalls sehr stark auf den mittel- und süddeutschen Raum ${ }^{77}$. Ist das vor einiger Zeit noch stark vom reichsstädtischen Bürgertum bestimmte Bild des deutschen Humanismus in der jüngsten Forschung wieder ständisch diffuser geworden ${ }^{78}$, so scheint sich die räumliche Abgrenzung um so mehr bestātigt zu haben ${ }^{79}$.

Insgesamt beherrschte alle diese neuen Gebildeten die Überzeugung, daß eine deutsche Bildungsepoché Wirklichkeit wurde, wie sie Konrad Celtis in seiner berühmten Ingolstädter Rede 1492 ins Wort brachte ${ }^{80}$ und etwa des Trithemius "Catalogus illustrium virorum Germaniae“ mit nationalgeschichtlicher Dimension versah ${ }^{81}$. Und was die Humanisten zunächst einhellig an Luther rühmend bewunderten, war seine Gelehrtheit, nicht seine Lehre ${ }^{82}$. Das epochale Selbstverstāndnis ${ }^{83}$ war dem Humanismus zwar allgemein; 1469 formulierte aus eben diesem Selbstbewußtsein heraus der $\mathrm{Hu}-$ manist Giovanni Andrea Bussi die neue triadische Geschichtsgliederung von alter, mittlerer und - jetzt einsetzender - neuer Zeit. Doch nördlich der Alpen erhielt es mit der nationalen Akzentuierung eine zusätzliche Dynamik. War nicht gerade für Deutschland eine neue Epoche angebrochen?

Dieses Selbstbewußtsein der humanistischen Gelehrten mußte in einer Zeit, die durch den Buchdruck ${ }^{85}$ und mannigfache Kommunikationsmöglichkeit erst so etwas wie allgemeine Öffentlichkeit erhielt ${ }^{86}$, über kurz oder lang sozialpsychologische Konsequenzen haben, zumal - wie schon gesagt - die Breitenbildung, das Bildungsinteresse überhaupt immer mehr zunahmen ${ }^{87}$. Andererseits dürfte intellektuell höchst anfordernde Abstraktion, wie sie die Spätscholastik betrieb, gerade dort an Verständnisgrenzen gestoßen $\operatorname{sein}^{88}$. Wesentlich und willkommen war, daß mit der neuen literarischen Sprachbildung ${ }^{89}$ nun eine wirkungsvolle Alternative zu jener rationalen Spekulation angeboten wurde, deren man weithin überdrüssig war. Doch mußte man in Deutschland naturgemäß unter dem Bewußtsein leiden, Importware zu nutzen ${ }^{90}$, und war sich wohl über die ganz und gar negative Bewertung der Deutschen bei den Italienern $^{91}$ im klaren ${ }^{92}$. Vielleicht erklärt sich auch so die nachdrückliche Betonung der humanistischen Eigenbedeutung ${ }^{93}$, die in der Umformung des allgemeinen geschichtlichen Interesses der Humanisten in das nationalgeschichtliche deutsche zum Ausdruck kommt ${ }^{94}$, wie etwa im allgemeinen Germanenkult ${ }^{95}$ oder $z$.B. in der Planung einer „Germania illustrata“ durch Konrad Celtis"

Was aber wichtiger zu sein scheint als dieses nationalgeschichtliche Sonderphänomen, ist eben jener selbstbewußte Elan, den der deutsche Humanismus in die damalige deutsche Situation eingebracht hat ${ }^{97}$. Gewiß wurde dieser Optimismus durch Luthers eschatologische Zeitinterpretation erheblich belastet, bzw. durch die Geschichtslosigkeit seiner Theologie ${ }^{98}$ überhaupt entwertet. Aber die Dynamik der deutschen Humanisten trug die Reformation darüber gleichsam hinweg99. Der niederländische Humanismus stand dieser speziell deutschen Aufbruchsituation so fern, daß sie für ihn kaum je motivierend werden konnte. Die kulturelle und politische Situation der Niederlande im europäischen Großraum prädisponierte ihn viel stärker für jenen Kosmopolitismus, der in Erasmus seine Ausprägung fand ${ }^{100}$.

Daß die Reformation Produkt einer großen Zeitkrise gewesen sei, wird man dem heutigen Forschungsstande nach nur sehr differenzierend vertreten können ${ }^{101}$. Die 
einzelnen Lebenskreise dürften hier stärker zu unterscheiden sein. Vor dem Hintergrund des gerade in Deutschland so lebendigen humanistischen Aufschwungs ${ }^{102}$ stimmt es sicher nicht ${ }^{103}$. Aber man wird für Deutschland doch von einer spannungsgeladenen Situation sprechen können. Die eigentlich kritischen Jahre kamen allerdings schon bald nicht zuletzt deshalb, weil der Optimismus in der geschichtlichen Wirklichkeit nicht einlösbar war. Auch der Humanismus mußte sich ihr entsprechend allmählich in einer au fond anderen, nämlich in einer religiösen Welt einrichten.

Wenn der deutsche Humanismus als bedingendes Moment in die Reformationsgeschichte integriert wird, ist in der Regel von der kritischen humanistischen Textexegese die Rede ${ }^{104}$, von der literarischen Bildung im weitesten Sinne, die gerade den christlichen Humanismus als Vorstufe der Reformation erscheinen lassen müssen ${ }^{105}$. Die in andere Richtung zielenden Hinweise, wie ich sie hier versucht habe ${ }^{106}$, beabsichtigen in keiner Weise, die in strengerem und engerem Sinne „humanistische“ Entwicklung in ihrer Bedeutung für die Reformation beiseitezuschieben oder zu mindern, und das Problemfeld Humanismus-Reformation darf gewiß nicht darauf reduziert werden. Aber nur so, aus der Kombination von literarischem Engagement und bildungsgeschichtlicher Erwartung heraus wird die allgemeine Enttäuschung verständlich, daß ausgerechnet Erasmus sich der Reformation versagte ${ }^{107}$.

$\mathrm{Daß}$ sich gleichwohl viele Reformatoren als Erasmianer ansahen ${ }^{\mathbf{1 0 8}}$, wird davon nicht berührt; denn sie waren ja weitgehend zugleich Humanisten. Offensichtlich gab es bei allen Übereinstimmungen aber dennoch keine Notwendigkeit zum Ủbertritt, wie sich ja insbesondere ältere deutsche Humanisten gegen Luther oder mindestens doch nicht für ihn entschieden haben ${ }^{109}$. Wenn hier ein Generationsproblem vorliegt ${ }^{110}$, so besagt auch dies, daß ein mit dem Selbstverständnis ${ }^{111}$ der deutschen Humanisten verbundener psychologischer Effekt ${ }^{112}$ wirkte, der jene Jüngeren mitriß ${ }^{113}$. Nun war es Sache der kühleren und klügeren Köpfe unter ihnen, im besonderen Melanchthons ${ }^{114}$, dieses „produktive Mißverständnis“, wie Moeller es nennt ${ }^{115}$, nachträglich aufzuarbeiten ${ }^{116}$, daß ein religiöser und ein Bildungsumbruch, zweierlei zum Teil sehr disparate Prozesse, in einem „ungleichen Bündnis“ zusammenschossen.

Auf das Verhältnis Luthers zum Humanismus kann ich hier nicht eingehen. Die Lutherforschung urteilt darüber zurückhaltend ${ }^{17}$. Andererseits betrifft Moellers Formulierung offensichtlich nur den in der genannten Weise situationell bestimmten, spezifisch deutschen Humanismus in den ersten Jahrzehnten des 16. Jahrhunderts. Als europäisches Phänomen weigert sich der Humanismus ganz entschieden, in solcher Engführung und Schwergewichtung ausschließlich für die deutsche Reformationsgeschichte thematisiert zu werden; denn dafür blühte er zu kräftig auch in allen Ländern, die bei der alten Religion blieben. In Alcalá, wo an der von Kardinal Ximenes gegründeten Universität die Complutenser Polyglotte entstand ${ }^{118}$, führten humanistische Studien zu keinerlei reformatorischen Konsequenzen ${ }^{119}$. Auch nicht der Einfluß der Devotio moderna; bekanntlich entstand auf Veranlassung des Kardinals eine katalanische Übersetzung der ,Nachfolge Christi', und das ,Exercitatorium spirituale* seines Neffen García steht ganz in der Tradition der Devotio. Auf der anderen Seite täte die Reduzierung der Reformation auf ihren humanistischen Zusammenhang ihr ebenso offensichtlich Unrecht, so daß man nach all dem, was ausgeführt wurde, doch 
wohl genauer sagen müßte (und ich glaube, das wäre auch im Sinne Moellers): „Ohne Humanismus (und zwar in seiner deutschen Situation und Ausprägung) auch keine Reformation."

Der Fortgang unserer Untersuchung ist damit vorgezeichnet. Sie hat das problematische Verhältnis von Reformation und Humanismus zu berücksichtigen. Andererseits ist aber auch der Entwicklung des Humanismus im Verhältnis zur religiösen Entwicklung in Europa insgesamt nachzugehen. Wenn wir aber, wie geschehen, dem Humanismus einen vom Christentum unabhängigen Selbststand zusprechen, wird darüber hinaus jedoch nicht minder auf seine Bedeutung für die europäische Geistesgeschichte als solche hinzuweisen sein.

Man mag über die Erfolgsgründe der deutschen Reformation mancherlei vorbringen, vom materiellen Kalkül der säkularisierenden ${ }^{120}$ Fürsten bis zur theologischen Notwendigkeit; eines dürfte in diesem Spektrum unbestritten sein: Ohne den Zutritt breiterer, selbstbewußter Bildungsschichten hätte es gewiß nicht zu einer solchen religiösen Bewegung kommen können. Dazu bedurfte es vor allem eines theologisch interessierten Bildungsreservoirs. Als der Humanismus in die deutschen Reichsstädte eindrang, hatte sich daś religiöse Bildungsinteresse, wie etwa die Einrichtung städtischer Prädikaturen zeigt ${ }^{121}$, schon ohne ihn auf breiter Front entwickelt. Wenn es die damals in neuer Weise bildungsbestimmende Kraft des Humanismus in sich einformte, so ist das eine andere Sache. Auch die Reformation versuchte, diese Bildungsmacht zu integrieren, wie das die Kirche in Italien schon seit über 100 Jahren erfolgreich und zunächst viel problemloser praktiziert hatte ${ }^{122}$. Es war unumgänglich, den Humanismus aufzunehmen, wenn man die geistigen Führungsschichten ${ }^{123}$ längerfristig halten wollte.

Zudem wurde recht bald klar, wer hier der Stärkere war, wer hier wem zu Diensten stand. Die religiöse Bewegung dominierte, und schon rasch akzeptierte Luther den Nutzen, den ein intensives Studium der Humaniora ${ }^{124}$, insbesondere der Grammatik, für die Ausbildung evangelischer Führungskräfte ${ }^{125}$, jedoch kaum für die christliche Schule schlechthin haben konnte ${ }^{126}$. Unterschiede im humanistischen Ansatz, wie sie zwischen Luther und Zwingli ${ }^{127}$ und den entsprechenden Kirchen- und Konfessionsformen bestanden, worauf hier nur am Rande verwiesen werden kann, nivellierten sich in der religiösen Bildungspraxis des 16. Jahrhunderts.

Nicht zuletzt jedoch: Das alles war nichts spezifisch Protestantisches. Maßgebliche katholische Gegner in der damaligen deutschen Bildungswelt hat man als nicht weniger engagierte Humanisten anzusehen ${ }^{128}$. Die erste Tagungsperiode des Konzils von Trient ${ }^{129}$ bezeugt die breit entwickelte humanistische Bildung in der kirchlichen Führungsschicht; nur genannt seien die Konzilslegaten Cervini und Pole, ferner Seripando und Sadoleto, sowie im Vorfeld von Trient vor allem Contarini.

Úbereinstimmend mit dem protestantischen Raum auch hier die intensive Verschulung des Humanismus. Bekanntlich nahm die Ratio studiorum ${ }^{130}$, die in der zweiten Jahrhunderthälfte entwickelte Erziehungsordnung der Jesuiten, die Humaniora sehr dezidiert in ihr Bildungsprogramm auf, und wenn ich recht sehe, ist außerhalb der angelsächsischen Bildungswelt ${ }^{131}$ die Rhetorik nirgendwo solange und so nachdrücklich gepflegt worden wie in den Schulen der Jesuiten ${ }^{132}$. Deren Bedeutung 
für die deutsche Bildungsgeschichte ist in der Forschung hinter dem protestantischen Schulhumanismus sicher zu stark zurückgetreten ${ }^{133}$. Gregor von Valencia, der in Deutschland führende Jesuitentheologe seiner Zeit, 1575-1597 Professor in Ingolstadt, früher nur als Scholastiker gesehen, verbindet aufs engste Scholastik und Humanismus ${ }^{134}$

Bei der Verschulung ${ }^{135}$ handelt es sich also um eine gesamteuropäische Entwicklung des Humanismus. Vielleicht ist sie wichtiger als die von der Forschung mannigfach diskutierte Frage nach der Stellung der Humanisten in und zu den Universitä$\operatorname{ten}^{136}$, mit der sie freilich, wie sich gleich zeigen wird, zusammenhängt. Die von Land zu Land, ja, von Universität zu Universität deutlichen Unterschiede können hier ebensowenig näher behandelt werden wie das doch allenthalben offenkundige, teils organische, teils konfliktreiche Eindringen des Humanismus in die Universitäten ${ }^{137}$. Für die Weiterentwicklung der europäischen Bildung wichtig wurde die Konzentration der studia humanitatis in neuen Schultypen wie Gymnasien und Kollegien ${ }^{138}$, deren Verhältnis zu den Universitäten im übrigen recht ambivalent war ${ }^{139}$. Diese Pädagogisierung des Humanismus ${ }^{\mathbf{1 4 0}}$ ist übrigens von seinen ureigenen Bildungszielen aus gesehen gar nicht so überraschend, da er ja von Anfang an grundsätzlich pädagogisch orientiert war ${ }^{141}$.

Mit dem Begriff "Verschulung" verbinden sich zwar in der Regel negative Vorstellungen. Es ergeben sich jedoch zweierlei recht unterschiedliche Tendenzen:

Die eine, negative, äußert sich seit der zweiten Hälfte des 16.Jahrhunderts in Klagen über die Abdrängung der studia humanitatis ins Mediokre ${ }^{162}$, ins gesamtgesellschaftlich gesehen Unerhebliche, zugleich mit einem pessimistischen Grundton, der aber als solcher wieder allgemein europäischen Charakter hat. Auf der anderen Seite wird mit dem Vorwurf des Pedantismus die Schuld dem inneren Sterilwerden humanistischer Bildung zugeschoben ${ }^{143}$.

Man hat für diese Entwicklung sicher mehrerlei zu berücksichtigen. Zunächst und das ist ein grundlegender geschichtlicher Sachverhalt: Es handelt sich um ein insgesamt ausgesprochen religiöses und von theologischen Fragen bestimmtes Jahrhundert. Man mag darüber nachdenken, ob und wieweit diese Grundstimmung den Konfessionalismus überhaupt erst hervorgebracht hat, ob das nicht eine seiner Grundbedingungen, vielleicht sogar -ursachen (natürlich neben anderen) gewesen ist. Als er dank Luther nun einmal da war ${ }^{144}$, hat er den theologischen Elan gesamteuropäisch enorm verstärkt, und nicht zuletzt dadurch ist die deutsche Reformation ein Ereignis von europäischer Bedeutung geworden. Für den europäischen Humanismus hieß das aber: Im Unterschied zu seiner Entfaltung in einer theologisch weniger geprägten Umwelt, wie sie das italienische Quattrocento bot, mußte er sich dem ihm überlegenen religiösen Interesse der neuen Zeit ${ }^{145}$ viel stärker ein- und unterordnen ${ }^{146}$. Möglicherweise ist unter diesem Aspekt gar zu fragen, wieweit die Konfessionalisierung geradezu einen konkurrenzbedingten Bildungszwang ${ }^{167}$ mit ganz unbeabsichtigten Förderungshilfen für den Humanismus zur Folge hatte und auf diese Weise im besonderen dem humanistischen Schulwesen Impulse $\mathrm{gab}^{148}$. Um so mehr wurde der Gymnasialhumanismus zu einer den gebildeten Europäer gleich welcher Konfession allgemein prägenden Formung ${ }^{149}$. 
Und von hier aus nun das zweite, Positive des Schulhumanismus: Diese allgemeinbildende Funktion bot enorme Einflußmöglichkeiten innerhalb einer Gesellschaft, die wie nie zuvor auf Bildung aus war. Mit welchem Widerwillen die Führungsschichten in ihrer Jugend wohl zu allen Zeiten Grammatik gepaukt haben, so blieben nicht nur die Merkschemata, sondern auch die antiken Stoffe und Ausdrucksformen lebenslängliches Bildungsgut ${ }^{150}$. Es gehörte zum standesgemäßen Renommee, nicht zuletzt aber auch über das Bürgertum hinaus, in der antiken Mythologie ${ }^{151}$ nicht ganz unerfahren zu sein, antike Literatur zu kennen. Die sich seit dem späteren 16. Jahrhundert ab-

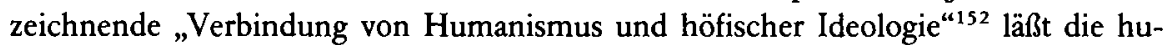
manistische Bildung dann aber nicht bloß „Bildungströdel“153 sein. Doch auch schon Celtis überschrieb in seiner ,Ars versificandi' ein Kapitel: „Quare et qui poetae a nobilibus legi debeant ${ }^{\text {“154 }}$.

Jedenfalls wird Europa seit dem 16. Jahrhundert in Kunst und Literatur mit antiken Göttern geradezu überschwemmt. Dieser Einbruch des Heidentums in das christliche Europa fand natürlich auch Kritik, wurde aber allmählich zu einer Selbstverständlichkeit $^{155}$. Die Koexistenz ${ }^{156}$ war jedoch nur deshalb möglich, weil die Antike einer literarischen Welt angehörte, die nicht die allgemeinverbindliche Alltagswelt war ${ }^{157}$. Gleichwohl fällt auf, wie stark kirchlicherseits durch die Pflege antik-christlicher Stoffe bzw. durch Verchristlichung antik-heidnischer Formen und Vorlagen die hier erkannte Diskrepanz zwischen beiden Welten überbrückt werden sollte ${ }^{158}$. Doch trotz allem ist die völlige Integration des Humanismus in das christliche Europa sicher nicht geglückt. Es stehe dahin, welche Rolle dabei die speziell dem 16.Jahrhundert eigene religiöse Dynamik gespielt hat oder wieweit sich hier substantiell Unvereinbares begegnete, das in allen Konfessionen zu spannungsvollem Austrag führen mußte. Es wäre entschiedener komparatistischer Untersuchung wert, wie sich Humanismus und Religion in den jeweiligen kirchlichen Situationen Europas zu bestimmten Problemen solcher Art verhalten haben.

In diesem Zusammenhang traten nun immer deutlicher zwei sehr unterschiedliche Aspekte des Humanismus auseinander, die freilich schon in das vorkonfessionelle Zeitalter zurückreichten, dort aber etwas anders gelagert sowie - was wichtiger ist nicht so scharf getrennt waren ${ }^{159}$. Auf der einen Seite führte die praktisch-moralische Lebensphilosophie des Humanismus zu immer deutlicheren religiösen Grundpositionen, ein Vorgang, der vom religiösen Engagement des 16.Jahrhunderts her fast zwangsläufig war. Von solchen Grundpositionen aus tendierten diese christlichen Humanisten im Konfessionsstreit zur Vermittlung ${ }^{160}$ oder zu einer allgemein-christlichen, dogmatisch offeneren Überkonfession ${ }^{161}$.

Auf der anderen Seite verwissenschaftlichte der Humanismus noch mehr und entzog sich mit dieser Tendenz, wenngleich das nicht immer möglich war, der religiösen Problematik. Zugleich konnte er auf solche Weise, als Schulhumanismus vulgarisiert, auch im Bildungsprogramm christlicher Erziehung weiterleben. In diesem Zusammenhang ist nicht uninteressant, daß in der jesuitischen Ratio studiorum unter den Humaniora die Moralphilosophie fehlt, nur Grammatik, Geschichte, Poetik und Rhetorik zu Wort kommen, während die Moralphilosophie unter den „Studia superiora“ erscheint $^{162}$. 
Das Weiterwirken humanistischer Zielsetzungen in der Schule ist vor allem auch deshalb von grundlegender Bedeutung, weil der ins allgemein Christliche gewendete Humanismus seit der Mitte des 16. Jahrhunderts von der Konfessionalisierung weitgehend $^{163}$ erdrückt wurde ${ }^{164}$. Symptomatisch dafür ist der Niedergang des Humanismus auf dem Tridentinum ${ }^{165}$. Dasselbe Bild zeigt der protestantische Raum ${ }^{166}$. Exemplarisch sei, weil es für alle Konfessionen gilt, das Verdikt über Erasmus angeführt, den man katholischerseits bekanntlich auf den Index setzte ${ }^{167}$. Auch „auf protestantischer Seite“, so Flitner in seinem Buch über Erasmus im Urteil der Nachwelt, „treffen wir keine positiv urteilende Erasmusliteratur im Luthertum bis an die Schwelle des 18. Jahrhunderts" ${ }^{\text {168. }}$.

Man würde die Proportionen aber verzeichnen, wenn man den Humanismus des 16.Jahrhunderts ausschließlich von seinem Verhältnis zum Christentum her sähe und seine Entwicklung allein von hier aus wertete ${ }^{169}$. Auch weiterhin, und in nicht geringem Maße, wirkte er als eigenständige wissenschaftliche Kraft und hat auf diese Weise die europäische Bildungs- und Wissenschaftsgeschichte - und zwar, wie man doch wohl sagen muß: säkularisierend ${ }^{170}$ - mitbestimmt. Das Gesamtbild ist also durch Selbständigkeit wie durch ständige - sei es freundliche, sei es konfliktgeladene - Berührung mit seiner Zeit bestimmt ${ }^{171}$. Ein instruktives Beispiel für diese Ambivalenz ist die neue rhetorische $\operatorname{Logik}^{172}$.

Bezeichnenderweise war es ein Nicht-Italiener, der Niederländer Agricola ${ }^{173}$, der, ebenso bezeichnend, in Italien und durch italienische Humanisten, wie Valla, angeregt ${ }^{174}$, eine neue humanistische Logik begründete, die nicht durch syllogistische Apodiktik, sondern durch die dialektischen Wahrscheinlichkeitsschlüsse der Topik ${ }^{175}$ und damit in humanistischer Weise praktisch-rhetorisch bestimmt war ${ }^{176}$. Im Unterschied zur „Demonstratio“ mit dem Ziel logischer Sicherheit ging es ihr um „Probabilitas“ zum Zwecke der „Inventio“177. An die Stelle der Apodiktik sollte ein Ordnungsinstrumentarium treten, um die Erfahrungswirklichkeit zu erschließen ${ }^{178}$; doch die Ordnungsabsicht als solche dominierte dann immer mehr. Die Topik bot in ihren Loci communes ${ }^{179}$ logische Sachverhalte, die den einzelnen Schritten des Argumentationsganges die jeweilige Legitimation verliehen und die es darum jeweils zu suchen und richtig anzuwenden galt. Die Loci wurden zu diesem Zwecke in ein mannigfach untergliedertes System gebracht, das man z. B. in Stammbaumform tabellierte.

Wie schon angedeutet, hat man zu fragen, was hier geschichtlich wirksamer war: die Topik selbst oder der ungeheure Systematisierungsdrang, der die Dialektiker ergriff ${ }^{\mathbf{1 8 0}}$. Jedenfalls war die Sache so attraktiv, daß Melanchthon sie 1521 in seinen berühmten ,Loci communes' auf die Theologie übertrug ${ }^{181}$. Aber die Jurisprudenz des 16. Jahrhunderts nahm die Methode der Loci communes ${ }^{182}$ in ähnlicher Weise auf ${ }^{183}$. Sie haben mit den theologischen Fragen der Reformation substantiell demnach nichts zu tun, sind humanistisch katexochen ${ }^{184}$.

Für die weitere Entwicklung bedeutsam wurde in der Nachfolge Agricolas der Kölner Caesarius ${ }^{185}$, im besonderen mit seiner 1532 erschienenen ,Dialectica ${ }^{4186}$. Schon 1530 waren auch in Wittenberg Melanchthon und Caesarius nebeneinander in Gebrauch $^{187}$. 1529 wurde Agricola in Paris eingeführt und erlebte hier im selben Jahre seine 2. Auflage ${ }^{188}$. Die humanistische Logik führte bei Petrus Ramus (Pierre de la Ra- 
mée $1515-1572)^{189}$ dann zu einer kaum noch unterbietbaren Vulgarisierung und Verflachung ${ }^{190}$, die den Lehrern des Organon nun doch zum Ekel werden mußte. Zugleich wurde die Dialektik aus ihrer engen Bindung an die Rhetorik gelöst und logisch formalisiert. Damit hörte sie auf, eine „humanistische“ Angelegenheit zu sein.

Melanchthon verarbeitete 1547 in seinen ,Erotemata dialectices zwar die Logik Agricolas und seines italienischen Anregers Lorenzo Valla; aber es zeichneten sich zwei deutlich gegenstrebende Tendenzen $a^{191}: 1$. Da die Dialektik Teil der christlichen Erziehung sein soll, werden die Argumente überwiegend biblischen Fragestellungen entnommen. 2. Die praxisbezogene rhetorische Dialektik wird aus ihrer humanistischen Dynamik an den traditionellen Aristoteles zurückgebunden ${ }^{192}$. Hinzu tritt, sicher auch als Reaktion auf die unbefriedigende Pragmatik dieser Logik ${ }^{193}$, das neue Interesse an der Metaphysik ${ }^{193 a}$, wovon sogleich noch zu sprechen ist. Und so kommt es denn gerade im evangelischen Schulbetrieb gegen Ende des 16. Jahrhunderts zur Auseinandersetzung zwischen philippistischem Aristotelismus und dialektischem Ramismus $^{194}$, der von Paris aus schon bald nach Deutschland eindrang ${ }^{195}$. Aber man darf nicht vergessen, daß auch Melchior Cano, der spanische Begründer katholisch-theologischer Methodenlehre und Verfasser der 1563 erstmals gedruckten ,Loci theologici“ sich ganz auf Agricola stützte ${ }^{196}$.

Die souveränste wissenschaftliche Leistung erreichte der Humanismus, wo er am wenigsten nach außen gewendet war, nämlich in der Philologie im engeren Sinne. Die Führung ist hier im 16. Jahrhundert ganz auf die Niederlande ${ }^{197}$ und Frankreich ${ }^{198}$ übergegangen. Die deutschen Philologen wie Joachim Camerarius und Hieronymus Wolf, beide Schüler Melanchthons, gerieten unter den wachsenden Einfluß des französischen Humanismus. Gleichwohl gehen auf sie wie auf ihre jüngeren Nachfolger Wilhelm Holtzmann (Xylander), Friedrich Sylburg und David Hoeschel, die wie jene allesamt aus dem süddeutschen Raum stammten, beachtliche Editionen zurück. Doch zeichnete sich in der zweiten Jahrhunderthälfte eine immer offenkundigere Mediokrität ab. Manche deutschen Philologen zogen in die Niederlande ${ }^{199}$.

Hier gelangte die Philologie in Gelehrten wie Justus Lipsius und Joseph Justus Scaliger in der zweiten Jahrhunderthälfte auf ihren unbestrittenen Höhepunkt ${ }^{200}$. Der erste wechselte, je nachdem wo er Professor war, dreimal sein Bekenntnis und war nacheinander katholisch, lutherisch, calvinisch und wieder katholisch; Scaliger ging vom katholischen zum reformierten Bekenntnis über. Von einer intensiven Grundbeziehung zwischen Humanismus und Religion kann da wohl keine Rede sein ${ }^{201}$. Im übrigen ist aufschlußreich, daß Scaliger als Nachfolger des Lipsius in Leiden von der Vorlesungspflicht befreit wurde ${ }^{202}$; auch der pädagogische Bezug entfiel also.

Die sich hier entfaltende klassische Philologie wird in ihrer Aktualität ganz verständlich aber nur vor dem Hintergrund einer umfangreichen neulateinischen ${ }^{203}$ Literatur ${ }^{204}$, deren kulturelle Bedeutung für die frühe Neuzeit gerade in der jüngeren Forschung auf breiter Front erschlossen wird ${ }^{205}$. Sprache und Geist des gebildeten Europäers sind für lange Jahrhunderte davon vielleicht stärker geformt worden, als er sich dessen bewußt war oder später und bis heute eingestanden hat.

Eine wissenschaftliche Konkurrenz von weitestreichender Bedeutung erwuchs dem Humanismus gerade auch in Deutschland durch die Neuscholastik des 16.Jahrhun- 
derts $^{206}$. Von der unbesehenen Identifizierung des Humanismus mit Platonismus hat die seriöse Humanismusforschung schon seit längerem Abstand genommen ${ }^{207}$; das Weiterleben des Aristoteles ${ }^{208}$ stellt ein wichtiges Element europäischer Bildungskontinuität dar ${ }^{209}$. Der Aristotelismus Melanchthons erscheint unter diesem Aspekt kaum noch als irritierend. Stand der Stagirit überhaupt als solcher zur Frage? Oder ging es nicht primär um den textuell (und natürlich damit auch sachlich) richtigeren Aristoteles ${ }^{210}$ ? Warum Textbemühung, wenn die Sache es gar nicht wert gewesen wäre? Was in Ungnade fiel, war die Metaphysik, wozu aber zu bemerken ist, daß das Interesse daran schon innerhalb der Spätscholastik selbst zurückgegangen $\operatorname{war}^{211}$.

In der zweiten Jahrhunderthälfte drang sie in Europa allmählich wieder beherrschend vor, seit dem Ende des Jahrhunderts auch im protestantischen Bereich ${ }^{212}$. Die Entwicklung erreichte ihren Höhepunkt in den ,Disputationes metaphysicae‘ des Jesuiten Francisco de Suárez 1597. Sie wirkten sehr rasch auch im evangelischen Raum und müssen „als gemeinsame Grundschrift für die aristotelische Metaphysik aller drei Konfessionen im 17.Jahrhundert angesehen werden“213. Die religiös solidierte Verbindung von Humanismus und Scholastik prägt vom 16. ins 17.Jahrhundert hinein die europäische Schule ${ }^{214}$. Wiederum ging eine wissenschaftliche Entwicklung über die Konfessionsgrenzen hinweg, und so könnte sich von hier aus rückblickend dann noch einmal das Verhältnis von Humanismus und Reformation in dem von uns angedeuteten Sinne bedenken lassen.

Es zeugt für die Kraft des Humanismus, wenn er der Neuscholastik und ihrer Metaphysik dann im Neostoizismus seinerseits eine primär moralphilosophische Initiative zur Seite stellte. Der Neostoizismus bedeutet die Fortsetzung der auf den Menschen und seine Selbstbestimmung in der Welt gerichteten pädagogischen Tendenzen, die dem Humanismus von eh und je eigen waren, wie auch der Stoizismus selbst als eine Grundäußerung des Renaissance-Humanismus insgesamt ${ }^{215}$ und von Anfang an ${ }^{216} \mathrm{zu}$ sehen ist. Seine neue Blüte entspringt einem allgemeinen europäischen Bedürfnis ${ }^{217}$ und ist auch als politische Haltung nicht so ausschließlich mit Justus Lipsius verknüpft $^{218}$, wie es etwa Oestreich in Fortführung von Dilthey ${ }^{219}$ annahm $^{220}$. Die Stellung, die das Christentum in und zu diesem Neostoizismus einnahm, ist zwiespältig. In seinem Rationalismus strebte er über das Zeitalter des konfessionellen Glaubens, aber auch schon über den Glauben als solchen hinaus ${ }^{221}$.

Kommen wir zum Ende. Im Grunde gibt es keine große geistige Bewegung, die solange geschichtliche Kontinuität besteht - nicht fortdauernde Wirkungen, wenngleich in sich abflachender Intensität, gezeitigt hätte. So hat auch der Humanismus der europäischen und damit gleicherweise der deutschen Bildung eine erst im Zeitalter der Technisierung allmählich verblassende literarisch-klassische Färbung gegeben. Man pflegt geschichtliche Darstellungen des Humanismus in der Regel zeitlich zu früh abzubrechen ${ }^{222}$. Mit der Ausbreitung über Europa ${ }^{23}$ hörte der italienische Humanismus ebensowenig auf, obwohl man das manchen Büchern vielleicht entnehmen könnte ${ }^{224}$, wie der deutsche mit Luther oder mit späteren Entwicklungen im Protestantismus $^{225}$. Zu leicht übersieht man seine Einwandlung in den geistigen Pluralismus Europas, der das humanistische Literatentum und die Reduktion der Seinsanalyse auf dialektische und moralphilosophische Praxisfragen in der Entfaltung seiner 
immer vielseitigeren Interessen als viel zu langweilig empfand. Neue Fragen wurden gestellt, neue Horizonte geöffnet, neue Interessen geweckt ${ }^{226}$.

Innerhalb dieser europäischen Gesamtentwicklung hat der deutsche Humanismus allerdings für kurze Zeit eine bedeutsame Sonderrolle gespielt, die über den Bildungsbereich hinausging. Seine initiatorische Mitwirkung bei der deutschen Reformation hatte europäische Konsequenzen, die über ihn selbst aber der Sache und der Intention nach rasch hinausführten. Mit der Verbindung von Humanismus und Reformation war die Sonderrolle im Grunde auch schon überholt. Die langfristigen Probleme, die sich nun ergaben, stellen auf die Gesamtheit der das 16.Jahrhundert bestimmenden Kräfte hin gesehen nur noch in Grenzen etwas Besonderes dar. Möglicherweise wäre vor allem negativ auf Ausfälle hinzuweisen, etwa in der Moralistik ${ }^{227}$, im Bereich des politischen Humanismus ${ }^{228}$, nicht zuletzt auch und vor allem in der Sprachkunst ${ }^{229}$. In positiver Weise hat dagegen der niederländische Schwerpunkt eine in mehrfacher Hinsicht europäische Bedeutung erlangt, die sich gewiß nicht mit der italienischen Initiative des Quattrocento messen kann, aber auch nicht bloßes Mitschwimmen im großen Strome ist.

Eigenes $^{230}$ und Allgemeineuropäisches komparatistisch abzuklären ${ }^{231}$, hat Aufgabe der deutschen Humanismusforschung zu sein. In einem kurzen Vortrag konnte dies allerdings nur sehr skizzenhaft angedeutet werden. Er versteht sich deshalb vor allem als Aufforderung, den deutschen Humanismus noch mehr in seinen europäischen Entwicklungen zu sehen, als das schon bisher geschehen ist.

* Ich gebe den Vortrag hier wieder, wie er im Rahmen des Kolloquiums gehalten wurde. Viele Fragen konnten bei einem so breit gestellten Thema darin naturgemäß nicht berücksichtigt, andere allenfalls nur gestreift werden. Da ich sie gleichwohl nicht beiseite lassen möchte, entschloß ich mich, den Anmerkungsapparat hier und da über Gebühr vollzustopfen. Die Anmerkungen finden sich daher im Anschluß an den Beitrag. Doch ging es mir nicht um eine unnötige Wiederholung dessen, was $L$. W. Spitz in seinem grundlegenden Uberblick „The Course of German Humanism“ (s. u. Anm. 14) schon so vorzüglich dargeboten hat, sondern um die Herausarbeitung forschungsbestimmender Probleme. Viele der im folgenden zitierten Aufsätze verdanke ich lediglich kollegial-freundlicher Zusendung. Daß vieles mehr hätte genannt werden können, bei größerem Raum notwendigerweise zu nennen gewesen wäre, braucht hier nur angedeutet zu werden. Der für den ganzen Band maßgeblichen Regelung entsprechend sind die Erscheinungsorte nur bei außerdeutschen Publikationen angegeben.

1 Jetzt als knappe Einführung: J.-C. Margolin, L'humanisme en Europe au temps de la Renaissance (Que sais-je? 1945) (Paris 1981). Zur Forschungssituation zuletzt: $A$. Buck, Überlegungen zum gegenwärtigen Stand der Renaissanceforschung, in: Bibliothèque d'Humanisme et Renaissance (künftig: BHR) 43 (1981) 7-38. Der Bericht knüpft an das entsprechende Referat von $C$. Trinkaus an: Humanism, Religion, Society: Concepts and Motivations of Some Recent Studies, in: Renaissance Quarterly (künftig: RenQ) 29 (1976) 676-713. Zur Einführung in den allgemeinen Forschungsstand, freilich weitgehend auf Italien bezogen, s. auch: Il Rinascimento. Interpretazioni e problemi (Rom-Bari 1979) (Einzelbeiträge führender Renaissanceforscher); jetzt auch in englischer Ubersetzung: The Renaissance. Essays in Interpretation (London und New York 1982).

${ }^{2}$ Vgl. allein schon die Titelliste unter „Humanismus. Begriffsbestimmung“ bei $W$. Totok, Handbuch der Geschichte der Philosophie III (1980) 35 f., die viele jüngsterschienene Arbeiten noch 
gar nicht erfaßt. Zum Thema „Humanismus“ insgesamt s. ebd. 28 ff. (doch auch hier viele Lükken, wie das Handbuch als solches weithin unbefriedigend ist). Über den Renaissance-Humanismus hinaus erstreckt sich die Zielsetzung des Sammelbandes ,Humanismus', hg. von $H$. Oppermann (Wege der Forschung 17) $\left({ }^{2} 1977\right)$. Ebenso H. Rüdiger, Wesen und Wandlung des Humanismus $\left(1937,{ }^{2} 1966\right)$. Eine vorzügliche Übersicht der Diskussion um den Humanismus-Begriff an zunächst unvermuteter Stelle bei $R$. Landfester, Historia Magistra Vitae. Untersuchungen zur humanistischen Geschichtstheorie des 14. bis 16. Jahrhunderts (Genf 1972) 17-31, mit umfangreicher Literatur.

${ }^{3}$ P. O. Kristeller, Studies in Renaissance Thought and Letters (Rom 1956) (dort etwa 553-589: Humanism and Scholasticism); ders., Humanismus und Renaissance I-II (1974-1976; als Taschenbuch 1980). Vgl. auch G. M. Logan, Substance and form in Renaissance humanism, in: Journal of Med, and Ren. studies 7 (1977) 1-34, über die "Offenheit“ des substantiell nicht festgelegten „Humanismus" (im Kristellerschen Sinne). Die jüngste, allerdings (auch im Ton) völlig überzogene Kritik von $R$. Waswo in seiner Rezension der Kristellerschen Aufsatzsammlung: Renaissance Thought and its Sources (New York 1979), in: BHR 43 (1981) 167-171, vermißt wie auch schon ältere Stellungnahmen zu Kristeller im besonderen den weiterführenden (und somit auch seinen Humanismusbegriff sprengenden) Fragehorizont. Zum Begriffsproblem s. auch $A$. Buck, Der Wissenschaftsbegriff des Renaissance-Humanismus, in: Wolfenbütteler Beiträge 2 (1973) 45-63. Von dems. ist schließlich noch mit Nachdruck zu nennen: Die „studia humanitatis“ und ihre Methode, in: BHR 21 (1959) 273-290 (Wiederabdruck in: A. Buck, Die humanistische Tradition in der Romania (1968) 133-150).

Zur Unterrichtung über den heutigen Stand literaturwissenschaftlicher Forschung zum 16. Jahrhundert auf europäischer Basis sei auf den von $W$. M. Jones herausgegebenen Sammelband einer Vorlesungsreihe: The Present State of Scholarship in Sixteenth-Century Literature (Columbia und London 1978) verwiesen; über die deutsche Literaturwissenschaft: 169-196 (s.u. Anm. 229).

'A. Campana, The Origin of the Word ,Humanist', in: Journal of the Warburg and Courtauld institutes 9 (1946) 60-73. Vgl. auch $A$. Renaudet, Autour d'une définition de l'humanisme, in: BHR 6 (1945) 7-49.

${ }^{6}$ Epistolae VI 6 (Epistolarum libri VIII, rec. L. Mebus, Florenz 1741, II 49). Dazu Buck, Die „studia humanitatis“(s.o. Anm. 3) 275.

' Statt weiterem s. Buck, Die "studia humanitatis“ 273-275, sowie die unten in Anm. 141 genannte Literatur.

${ }^{8}$ Ad Petrum Paulum Histrum Dialogus II; E. Garin, Prosatori Latini del Quattrocento (MailandNeapel 1952) 44. Die Datierung nach $H$. Baron, The Crisis of the Early Italian Renaissance (Princeton 1955) $190 \mathrm{ff}$.

${ }^{9}$ Humanismus und Renaissance (s.o. Anm.3) I 177 f. Die von J. Engel, in: Handbuch der europäischen Geschichte, hg. von T. Schieder, III (1971) 60, dafür vorgeschlagene Bezeichnung „Humanistik“" wäre für den „Humanismus“-Begriff geradezu verhängnisvoll, da er diesem den letzten Rest von allgemeinverbindlicher Benutzbarkeit nähme.

${ }^{10} \mathrm{Im}$ Hinblick auf den deutschen Raum nenne ich hierfür lediglich: F.J. Worstbrock, Deutsche Antikerezeption 1450-1550 I. Verzeichnis der deutschen Übersetzungen antiker Autoren. Mit einer Bibliographie der Übersetzer (1976); Die Rezeption der Antike. Zum Problem der Kontinuitāt zwischen Mittelalter und Renaissance (Wolfenbütteler Abhandlungen zur Renaissanceforschung I) (1981) (Sammlung von Vorträgen, hg. von $A$. Buck). Die Rezeption erfolgte nicht nur äußerlich als Übernahme eines an und für sich fremden Bildungsgutes; vielmehr (Buck, Die „studia humanitatis“, s. o. Anm. 3, 273): „Grundlage des Humanismus ist die Begegnung mit der Persönlichkeit des antiken Autors in dessen Werk“ „als ein Zwiegespräch“, (278 ff.) als „Aneignung“. ${ }^{11}$ Nachdrückliche Betonung der Moralis Philosophia als Basis für das Verständnis des Humanismus insgesamt etwa durch L. Borinski, Das Wesen des europäischen Humanismus, in: Antike und Abendland 14 (1968) 19-35, wo aber gleichzeitig die Gefahr definitorischer Undeutlichkeit bei zu großer Offenheit im Begriffsverständnis deutlich wird. - Bezeichnenderweise hält auf Raffaels "Schule von Athen" Aristoteles seine "Ethik" in der Hand. 
12 Dies vor allem auch deshalb, weil ein allgemeines, den Humanismus im engeren Sinne übersteigendes Verlangen nach einer anerkannten moralischen Autorität im 15. Jahrhundert heranwuchs. Dementsprechend ist auch Kristellers Humanismusverständnis hier offener geworden; vgl. etwa: The Moral Thought of Renaissance Humanism, in: Renaissance Thought II (New York 1965) 20-68 = Das moralische Denken des Renaissance-Humanismus, in: Humanismus und Renaissance II (s.o. Anm. 3) 30-84; ders., Die Stellung der Ethik im Denken der Renaissance, in: Quellen und Forsch. aus ital. Arch. u. Bibl. 59 (1979) 273-295. Vgl. dazu auch den Sammelband: Ethik im Humanismus (Beiträge zur Humanismusforschung V) (1979); dort u.a. A. Buck, Die Ethik im humanistischen Studienprogramm (31-44). Im übrigen bleibt Kristeller (etwa im Gegensatz zu Garin) beim Ausschluß der Philosophie; s. seine neuerlichen Beiträge: Rhetoric and Philosophy from Antiquity to the Renaissance, in: Renaissance Thought and Its Sources, hg. von M. Mooney (New York 1979) 211-259, in deutscher Úbersetzung in: Studien zur Geschichte der Rhetorik und zum Begriff des Menschen in der Renaissance (Gratia. Bamberger Schriften zur Renaissanceforschung hg. von $D$. Wrttke 9) (1981) 11-62 und 115-139, sowie: Il Rinascimento nella storia del pensiero filosofico, in: Il Rinascimento (s. o.Anm.1) 149-179. Grundsätzliches zum Verhältnis von Philosophie und Rhetorik im Humanismus auch bei E. Kessler, Petrarca und die Geschichte (1978), Kapitel E (159-197): „Philosophie und Rhetorik“.

${ }^{13}$ Ich erspare mir detailliertere Belege und darf dafür auf die übersichtliche Darstellung bei Landfester, Historia Magistra Vitae (s. o. Anm. 2) $17 \mathrm{ff}$., verweisen, soweit es um den RenaissanceHumanismus geht. Bekanntlich hat man darüber hinaus jedes Denken (und Handeln), das den Menschen in den Mittelpunkt stellt, als Humanismus bezeichnet, bis hin zum „sozialistischen Humanismus“ oder zu allgemein praktizierter „Humanität“, „Menschlichkeit“. Vgl. dazu den Abschnitt ,Humanismus' bei $H$. E. Bödeker, Menschheit, Humanităt, Humanismus 1121-1126, in: Geschichtliche Grundbegriffe. Historisches Lexikon zur politisch-sozialen Sprache in Deutschland III (1982).

${ }^{14}$ Den jüngsten Gesamtüberblick über den deutschen Humanismus mit Einführung in die Forschungssituation bot L. W. Spitz, The Course of German Humanism, in: Itinerarium Italicum. The Profile of the Italian Renaissance in the Mirror of its European Transformations. Dedicated to P. O. Kristeller on the occasion of his 70 th birthday. Ed. by H. A. Oberman with T. A. Brady, $J r$. (Leiden 1975) 371-436 (daß ich mit ihm nicht immer übereinstimme, kann nur gelegentlich erwähnt werden). Dort 401 die Formulierung: „The High Generation“, freilich auf die engere Zeit $1500-1520$ bezogen. Allenfalls als flüchtige erste Orientierung kann der kürzlich von $W$. Trillitzscb gelieferte einleitende „Historische Abriß des deutschen Renaissancehumanismus“ zu der von ihm herausgegebenen Textsammlung: Der deutsche Renaissancehumanismus. Abriß und Auswahl (1981) 7-109, dienen. Mancherlei, wie etwa die Bestimmung des Begriffs „Humanist", entspricht nicht dem heutigen Forschungsstand. Über diesen recht informativ im besonderen noch $O$. Herding, Über einige Richtungen in der Erforschung des deutschen Humanismus seit etwa 1950, in: Deutsche Forschungsgemeinschaft. Humanismusforschung seit 1945. Kommission für Humanismusforschung, Mitteilung II (1975) 59-110. Leider nur sehr knapp: E. Bernstein, Die Literatur des deutschen Frühhumanismus (1978). Eine Reihe wichtiger Beiträge, auf die noch im einzelnen zurückzukommen ist, enthält die Vortragssammlung: L'Humanisme allemand (1480-1540). XVIII ${ }^{\mathrm{e}}$ Colloque International de Tours (München und Paris 1979). Ein resümierender Vorbericht von J.-C. Margolin, in: BHR 38 (1976) 145-156. Zum ostmitteleuropäischen Humanismus, der natürlich auch das "deutsche“ Thema stark berührt (Böhmen, Ungarn, Polen, die Beziehungen zu Deutschland): I. N. Golenišcev-Kutuzov, Il Rinascimento italiano e le letterature slave dei secoli XV e XVI, a cura di S. Graciotti e J. Křsálková (Mailand 1973) (mit umfangreicher Bibliographie). Zu Slovenien (im Ausstrahlungsbereich von Wien): P. Simoniti, Humanizem na slovenskem in slovenski humanisti do srede XVI. stoletja (Ljubljana 1979) (mit deutschem Resümee). Weitere Titel s. bei L. V. Ryan, Neo-Latin Literature, in: Jones (Hg.), Present State (s.o. Anm. 4) 252-257.

${ }^{15}$ G. Livet in dem Einführungsvortrag zu: L'Humanisme allemand (s.o. Anm. 14) 8: „s'est développé entre 1480 et 1530 ce qu'on est convenu d'appeler, l'humanisme allemand"“. Über die Zuordnung der 80 er Jahre des 15 . Jahrhunderts, wie sie hier vorgenommen wird, könnte man geteil- 
ter Meinung sein, wie überhaupt die Grenzdaten 1480 und 1530 (im Titel des Buches selbst statt dessen: 1540!), was auch eingestanden wird, nicht ohne Willkür gewählt sind. Bernstein, Literatur des deutschen Frühhumanismus (s.o. Anm.14) 1, begrenzt die von ihm behandelte Epoche auf 1450-1480, spricht ebd. 4 aber von den „,mageren“ Achtzigern“.

${ }^{16}$ Vgl. den Forschungsbericht von F. Krafft, Renaissance der Naturwissenschaften - Naturwissenschaften der Renaissance. Ein Überblick über die Nachkriegsliteratur, in: Deutsche Forschungsgemeinschaft. Kommission für Humanismusforschung, Mitteilung II (s. o. Anm. 14) 111183 , sowie insgesamt: Humanismus und Naturwissenschaften, hg. von $R$. Scbmitz und F. Krafft (Beiträge zur Humanismusforschung VI) (1980). Im Oktober 1982 fand ein weiteres Kolloquium über „Humanismus und Medizin“ statt, dessen Beiträge in derselben Reihe erscheinen werden. Auch in dem Kolloquiumsband ,L'Humanisme allemand' (s. o. Anm. 14) 141-230 sind in der Abteilung: „Humanisme, Science et Philosophie“ mehrere Beiträge diesem Thema gewidmet. Eine knappe Einführung in die Renaissance-Naturwissenschaft bot kürzlich $A$. G. Debus, Man and Nature in the Renaissance (Cambridge usw. 1978). Insgesamt überwog in der Forschung lange die Tendenz, dem Humanismus für die Entwicklung der Naturwissenschaft jede Bedeutung abzusprechen; vgl. etwa G. Sarton, The Appreciation of Ancient and Medieval Science during the Renaissance (1450-1600) (Philadelphia 1955); J. H. Randall Jr., The School of Padua and the Emergence of Modern Science (Padua 1961). Prinzipiell weiter gesehen wurde dieser Sachverhalt in dem allgemeinen Gegensatz von zwei verschiedenen Kulturen, der keine Erfindung heutiger Gelehrter ist, sondern schon im 16. Jahrhundert bei Sperone Speroni in zwei unterschiedlichen Wissenschaftsverstandnissen auftritt; vgl. E. Cocbrane, Science and Humanism in the Italian Renaissance, in: American Hist. Rev. 81 (1976) $1043 \mathrm{f}$, nach C. Vasoli, Studi sulla cultura del Rinascimento (Manduria 1968) $264 \mathrm{ff}$. Programmatisch in unserer Zeit: C. P. Snow, The Two Cultures and the Scientific Revolution (Cambridge 1959); Neufassung: The Two Cultures: And a Second Look (Cambridge 1964). Doch betont die jüngste Forschung wieder stärker den Zusammenhang zwischen dem Humanismus und dem Aufblühen moderner Naturwissenschaft. Vgl. etwa P. L. Rose, The Italian Renaissance of Mathematics: Studies on Humanists and Mathematicians from Petrarch to Galileo (Genf 197.5); ders., Humanist Culture and Renaissance Mathematics: The Italian Libraries of the Quattrocento, in: Studies in the Renaissance 20 (1973) 46-105. So auch die Tendenz des genannten Sammelbandes ,Humanismus und Naturwissenschaften'. Die prinzipielle Einheit der Renaissance unterstrich vor allem $J$. Gadol, The Unity of the Renaissance: Humanism, Natural Science and Art. Vgl. die deutsche Úbersetzung in dem hier auch noch generell zu nennenden Sammelband: Zu Begriff und Problem der Renaissance, hg. von $A$. Buck (Wege der Forschung 204) (1969) 395-426.

${ }^{17}$ So etwa $H$. Rupprich, Die deutsche Literatur vom späten Mittelalter bis zum Barock I. Das ausgehende Mittelalter, Humanismus und Renaissance. 1370-1520 (1970) 452-460, wo z. B. Nikolaus von Kues, Regiomontanus, Kopernikus als Repräsentanten des deutschen Humanismus genannt werden. Daß Cusanus kein „Humanist“ war, hat $M$. Seidlmayer, Nikolaus von Cues und der Humanismus, in: Studien und Texte zur Geistesgeschichte des Mittelalters, hg. von J. Koch, III (1953) 1-38, wiederabgedruckt in: M. Seidlmayer, Wege und Wandlungen des Humanismus (1965) 75-106, hinreichend dargetan. Gleichwohl wird Nikolaus weiterhin recht regelmäßig als "Humanist" bezeichnet; vgl. etwa $E . F$. Jacob, Christian Humanism, in: Europe in the Late Middle Ages, ed. by J. R. Hale usw. (London 1965) 459-463, und G. Livet in dem Einleitungsreferat: ,Humanisme allemand, réforme et civilisation européenne' zu dem oben in Anm. 14 genannten Sammelwerk: L'Humanisme allemand 16: „un premier représentant de ce nouvel esprit“, nämlich des in Deutschland eindringenden „humanisme italien“. Bei $E$. Colomer, Das Menschenbild des Nikolaus von Kues in der Geschichte des christlichen Humanismus, in: Mitt. u. Forsch.beiträge d. Cusanus-Gesellschaft 13 (1978) 117-143 (dazu die Diskussion in: 14 (1980) 80-84), wird vom Kristellerschen Verstāndnis ausdrücklich abgewichen und „das Interesse für die ethischen und menschlichen Probleme und die Bejahung des Wertes und der Würde des Menschen und seiner einzigartigen Bedeutung im Mittelpunkt des Weltalls“ als Wesen des Humanismus bestimmt. Ähnlich etwa im gleichen Band 13 (1978) 411-421 P. T. Sakamoto in seinem Vergleich des cusanischen Humanismus mit dem von Buddhismus und Konfuzianismus geprāgten japanischen Humanismus. $P . M$. Watts, Nicolaus Cusanus. A fifteenth-century vision 
of man (Studies in the History of Christian Thought XXX) (Leiden 1982), ist ebenfalls ganz einem „weiten" Humanismus im Sinne von Charles Trinkaus (s. u. Anm. 35) verpflichtet.

${ }^{18}$ Das schließt natürlich humanistische Interessen der Naturforscher im eigentlichen Sinne keineswegs aus, im Gegenteil; werden sie zu ihren naturforschenden Studien von dort aus doch oft erst angeregt. Über das Verhältnis von Humanismus und Naturwissenschaft unter methodengeschichtlichem Aspekt: N.W. Gilbert, Renaissance Concepts of Method (New York 1960) 81-107; ebendort 81: „In mathematics, the usual Humanist emphasis on recovery of the sources ... of the discipline was very beneficial. Such recovery presupposed a knowledge of the Greek language as well as of mathematics, and this linguistic sophistication was the contribution of Humanism. In addition, mathematics in the educational programs of the day received an impetus from the $\mathrm{Hu}$ manist reevaluation of the arts curriculum." - Man sollte mit dem Epitheton "Humanist" ebenso vorsichtig wie mit dem Begriff "Humanismus" deutlich umgehen und könnte auf diese Weise mit einem "Mehr-oder-weniger" humanistischer Prägung vielen Gelehrten auch unter ,humanistischem" Aspekt gerecht werden, ohne sie schematisch hierhin oder dorthin zuzuordnen. So hat der Mathematiker und Astronom Georg von Peurbach durch seine Vorlesungen über römische Klassiker in Wien bei der Einführung des literarischen Humanismus nördlich der Alpen mitgewirkt, ohne daß man deshalb auch schon seine Mathematik als "humanistisch" bezeichnen müßte. Dementsprechend zugleich differenzierend wie kombinierend die Titel einschlägiger Arbeiten etwa von $K$. H. Burmeister, Achilles Pirmin Gasser (1505-1577). Arzt und Naturforscher, Historiker und Humanist (1970), oder, von dems.: Der Humanist und Botaniker Gabriel Hummelberg (ca. 1490-1544), in: Festschrift für C. Nissen (1973) 43-71. Ein gutes Beispiel für das vielfältige wissenschaftliche Interesse eines Humanisten ist Joachim Camerarius; s.u. Anm. 114. ${ }^{19}$ Weitgehend so in der in Anm. 18 angeführten Forschung. Sehr instruktiv im besonderen $K$. Meier Reeds, Renaissance Humanism and Botany, in: Annals of Science 33 (1976) 519-542. Zum ganzen Fragenkreis s. auch M. Boas Hall, Il Rinascimento scientifico, in: Il Rinascimento (s.o. Anm. 1) 323-352; dort 341-344 über den Zusammenhang von Humanismus und Naturwissenschaft: 1) ,il modo di concepire l'uomo e le sue attività entro termini puramente umani“ (im Sinne der weiteren Humanismusdefinition) und 2) „la riscoperta e la tradizione dei testi antichi rappresentò un notevole contributo per la scienza“.

${ }^{20}$ R. S. Westman, Humanism and Scientific Roles in the Sixteenth Century, in: Humanismus und Naturwissenschaften (s.o. Anm. 16) 83-99, scheint an die Möglichkeit einer solchen pädagogischen Umsetzung im 16. Jahrhundert zu denken, die über die Funktion der mathematischen Fächer als "ancillary subjects of the trivium“ (87) hinausgeht. Was dann zur Sprache kommt, ist jedoch nicht Persönlichkeitsbildung, sondern Naturwissenschaft. Vgl, demgegenüber Gilbert, Renaissance Concepts of Method (s.o. Anm. 18) 222 ff., zum Spannungsverhältnis zwischen Humanismus und Naturwissenschaft; dort 222: „Through Humanist usage, the term ,methodus' had come to have an almost rhetorical meaning." Tut man der geschichtlichen Bedeutung des Renaissance-Humanismus im übrigen Abbruch, wenn man das umfangreiche Bildungs- und Wissenschaftsensemble der Renaissance nicht insgesamt damit etikettiert? Für den Positionsbezug der "humanistischen Naturwissenschaft" instruktiv ist die dezidierte Stellungnahme von $F$. Krafft, Der Naturwissenschaftler und das Buch in der Renaissance, in: Das Verhältnis der Humanisten zum Buch (Kommission für Humanismusforschung IV) (1977) 13-45, in engagierter Auseinandersetzung mit $H$. Friedrich, Abendländischer Humanismus (1954/1967).

${ }^{21}$ E. Cocbrane (Hg.), The Late Italian Renaissance 1525-1630 (London 1970) 77-208: „Continuation and Change in the Humanistic Disciplines“. Insgesamt betrifft das ganze Problem eine spätere Phase des Humanismus, weniger das 15., als das 16. Jahrhundert. Im Laufe der Zeit wurden von ihm nicht nur immer mehr Länder, sondern auch Diziplinen und Lebensbereiche berührt. ${ }^{22}$ Gerade in letzter Zeit hat die Forschung diesen grundlegenden Tatbestand wieder nachdrücklicher bewußt gemacht. Vgl. z.B. den Sammelband: The Darker Vision of the Renaissance: Beyond the Fields of Reason, hg. von R. S. Kinsman (Berkeley usw. 1974). Ferner: W. Shumaker, The Occult Sciences in the Renaissance. A Study in Intellectual Patterns (Berkeley usw. 1972) mit einem ausführlichen Kapitel über Agrippa von Nettesheim. Zu diesem im übrigen: $C$. $G$. Nauert, Jr., Agrippa and the Crisis of Renaissance Thought (Urbana 1965); dazu L.W. Spitz, Occultism and Despair of Reason in Renaissance Thought, in: Journal Hist. Ideas 27 (1966) 
464-469; P. Zambelli, Agrippa von Nettesheim in den neueren kritischen Studien und in den Handschriften, in: Archiv f. Kulturgesch. 51 (1969) 264-295; dies., Corneille Agrippa, Érasme et la théologie humaniste, in: Colloquia Erasmiana Turonensia (s. u. Anm. 55) 113-159; dies., Magia e riforma radicale in Agrippa (Florenz 1974), sowie Crabay, Un manifeste religieux (s. nächste Anmerkung). Wichtig in diesem Zusammenhang auch die Rolle der Kabbalah; $F$. Secret, Les Kabbalistes chrétiens de la Renaissance (Paris 1964); speziell für Deutschland: J.L. VieillardBaron, Platonisme et Kabbale dans l'œuvre de Johann Reuchlin, in: L'Humanisme allemand 159-167.

${ }^{23}$ Vgl. etwa das von $R$. Crabay vorgeführte Beispiel: Un manifeste religieux d'anticulture: Le „De incertitudine et vanitate scientiarum et artium" de Corneille Agrippa, in: Acta Conventus NeoLatini Turonensis (künftig: ACTours) (Paris 1980) 889-924; dort 900: durch Zweifel und ,tradition secrète“ hindurch gelangt Agrippa zu einer „position fidéiste qui, devant la précarité de tout système de pensée, lui permet de garder confiance à la fois dans la part de vérité qu'un esprit éclairé par Dieu peut découvrir dans les écrits de magie et, au moins provisoirement, dans le résultat d'expériences“. Crahay betont, daß Agrippa katholisch blieb.

${ }^{24}$ Die Eskalation von Hexen- und Satansglauben gerade im ,theologischen“ 16. Jahrhundert ist gewiß nicht zufällig, und man sollte die Entwicklung der europäischen Aufklärung emotionsfrei auch einmal von dieser Seite sehen. Welche Fülle an einschlägiger Literatur zum Thema „Nachtseite der Renaissance" die letzten Jahre hervorgebracht haben, zeigt die Titelliste bei Buck, Überlegungen zum gegenwärtigen Stand der Renaissanceforschung (s. o. Anm. 1) 20-25. Die gängige Vorstellung vom „optimistischen“ Menschenbild der Humanisten (im Gegensatz zum „Pessimismus" der Reformatoren) bedarf von hier aus gewisser Revisionen. Eindeutig und unbestritten ist, daß die „dunklen“ Tendenzen vom 15. ins 16. Jahrhundert hinein zu voller Entwicklung gelangten. Okkultismus und Hexenverfolgung hat auch Spitz, Course of German Humanism (s.o. Anm. 14) 382, in unmittelbaren Zusammenhang gebracht. Ebenso $L$. White, jr., Death and the Devil, in: Kinsman, The Darker Vision (s.o. Anm. 22) 25-46. Wenngleich Zambelli(s.o. Anm. 22) darauf hinweist, daß die deutschen Hermetiker und Kabbalisten die Hexen widersprüchlich beurteilt haben und zwischen Magie und Hexerei unterschieden, so ändert das doch wenig an der Grundtendenz, die beide verband.

${ }^{25}$ Vgl. etwa die Beurteilung der deutschen Entwicklung innerhalb des gesamteuropäischen Niveaus durch $J . \cdot C$. Margolin, L'Avènement des temps modernes (Paris 1977) 237; dort 221-253 eine gedrängte, aber überaus dichte Darstellung des europäischen Humanismus um 1500, auf die hier auch wegen der vorzüglichen Literaturauswahl für die einzelnen Länder verwiesen sei.

${ }^{26}$ Erste Information bei Spitz, Course of German Humanism (s.o. Anm. 14) 404 f. Ausführlich $F$. L. Borchardt, German antiquity in renaissance myth (Baltimore und London 1971); G. Strauss, The Course of German History: The Lutheran Interpretation, in: Renaissance Studies in Honor of H. Baron, ed. by $A$. Molho and J. A. Tedeschi (Dekalb 1971) 663-686. Aus der alteren Literatur grundlegend P. Joachimsen, Die humanistische Geschichtsschreibung in Deutschland 1. Die Anfänge. Sigismund Meisterlin (1895), sowie: Geschichtsauffassung und Geschichtsschreibung in Deutschland unter dem Einfluß des Humanismus (1910, ND 1968). Vgl. auch unten Anm. 84. Offensichtlich recht unbemerkt blieb die Mainzer philosophische Dissertation (1955) von $I$. Buchbolz, Die Varus-Schlacht im Urteil der Humanisten. Bezeichnenderweise greift das Buch von D. R. Kelley, Foundations of Modern Historical Scholarship. Language, Law, and History in the French Renaissance (New York und London 1970), gerade auch auf das Geschichtsinteresse der deutschen Humanisten zurück.

${ }^{27}$ In enger Interessenverbindung mit ihr stand die Kulturgeographie. So plante Celtis eine „Germania illustrata“ (im Anschluß an Flavio Biondos „Italia illustrata"), brachte Johannes Cochlaeus 1512 seine „Brevis Germaniae Descriptio“ heraus, Franciscus Irenicus 1518 seine „Exegesis Germaniae“, Willibald Pirckheimer 1530 die „Germaniae ex variis scriptoribus perbrevis explicatio“; vgl. D. Wuttke, Humanismus in Nürnberg um 1500, in: Caritas Pirckheimer 1467-1532 (Kata$\log$ (1982) 130. Grundlegend: G. Strauss, Sixteenth-Century Germany. Its Topography and Topographers (Madison 1959).

${ }^{28}$ Nicht also das theoretische Interesse an der Geschichtswissenschaft. In dem Buch von E. Kessler, Theoretiker humanistischer Geschichtsschreibung. Nachdruck exemplarischer Texte aus dem 
16. Jahrhundert (1971), kommen ausschließlich Italiener zu Wort. Bei Landfester, Historia Magistra Vitae (s.o. Anm. 2), macht das Quellenreservoir für humanistische Geschichtstheorie zwar einen wesentlich europäischeren Eindruck, doch stehen deutsche Autoren auch hier nur am Rande. Dagegen nehmen Deutsche an dem sich im 16. Jahrhundert entwickelnden neuen Genus der „Historia philosophica“, also der darstellenden Philosophiegeschichte, lebhaften Anteil; vgl. dazu die von G. Santinello initiierte „Storia delle storie generali della filosofia“ 1 : Dalle origini rinascimentali alla "historia philosophica" (Brescia 1981), wo von den zur Sprache kommenden 28 Autoren des 16. Jahrhunderts 12 Deutsche und 3 weitere Niederländer sind. Speziell zu Italien s. im übrigen E. Cochrane, Historians and Historiography in the Italian Renaissance (Chicago und London 1981).

${ }^{29}$ Auf die älteren Versuche, den deutschen Humanismus aus autochthonen Wurzeln hervorwachsen zu lassen, braucht heute nicht mehr eingegangen zu werden. Bezeichnend ist aber, daß sie Humanismus und Religion dabei eng verknüpfen, z. B. Hyma (s. u. Anm.60) mit der Devotio moderna, H. Hermelink, Die religiösen Reformbestrebungen des deutschen Humanismus (1907), mit Tendenzen der Via antiqua. Dagegen Herding, Über einige Richtungen (s.o. Anm. 14) 76: „Es ist sehr eindrucksvoll, wie wenig immer wieder angestellte Versuche gelingen, den Humanismus ohne diese Impulse“ (nämlich: aus Italien) „zu erklären“. Ferner: F. Luchsinger, Der Basler Buchdruck als Vermittler italienischen Geistes 1470-1529 (Basel 1953); P. G. Bietenbolz, Der italienische Humanismus und die Blütezeit des Buchdrucks in Basel (Basel 1958). Recht eindrucksvoll auch Spitz, Religious Renaissance (s. u. Anm.32) 12 ff., über die Einwirkung des Florentiner Humanismus auf die deutschen Humanisten. Vgl. im übrigen das geradezu erdrückende Material in den Beiträgen von Spitz und IJsewijn, in: Itinerarium Italicum (s. o. Anm. 14 und unten 53); und eben dieses Ergebnis programmatisch resümierend $H$. A. Oberman, Quoscunque Tulit Foecunda Vetustas, ebd. IX-XXVIII. Weiterhin schon bald danach noch $R$. Walsh, The Coming of Humanism to the Low Countries: Some Italian Influences at the Court of Charles the Bold, in: Humanistica Lovaniensia 25 (1976) 146-197. Eindrucksvoll auch Sicherl, Johannes Cuno (s.u. Anm. 56) 45-118 („Wanderjahre in Italien“); ebd. 23-33 zum italienischen Ursprung des deutschen Humanismus anhand vieler Einzelbeispiele. Schließlich sei auf die zahlreichen Studien von $A$. Sottili hingewiesen, der die italienisch-deutsche Vermittlung in mühevoller Kleinarbeit aus den handschriftlichen Belegen erschließt; vgl. zuletzt unten Anm. 90.

${ }^{30}$ Dazu sehr präzise und überzeugend: $L . W$. Spitz, Humanism in the Reformation, in: Renaissance Studies (s.o. Anm. 26) 641-662. Von großem Nutzen ist der jährliche Literaturbericht im ,Beiheft - Supplement' zum Archiv für Reformationsgeschichte (künftig: ARG) mit einem eigenen Abschnitt (3.2) „Humanismus“; doch ist darüber hinaus der jeweilige Literaturbericht insgesamt zu konsultieren. Der kürzlich erschienene Vortragsband: Humanismus und Reformation als kulturelle Kräfte in der deutschen Geschichte. Ein Tagungsbericht, hg. von L. W. Spitz (BerlinNew York 1981), enthält, seinem zu allgemein formulierten Titel zuwider, weitgehend recht spezielle, wenngleich im einzelnen ganz interessante Detailstudien. Im Rahmen thematisch weiter gefaßter Úberblicke ist das Verhältnis von Humanismus und Reformation letztens behandelt worden von $H$. Lutz, in: Reformation und Gegenreformation (Oldenbourg Grundriß der Geschichte 10) (München und Wien 1979, ${ }^{2} 1982$ ) 128-130, und von $R$. Woblfeil, in: Einführung in die Geschichte der deutschen Reformation (Beck'sche Elementarbücher) (1982) 114-118. Vgl. auch die bedenkenswerten Bemerkungen von $H$. Lutz, Humanismus und Reformation, in: Wort und Wahrheit 27 (1972) 65-77; jetzt Neudruck in: H. Lutz, Politik, Kultur und Religion im Werdeprozeß der frühen Neuzeit (Klagenfurt 1982) 3-14. Ferner: H. A. Oberman, Reformation: Epoche oder Episode, in: ARG 68 (1977) $74 \mathrm{ff}$. („Die Emanzipierung der studia humanitatis“); $C$. Augustijn, Die Stellung der Humanisten zur Glaubensspaltung 1518-1530, in: Confessio Augustana und Confutatio, hg. von E. Iserloh (1980) 36-48, mit Diskussionsbeiträgen ebendort 49-61. Jüngstens, bei aller Kürze das Wesentliche treffend und mit weiterer Literatur: $S$. Ozment, The Age of Reform 1250-1550. An Intellectual and Religious History of Late Medieval and Reformation Europe (New Haven und London 1980) 290-317 (Chapter 8: Humanism and Reformation).

${ }^{31}$ Weltanschauung und Analyse des Menschen seit Renaissance und Reformation (Gesammeite Schriften II), hg. von G. Misch $\left({ }^{10} 1977\right)$ 1-89. Massiver in dieser Richtung dann etwa J. Haller, gegen dessen liberalen Protestantismus sich G. Ritter in seinem Aufsatz wendet. 
32 The Religious Renaissance of the German Humanists (Cambridge, Mass., 1963). Vgl. auch von dems.: The Renaissance and Reformation (Chicago 1971).

${ }_{33}$ P. Joachimsen, Der Humanismus und die Entwicklung des deutschen Geistes, in: Deutsche Vierteljahrsschrift für Literaturwissenschaft und Geistesgeschichte 8 (1930) 419-480; Wiederabdruck in: Gesammelte Aufsätze, hg. von N. Hammerstein (1970) 325-386; auch als Libelli 288 (1969). Vgl. auch U. Mublack, „Deutsche Neuzeit“. Zur Historiographie Paul Joachimsens, in: Zs. f. Hist. Forsch. 1 (1974) 88-115.

${ }^{34}$ Typisch dafür ist neuerdings etwa W.J. Bouwsma, Renaissance and Reformation: An Essay in their Affinities and Connections, in: H. A. Oberman (Hg.), Luther and the Dawn of the Modern Era. Papers for the Fourth International Congress for Luther Research (Leiden 1974) 127-149. Er bringt Renaissance und Reformation substantiell zusammen, indem er den Begriff der „Wiedergeburt" recht weit faßt. Als Replik darauf ebd. 150-157 B. Hägglund, Renaissance and Reformation, der sogar Melanchthons „humanistische“ Bedeutung gering veranschlagt (155): „Melanchthon, who himself wrote a textbook on rhetoric, ascribes only a rather modest role to this discipline."

${ }^{35}$ Glänzende Ausarbeitung dieses „Humanismus“ bei C. Trinkaus, In Our Image and Likeness. Humanity and Divinity in Italian Humanist Thought I-II (London-Chicago 1970); ders., II pensiero antropologico-religioso nel Rinascimento, in: Il Rinascimento (s.o. Anm. 1) 103-147. Über Picos rasche Verbreitung in Deutschland s. G. Scbulten, Giovanni Picos Brief über das humanistisch-christliche Lebensideal und seine europäische Rezeption, sowie: E. Keßler, Die Aufnahme von Picos Brief an seinen Neffen Gianfrancesco in Deutschland, in: Kontinuität und Umbruch (Spätmittelalter und frühe Neuzeit. Tübinger Beiträge zur Geschichtsforschung 2) (1978) 7-58. Kristeller weist Pico und den Platonikern der Renaissance hingegen einen eigenen Platz neben der humanistischen Bewegung und der aristotelischen Scholastik zu; P. O. Kristeller, Florentine Platonism and Its Relations with Humanism and Scholasticism, in: Church History 8 (1939) 201-211; ders., Rhetorik und Philosophie (s. o. Anm. 12) 56.

${ }^{36}$ Die geschichtliche Bedeutung des Humanismus, in: HZ 127 (1923) 339-453; wiederabgedruckt als Libelli 107 ( $\left.{ }^{2} 1963\right)$ : Die Renaissance ist ein „Verhängnis“; aber immerhin ist der deutsche Humanismus „echter, ehrlicher“ als der italienische, zeichnet sich aus „durch größere Ernsthaftigkeit".

${ }^{37}$ B. Moeller, Die deutschen Humanisten und die Anfänge der Reformation, in: Zs. f. Kirchengesch. (künftig: ZKG) 70 (1959) 47-61 (dort: 59), und auch später mehrfach in diesem Sinne. Vgl. zuletzt in: Deutschland im Zeitalter der Reformation (Deutsche Geschichte 4) (1977, ${ }^{2} 1981$ ) $121 \mathrm{f} .:$ „daß Reformation und Humanismus sich so früh zusammengefunden hatten“. Der erstgenannte Aufsatz findet sich in englischer Übersetzung ebenfalls in dem Sammelband: Imperial Cities and the Reformation (Philadelphia 1972) (= Reichsstadt und Reformation; s. u. Anm. 68).

${ }^{38} \mathrm{Vgl}$. etwa P. O. Kristeller, Paganism and Christianity, zuerst in: The Classics and Renaissance Thought (Harvard 1955), sodann wiederholt in: Renaissance Thought: The Classic, Scholastic and Humanist Strains (New York 1961) und in deutscher Übersetzung in: Humanismus und Renaissance I (s.o. Anm. 3) 69-86. Vgl. auch den Kristellerschen Sammelband: Medieval Aspects of Renaissance Learning (Durham, North Carolina, 1974), mit Wiederholung der schon früher erschienenen materialreichen Aufsätze: Thomism and the Italian Thought of the Renaissance (zuerst als Monographie unter dem Titel: Le Thomisme et la pensée italienne de la Renaissance, Montreal 1967) und: The Contribution of Religious Orders to Renaissance Thought and Learning (nach: The American Benedictine Review 21 (1970) 1-55).

39 Bekanntestes, aber keineswegs singuläres Beispiel ist Pomponazzi; B. Nardi, Studi su Pietro Pomponazzi (Florenz 1965). Im übrigen Randall, The School of Padua (s. o. Anm. 16), dem gegenüber jedoch Rücknahmen nötig sind; vgl. C. B. Scbmitt, A Critical Survey and Bibliography of Studies on Renaissance Aristotelianism 1958-1969 (Padua 1971). Entschärfend wirkte, daß „die Philosophie und speziell die Naturphilosophie in Italien als Vorbereitungsfach für die Medizin und nicht für die Theologie unterrichtet wurde“; P. O. Kristeller, Die italienischen Universitäten der Renaissance (1953); wiederabgedruckt in: Humanismus und Renaissance II (s.o. Anm.3) 207-222; dort: 217. Ebenso in dem sich dort anschließenden Aufsatz: Der Gelehrte und sein Publikum im späten Mittelalter und in der Renaissance 224. 
${ }^{10}$ Vgl. etwa die beiden Artikel von J. W. O'Malley, Giles of Viterbo: a Reformer's Thought on Renaissance Rome, in: RenQ 20 (1967) 1-11, und: Fulfilment of the Christian Golden Age under Pope Julius II: Text of a Discourse of Giles of Viterbo, 1507, in: Traditio 25 (1969) 265-338, die jetzt in seinem Sammelband: Rome and the Renaissance. Studies in Culture and Religion (London 1981) (Variorum Reprints) wiederabgedruckt sind. Vgl. etwa: Giles of Viterbo 8: „For Giles the popes of the Restoration, beginning with Nicholas V, brought new hope to the Church by their revival of culture and learning." Doch auch Erasmus verglich in der Widmung seiner Ausgabe des Neuen Testaments an Leo X. sein Werk mit dem im Bau befindlichen Petersdom. Im übrigen kann das reiche Belegmaterial, das Pastor für die Förderung des Humanismus durch die Päpste in seiner "Geschichte der Päpste im Zeitalter der Renaissance“" zusammengetragen hat, trotz seiner apologetischen Tendenz immer noch mit bestem Nutzen zur Kenntnis genommen werden. Dem widersprechende Publikationen, wie das jüngste Buch von E. Lee, Sixtus IV and Men of Letters (Rom 1978), könnten einzelne Pāpste in ihrem persönlichen Interesse vielleicht nüchterner sehen lassen, ändern am Gesamtbild des römischen Humanismus aber nicht sehr viel. Zu Lee vgl. u. a. die Rezension von T. Deutscher, in: RenQ 32 (1979) 362-364. Ferner auch das Urteil von D. Hay unten in Anm. 122.

4'P. O. Kristeller, The Role of Religion in Renaissance Humanism and Platonism, in: The Pursuit of Holiness in Late Medieval and Renaissance Religion, hg. von C. Trinkaus und H. A. Oberman (Leiden 1974) 367-370; ders., Studies on Renaissance Humanism during the Last Twenty Years, in: Studies in the Renaissance 9 (1962) 22: „Renaissance humanism as such was not Christian or pagan, Catholic or Protestant" usw.

${ }^{42} C$. Béné, Les Pères de l'Église et la réception des auteurs classiques, in: Die Rezeption der Antike. Zum Problem der Kontinuität zwischen Mittelalter und Renaissance (Wolfenbütteler Abhandlungen zur Renaissanceforschung 1) (1981) 41-53.

${ }^{43}$ C. Trinkaus, The Religious Thought of the Italian Humanists, and the Reformers: Anticipation or Autonomy?, in: Pursuit (wie Anm. 41) 339-366, bezeichnet das Ergebnis als "theologia rhetorica“. Vielleicht könnte man die Poesie ebenfalls hier einschließen und käme dann auf einen allgemeinen Lebensstil. An jüngeren Studien seien in diesem Zusammenhang noch genannt: $C . L$ Stinger, Humanism and the Church Fathers. Ambrosio Traversari (1386-1439) and Christian Antiquity in the Italian Renaissance (Albany 1977); A. Sottili, Griechische Kirchenväter im System der humanistischen Ethik: Ambrogio Traversaris Beitrag zur Rezeption der patristischen Literatur, in: Ethik im Humanismus (s.o. Anm. 12) 63-85; K. Elm, Mendikanten und Humanisten im Florenz des Tre- und Quattrocento. Zum Problem der Legitimierung humanistischer Studien in den Bettelorden, in: Die Humanisten in ihrer politischen und sozialen Umwelt (s.u. Anm. 87) 51-85; R. Arbesmann, Der Augustiner-Eremitenorden und der Beginn der humanistischen Bewegung (Cassiciacum 19) (1965). Vgl. im übrigen die oben in Anm. 38 genannten Arbeiten von $P$. o. Kristeller.

44 Freilich macht Ritter es sich zu einfach, wenn er Janssens Unterscheidung auf einen „Einfall Zarnckes" zurückführt; Ritter, Geschichtliche Bedeutung (wie oben Anm. 36) 434.

is G. Toffanin, Che cosa fu l'umanesimo (Florenz 1929); Storia dell'umanesimo (Dal XIII al XVI secolo) (Neapel 1933); La religione degli umanisti (Bologna 1950).

${ }^{46}$ So möchte ich doch die Zuspitzung von S. A. Nulli, Erasmo e il Rinascimento (Turin 1955) 445 , relativieren, von einem christlichen Humanismus könne man genauso wenig reden wie von einer „geometria cattolica“ oder einer „chimica cristiana“; denn immerhin betreffen Christentum und Humanismus dasselbe Objekt „Mensch“. Erst sekundār ergeben sich daraus gemeinsame Interessen an theologischen Fragen, die Augustijn, Stellung der Humanisten (s.o. Anm. 30) 36, in spezieller Bezugnahme auf das Verhältnis des Humanismus zur Reformation entscheidend sein läßt.

47 Zur Kirchen-, insbesondere Romkritik s. O'Malley, Rome and the Renaissance (wie oben Anm. 40). Vgl. auch J. W. O'Malley, Praise and Blame in Renaissance Rome. Rhetoric, Doctrine, and Reform in the Sacred Orators of the Papal Court, c. 1450-1521 (Durham, North Carolina, 1979); dort u. a. das Kapitel VI: „The Reform of Church and Society: In Apostolicae sedis specula locati“, 195-237. Das V. Laterankonzil verbot den Religiosen, „Bischöfe, Prälaten und andere Obere" in der Öffentlichkeit ungebührlich zu tadeln (Conciliorum Oecumenicorum Decreta (Bo- 
logna ${ }^{3}$ 1973) 637); vom Papst ist aber keine Rede. Ein ernstlicher Einwand hinsichtlich institutionaler Kritik ließe sich auf den ersten Blick mit. Vallas Inkriminierung der Konstantinischen Fälschung erheben. Die Entstehungsumstände des Werkes (s. W. Setz, Lorenzo Vallas Schrift gegen die Konstantinische Schenkung, 1975) lassen es jedoch vor allem von der quellenexegetischen Methode, nicht vom Sachbezug aus humanistisch erscheinen, zumal dasseibe kritische Bedenken sachlich schon ein halbes Jahrhundert vorher geäußert worden war; D. Menozzi, La critica alla autenticità della Donazione di Costantino in un manoscritto della fine del XIV secolo, in: Cristianesimo nella storia 1 (1980) 123-154.

${ }^{48}$ Dabei hat die antik-heidnische Literatur notwendigerweise Vorbereitungscharakter auf Christus zu empfangen. So für Erasmus letzthin dargelegt von M. O'Rourke Boyle, Christening Pagan Mysteries. Erasmus in Pursuit of Wisdom (Toronto 1981); von ders.: Erasmus on Language and Method in Theology (Toronto 1977). Vgl. auch Béné, Erasme et saint Augustin (s.u. Anm. 55) $256 \mathrm{f}$.

49 Dieses Ergebnis läßt sich im übrigen in recht naheliegenden Vergleich zu den oben in Anm. 18 angestellten Uberlegungen zum Verhältnis von Humanismus und Naturwissenschaft bringen. Hier wie dort ist auf die jeweils unterschiedliche Dominanz bzw. wechselseitige Durchdringung der beiden Sachverhalte zu achten. Auch hier spielt das Textinteresse die entscheidende Rolle. Eine insgesamt so belehrende Studie wie letzthin $M$. Scbär, Das Nachleben des Origenes im Zeitalter des Humanismus (Basler Beitrāge zur Geschichtswissenschaft 140) (BaselStuttgart 1979), hätte durch überlegtere Verwendung des Humanismusbegriffs noch gewonnen. ${ }^{50}$ Der Begriff scheint auf $J$. Lindeboom, Het Bijbelsch Humanisme in Nederland (Leiden 1913), zurückzugehen. Vgl. Augustijn, Stellung der Humanisten (s.o. Anm. 30) $36 \mathrm{f}$., der sich dieser Bezeichnung ausdrücklich anschließt. Freilich dürfte die in eine gewisse Ratlosigkeit mündende Diskussion, die sich an seinen Vortrag anschloß (ebd. 49 ff.), die Fragwürdigkeit des Begriffs hinreichend demonstriert haben. Im übrigen Augustijn recht entwaffnend selbst: „Obwohl die Forschung in zunehmendem Maße anerkennt, daß es einen biblischen Humanismus gibt, sind dessen Eigenheiten noch keineswegs hinreichend bestimmt."

${ }^{51}$ Das muß um so mehr betont werden, als das von J. IJsewijn, The Coming of Humanism to the Low Countries (s. u. Anm. 53) 223, für den niederländischen Humanismus so griffig formulierte Schlagwort des "transitus humanismi ad christianismum “ nicht nur den italienischen Humanismus aus dem "christlichen Humanismus“ ausschlösse. Die gerade von Deutschland aus erhobenen Vorwürfe gegen den amoralischen „heidnischen“ Charakter des italienischen Humanismus (etwa auch bei Erasmus) haben den Blick für die gesamteuropäische Breite des christlichen $\mathrm{Hu}$ manismus bisweilen zugestellt. Zu Erasmus s. S. Seidel Menchi, Alcuni atteggiamenti della cultura italiana di fronte a Erasmo, 1520-1536, in: Eresia e Riforma (s.u. Anm. 164) 71-133; dort alle weitere Literatur. S. auch unten Anm. 129 und Anm. 164 insgesamt.

52 Maßgeblich wurde hierzu vor allem das Werk von $A$. Renaudet, Préréforme et Humanisme à Paris pendant les premières guerres d'Italie (1494-1517) (Paris 1916, ${ }^{2} 1953$ ), der die Offenheit der französischen Humanisten gegenüber der Reformation betont. Anders jedoch dann J.-P. Massaut, Josse Clichtove. L'humanisme et la réforme du clergé I-II (Paris 1968): Ablehnung der Reformation.

${ }^{53}$ J. IJsewijn, The Coming of Humanism to the Low Countries, in: Itinerarium Italicum (s.o. Anm. 14) 193-301.

${ }^{54}$ Jüngstens etwa G. Bedouelle, Lefèvre d'Étaples et l'Intelligence des Écritures (Genf 1976); dort die Literatur. Das einschlägige Kapitel bei $P$. Chaunu, Église, culture et société. Essais sur Réforme et Contre-Réforme (1517-1620) (Paris 1981) 87-101, stützt sich fast ausschließlich auf Bedouelle.

${ }^{55}$ Hier nur einige jüngere Titel: $C$. Béné, Érasme et saint Augustin ou influence de saint Augustin sur l'humanisme d'Érasme (Genf 1969); L. E. Halkin, Érasme et l'humanisme chrétien (Paris 1969); J. D. Tracy, Erasmus. The Growth of a Mind (Genf 1972); R. Stupperich, Erasmus von Rotterdam und seine Welt (New York 1977); F. Bierlaire, Les colloques d'Érasme. Réforme des études, réforme des mœurs et réforme de l'Église au XVI ${ }^{e}$ siècle (Paris 1978); ferner: Colloquia Erasmiana Turonensia (Douzième stage international d'études humanistes, Tours 1969) (Paris 1972) (mit 50 Beiträgen). Für Titel der vorhergehenden Jahrzehnte sei auf die umfassenden Bibliogra- 
phien von J.-C. Margolin verwiesen: Douze années de bibliographie érasmienne (1950-1961) (Paris 1963); Quatorze années de bibliographie érasmienne (1936-1949) (Paris 1968); Neuf années de bibliographie érasmienne (1962-1970) (Paris usw. 1977).

${ }^{36}$ Exemplarisch sei der in jüngster Zeit wiederholt untersuchte Abt Trithemius genannt. Dazu K. Arnold, Johannes Trithemius (1462-1516) (1971); jetzt vor allem aber N. L. Brann, The Abbot Trithemius (1462-1516). The Renaissance of Monastic Humanism (Studies in the History of Christian Thought XXIV) (Leiden 1981). Weiterhin etwa H. D. Saffrey, Un humaniste dominicain, Jean Cuno de Nuremberg, Précurseur d'Érasme à Bâle, in: BHR 33 (1971) 19-62, sowie $M$. Sicherl, Johannes Cuno. Ein Wegbereiter des Griechischen in Deutschland (1978). Für das städtische Humanismuszentrum Nürnberg gerade in diesem Zusammenhang aufschlußreich: $F$. Machilek, Klosterhumanismus in Nürnberg um 1500, in: Mitt. d. Ver. f. Gesch. d. Stadt Nürnberg 64 (1977) 10-45; Caritas Pirckheimer (s. o. Anm. 27). Weiterhin V. E. Fiala, Humanistische Frömmigkeit in der Abtei Neresheim, in: Stud. Mitt. Gesch. Ben. Ord. 86 (1975) 109-129. In der Lefèvre- und Erasmus-Nachfolge ist natürlich Beatus Rhenanus zu nennen; s. letzthin J. F. D'Amico, Beatus Rhenanus and Italian Humanism, in: Journal of Med. and Ren. studies 9 (1979) 237-260, und ders, Beatus Rhenanus, Tertullian and the Reformation: A Humanist's Critique of Scholasticism, in: ARG 71 (1980) 37-63. Zum Einfluß des Erasmus auf den deutschen Südwesten s. im übrigen $E$. $W$. Kobls, Die theologische Lebensaufgabe des Erasmus und die oberrheinischen Reformer (1969), sowie Beumer, Erasmus von Rotterdam (s. u. Anm. 107), und J. D. Tracy, Erasmus becomes "German", in: RenQ 21 (1968) 281-288. Zum Einfluß Lefèvres in Deutschland s. D'Amico, Beatus Rhenanus and Italian Humanism, auch generell. Im übrigen brach 1525 aber auch Rhenanus mit Luther. Demgegenüber fortdauernde Nähe Lefèvres zu Luther: H. Heller, The Evangelicism of Lefèvre d'Étaples in 1525, in: Studies in the Renaissance 19 (1972) 42-77. Wie ambivalent das Verhältnis der Humanisten zu den kirchlichen Institutionen im Zusammenhang mit ihrer persönlichen Existenz war, zeigt $F$. Rapp, Die elsāssischen Humanisten und die christliche Gesellschaft, in: Die Humanisten in ihrer politischen und sozialen Umwelt (s.u. Anm. 87) 87-108.

${ }^{57} \mathrm{Vgl}$. letztens etwa $J$. H. Bentley, New Testament Scholarship at Louvain in the Early Sixteenth Century, in: Studies in Medieval and Renaissance History, N. S. 2 (1979) 53-79. Vgl. von dems., Erasmus' Annotationes in Novum Testamentum' and the Textual Criticism of the Gospel, in: ARG 67 (1976) 33-53.

${ }^{58}$ Natürlich făllt es mir nicht ein, dies absolut zu behaupten, etwa im Blick auf den Heidelberger Dalberg-Kreis und auf süddeutsche Humanisten wie Wimpfeling, die in Deventer bei den Fraterherrn studiert hatten. Andererseits spricht $H$. A. Oberman, Werden und Wertung der Reformation (1977, $\left.{ }^{2} 1979\right)$ 17, vom „Mythos des Tübinger Humanismus“, der (24f.) „einer nüchternen Definition des Begriffes ,Humanismus" immer weniger standhalten“ könne. Der süddeutsche Humanismus ist seiner Gesamterscheinung nach kein "christlicher" Humanismus. Im übrigen weist Herding, Uber einige Richtungen (s.o. Anm. 14) 77, darauf hin, daß auch der wesentliche Erzieher der westfälischen Humanisten, Alexander Hegius, seine humanistischen Anregungen nicht von der Devotio moderna, sondern von Agricola erhalten hatte.

${ }^{59}$ Speziell für Reuchlin sei auch noch auf seinen Aufsatz über: Reuchlin's Philosophy: Pythagoras and Cabala for Christ, in: ARG 47 (1956) 1-20, hingewiesen, in dem als kennzeichnend für Reuchlin seine "synthetische Religionsphilosophie“ mit stark neuplatonisch-kabbalistischem Einschlag und deutlicher Tendenz zur Gnosis, statt zu ,echter Soteriologie“ dargelegt wird. Spitz betont Reuchlins heteronomen Moralismus und die hohe Autorität, die nichtchristlichen Quellen beigemessen wird. Das bringe in seine Theologie ein universal-theistisches Element.

${ }^{60} R$. R. Past, De Moderne Devotie. Geert Groote en zijn stichtingen (Amsterdam 1940, ${ }^{2} 1950$ ); englisch: The Modern Devotion. Confrontation with Reformation and Humanism (Leiden 1968). Die „humanistische" Position vertritt A. Hyma, The Christian Renaissance. A History of the „Devotio Moderna“ (New York 1924; mit Additional Chapters: Hamden 1965); ders.: The Brethren of the Common Life (Grand Rapids 1950). Generell im Sinne von Post: W. Lourdaux, Moderne Devotie en christelijk humanisme. De geschiedenis van Sint-Maarten te Leuven van 1433 tot het einde der XVIe eeuw (Löwen 1967) (315: „Niemals ... begeisterte Hingabe an das humanistische Denken“). Kritisch zu Post dagegen Spitz, in: Itinerarium (s. o. Anm. 14) 373 f., mit ähn- 
lich lautenden Stimmen anderer, in die er auch Lourdaux einbezieht, obwohl dieser dem Löwener Martinskloster zunächst gerade eine Sonderstellung zugesprochen hatte. Freilich hat Lourdaux seine ursprüngliche Position allmählich geändert; vgl. etwa: De Broeders van het Gemene Leven, in: Bijdragen. Tijdschrift voor filosofie en theologie 33 (1972) 397-409; De Sint-Maartensschool te Leuven. Moderne Devotie en onderwijs, een omstreden probleem, ebd. 37 (1976) 172-211; De Moderne Devotie te Leuven en haar verhouding tot de theologie, in: Facultas S. Theologiae Lovaniensis 1432-1797 (Löwen 1977) 313-326 (314: „De Sint-Maartensschool te Leuven vormt hiervan", nämlich: Einbeziehung der Profanwissenschaften durch die Devotio Moderna, „een frappant voorbeeld“). Betont man diesen Sachverhalt der Einbeziehung, so steht dem wohl kaum noch so konträr das dezidierte Urteil von 0 . Herding (Über einige Richtungen, s.o. Anm. 14, 76f.) über „die irrige Meinung“ entgegen, „man könne den Humanismus aus ihr (der Devotio moderna) herleiten“. Gute, wahrscheinlich abschließende Bemerkungen zum ganzen Komplex jetzt, mehr en passant, bei Oberman, Werden und Wertung (s. o. Anm. 58) 57-62.

${ }^{61}$ Besonderer Tadel galt Ockham, Swineshead und der ganzen englischen Schule; W. Kölmel, Scolasticus Literator. Die Humanisten und ihr Verhältnis zur Scholastik, in: Hist.Jb.93 (1973) 301-335; dort Kap. II: „Der Angriff auf die Scholastik“ 311-327.

${ }^{62}$ Richtungweisend war u.a. P. O. Kristeller, Humanism and Scholasticism in the Italian Renaissance, in: Byzantion 17 (1944/45) 346-374; wiederabgedruckt in: Studies in Renaissance Thought (s.o. Anm.3) und in: Renaissance Thought (s.o. Anm.38) zusammen mit thematisch ähnlichen Studien, die in deutscher Übersetzung jetzt bei Kristeller, Humanismus und Renaissance I (s.o. Anm. 3) zugänglich sind.

${ }^{63}$ Man muß sich nur hüten, den Renaissance-Humanismus nun wiederum ganz oder maßgeblich aus dem Mittelalter abzuleiten, wie es jüngst etwa W. Ullmann, Medieval Foundations of Renaissance Humanism (London 1977), tut. Vgl. auch Ullmanns Beitrag: Origini medievali del Rinascimento, in dem oben Anm. 1 genannten Sammelband: Il Rinascimento 43-102. Ebenso jetzt $W$. Kölmel, Aspekte des Humanismus (1981); dazu die harsche Rezension von A. Buck, in: Wolfenbütteler Renaissance Mitteilungen 6 (1982) 60-63. Vgl. zum Thema insgesamt: Die Rezeption der Antike (s. o. Anm. 42).

${ }_{632}^{63}$ S. o. Anm. 39.

${ }^{64}$ Kristeller, Humanismus und Scholastik (wie oben Anm.62) 108: „Streit der Künste, kein Kampf ums Dasein." Vor einer Überschātzung der Gegensätze warnte schon Ritter, Geschichtliche Bedeutung (s.o. Anm. 36) 404 ff. Ferner: J. H. Overfield, Scholastic Opposition to Humanism in Pre-Reformation Germany, in: Viator 7 (1976) 391-420; dort 419: „Many ,humanists" saw value in scholasticism and perceived dangers in the rejection of tradition and the unbridled pursuit of pagan literature." In gleicher Richtung: $J$. V. Mebl, Ortwin Gratius', Orationes Quodlibeticae': humanist apology in scholastic form, in: Journal of Med. and Ren. stud. 11 (1981) 57-69.

${ }^{65}$ Z.B. Ersetzung des Petrus Hispanus (der seinerseits soeben eine kurzfristige Spätblüte erlebt hatte) durch Handbücher der neuen rhetorischen Dialektik 1515-1535; A. Seifert, L'integrazione dell'Umanesimo nelle università tedesche, in: Annali dell'Istituto storico italo-germanico in Trento V (1979) 25-41; dort: 28-30; ders, Logik zwischen Scholastik und Humanismus. Das Kommentarwerk Johann Ecks (1978) (das Buch geht über Eck hinaus, der lediglich „einer ephemeren Übergangsperiode der Logikgeschichte“ (27) angehört, auf grundlegende Probleme der humanistischen Logik ein); zu Eck im übrigen E. Iserlob, Johannes Eck (1486-1543). Scholastiker, Humanist, Kontroverstheologe (1981). Die führenden Logiker wie Nifo, Zimara, Zabarella bauten humanistische Elemente in ihre eigenen traditionalistischen Kurse ein; $A$. Poppi, Introduzione all'Aristotelismo Padovano (Padua 1970). Lehrreich im übrigen C. B. Schmitt, Filosofia e scienza nelle università italiane del XVI secolo, in: Il Rinascimento (s.o. Anm.1) 353-398. Wenn die traditionelle Logik erst in den 20er Jahren zu Fall kam, so deshalb, weil sich zunächst die humanistische Grammatik durchsetzen mußte; T. Heath, Logical Grammar, Grammatical Logic, and Humanism in Three German Universities (nämlich: Freiburg, Ingolstadt und Tübingen), in: Studies in the Renaissance 18 (1971) 9-64. Zur Eck-Interpretation von Heatb jedoch kritisch Seifert, Logik 99 Anm. 3. Ein Überblick über die "humanistische" Reformierung der Curricula an deutschen Universitäten 1516-1543 bei Overfield, Scholastic Opposition (s. o. Anm. 64) $417 \mathrm{f}$. 
66 Über Erasmus braucht in diesem Zusammenhang kein Wort verloren zu werden. Zu Beatus Rhenanus s.o. Anm. 56 D'Amico, Beatus Rhenanus. Aber auch schon im Zusammenhang mit der neuen rhetorischen Logik spricht Seifert, Logik 22 (s. o. Anm.65), von einer „Fassadenrenovierung, die über die Revision der Fachterminologie hinweg bis tief in die Substanz der Logik Auswirkungen zeigte".

${ }^{67} \mathrm{Vgl}$. nur Salutatis Bildwendungen: „Emerserunt parumper nostro seculo studia litterarum .. Emerserunt et ista lumina Florentina“; Epistolario di Coluccio Salutati ed. F. Novati III (Rom 1896) 84. Oder: „Meonidas longo situ etatis nostre vitio et vetustate obductas iuvenescere“; a.a.O. IV (Rom 1911) 244. Overfield, Scholastic Opposition (s. o. Anm. 64) 419, weist darauf hin, daß sich die deutschen Humanisten den scholastischen Gegner z.T. erst künstlich aufbauten: „If by "sophist" is meant someone in opposition to humanism who rigidly defended scholasticism, it is remarkable how few „sophists“ had ever existed. The campaign of anti-humanist obstructionism, it seems, was grossly exaggerated by its intended victims."

${ }^{68}$ B. Moeller, Reichsstadt und Reformation (Schriften des Vereins für Reformationsgeschichte 180) (1962) 61: „Die norddeutschen Stādte sind geistig viel weniger lebendig als ihre süddeutschen Schwestern ... Der geistige und kulturelle Schwerpunkt Deutschlands liegt bis 1550, nimmt man die Breite der Durchbildung zum Maßstab, eindeutig im Süden. Das kommt etwa darin zum Ausdruck, daß es am Anfang des 16. Jahrhunderts in den norddeutschen Kleinstädten nur erst ganz zaghafte Anfänge des Humanismus gibt."

${ }^{69}$ Dazu auch der soeben erschienene Vortragsband: Humanismus und Ökonomie (Mitteilung VIII der Kommission für Humanismusforschung, hg. von $H$. Lutz) (1983). Wie darin W. Zorn, Humanismus und Wirtschaftsleben nördlich der Alpen (31-60), zeigt, hatten die Humanisten, die bloß literarisch interessiert waren, ein distanziertes Verhältnis zu Wirtschaftsfragen.

${ }^{70}$ Z. B. im Städtelob zum Ausdruck kommend; vgl. etwa J. Lebeau, L'éloge de Nuremberg dans la tradition populaire et la littérature humaniste de 1447 à 1532, in: Hommage à Dürer (Strasbourg et Nuremberg dans la première moitié du XVI ${ }^{\mathrm{e}}$ siècle = Publications de la Société Savante d'Alsace et des régions de l'Est. Recherches et Documents XII) (Straßburg 1972) 15-35. Zur Gattung insgesamt s. P. G. Schmidt, Mittelalterliches und humanistisches Städtelob, in: Die Rezeption der Antike (s.o. Anm. 42) 119-127. Eine neue umfassende Untersuchung ist wünschenswert.

${ }^{11}$ Moeller, Reichsstadt und Reformation (s.o. Anm. 68) 18: „Mit dem Reichtum sind die geistigen Bedürfnisse der Bürger gewachsen. Der Vergleich mit den italienischen Verhältnissen ist lehrreich." Dagegen neuerdings T. A. Brady, Jr., Ruling Class, Regime and Reformation at Strasbourg 1520-1555 (Leiden 1978) 189-193, die politische Führungsschicht sei dort nicht besonders stark universitär-fachlich gebildet gewesen; doch er fährt darüberhinaus fort (190): „Nor did the brief flowering of literary humanism during the 1510 s make much lasting impression, particularly on lay education, for the members of the Strasbourg literary group (or sodality) were mostly clerics" (unter Berufung auf Rapp, Réforme et Réformation à Strasbourg, Paris 1974). Daß es breitere Allgemeinbildung gab, zeigt $\mathrm{H}$. Kramm, Besitzschichten und Bildungsschichten der mitteldeutschen Städte im 16. Jahrhundert, in: VSWG 51 (1964) 454-491. Eine instruktive Monographie am Beispiel einer Stadt: U.M. Zabnd, Die Bildungsverhältnisse in den bernischen Ratsgeschlechtern im ausgehenden Mittelalter. Verbreitung, Charakter und Funktion der Bildung in der politischen Führungsschicht einer spätmittelalterlichen Stadt (Bern 1979) (mit āhnlich zurückhaltendem Ergebnis wie Brady, überwiegender Anteil des Klerus an der Universitätsbildung). Vgl. auch die Diskussion zwischen B. Moeller und T. A. Brady, Jr., in: Stadtbürgertum und Adel in der Reformation, hg. von W.J. Mommsen (1979), 25-43.

${ }^{72}$ Vgl. etwa die Beispiele Conrad Peutinger: H. Lutz, Conrad Peutinger - Beiträge zu einer politischen Biographie (1958), und Willibald Pirckheimer: N. Holzberg, Willibald Pirckheimer. Griechischer Humanismus in Deutschland (1981) (über das im Untertitel genannte Thema der Griechisch-Studien weit hinausgehend zur Persönlichkeit des Humanisten Pirckheimer insgesamt mit der einschlägigen älteren Literatur); vgl. dort etwa 56-167 das Kapitel „Der Autodidakt“. Das Gesamtbild der Forschung ist nach all dem doch noch recht uneinheitlich. Vielleicht unterliegt sie von Anfang an einem Fehler, wenn sie Klerus- und Laienbildung zu scharf gegenübersetzt. Die entsprechenden Unterschiede zwischen Klerus und Laienschaft waren weniger ständischer als formalrechtlicher Natur; es gab eine breite Schicht de facto „weltlich“ lebender Kleriker. 
${ }^{73}$ Der mitteldeutsche Humanismus ist noch immer unzureichend erforscht. Die Arbeit von $M$. Grossmann, Humanismus in Wittenberg 1485-1517, in: Luther-Jahrbuch 39 (1972) 11-30; erweitert als: Humanismus in Wittenberg (Nieuwkoop 1975), stellt hierfür einen neuen Ansatz dar, der an die nun schon fast ein Jahrhundert zurückliegenden Studien von G. Bauch anknüpft. Nützlich, aber nicht ganz befriedigend seitdem noch: E. C. Reinke, The Dialogus of Andreas Meinhardi. A Utopian Description of Wittenberg and Its University, 1508 (Ann Arbor, Mich., 1976). Zur Situation in Erfurt s. letztens $R$. W. Scribner, The Erasmians and the Beginning of the Reformation in Erfurt, in: Journal of Religious History 9(1976) 3-31. Im übrigen: E. Kleineidam, Universitas Studii Erffordensis. Überblick über die Geschichte der Universität Erfurt im Mittelalter 1392-1521. Teil II: 1460-1521 (1969) 38-63 („Der Frühhumanismus an der Universität Erfurt“; ebd. 38 die ältere Literatur: G. Bauch, G. Oergel, R. Abe) und 178-225 („Der Hochhumanismus im Angriff“, nämlich 1506-1516).

${ }^{74}$ Doch ist Vorsicht gegenüber voreiligen Frühdatierungen geboten, wie sie sich z. B. für die „humanistische“ Nürnberger Schulordnung von angeblich 1485 finden. Vgl. dazu die jüngste Richtigstellung bei Sicherl, Johannes Cuno (s.o. Anm. 56) $207 \mathrm{f}$.: erst 1511 (nach Bauch, Reicke und Machilek).

${ }^{75}$ In diesem Zusammenhang ist auch der Aufschwung der Biographie im deutschen Humanismus zu sehen, die freilich eine allgemein typische Ausdrucksform des europäischen Humanismus ist. $\mathrm{Zu}$ diesem Thema ist angezeigt worden eine letztens in Chicago abgeschlossene Dissertation von J. M. Weiss, Friendship and Rhetoric: The Development of Humanists' Biographies in Sixteenth-Century Germany, die ich noch nicht zu Gesicht bekommen habe. Wohl von dems. erschien kürzlich: Johannes Fichardus and the Uses of Humanistic Biography, in: ACTours (s.o. Anm. 23) 263-276.

${ }^{76}$ Vgl. zuletzt E. Schubert, Motive und Probleme deutscher Universitätsgründungen des 15. Jahrhunderts, in: Beiträge zu Problemen deutscher Universitätsgründungen der frühen Neuzeit (Wolfenbütteler Forschungen IV), hg. von P. Baumgart und N. Hammerstein (1978), 13-74; zum fürstlichen Prestigedenken (das übrigens eine lange mittelalterliche Tradition hat): $21 \mathrm{f}$. Ferner: 0. Herding, Pädagogik, Politik, Geschichte bei Jakob Wimpfeling, in: L'Humanisme allemand (s.o. Anm. 14) 113-130, mit charakteristischen Äußerungen dieses fürstlichen Interesses.

${ }^{77}$ H. Rössler, Adelsethik und Humanismus, in: Deutscher Adel 1430-1555 (Schriften zur Problematik der deutschen Führungsschichten in der Neuzeit I) (1965) $246 \mathrm{f}$. Als Beispiel für eine süddeutsche Landschaft sei lediglich genannt: $A$. Kraus, Gestalten und Bildungskräfte des fränkischen Humanismus, in: M. Spindler (Hg.), Handbuch der bayerischen Geschichte III (1971) 556602, doch mit der bemerkenswerten Einschränkung a.a.O. 569: „Es fehlten wesentliche soziologische Voraussetzungen für eine selbstverständliche Blüte des Humanismus im geistlichen und fürstlichen Franken ..., es fehlte das bürgerliche Bedürfnis, durch gehobene Bildung dem Adel und Klerus ebenbürtig gegenübertreten zu können."

${ }^{78}$ Zur Frage Adel und Humanismus s. jetzt auch $V$. Press, Führungsschichten in der Neuzeit. Eine Zwischenbilanz (Deutsche Führungsschichten in der Neuzeit 12) (1980) 67; dennoch 74: „Dies darf aber nicht darüber hinwegtäuschen, daß der allgemeine Quellgrund des europäischen und somit auch des deutschen Humanismus das städtische Bürgertum war." Parallel, nicht ohne Beziehung zum Humanismus-Problem, entwickelte sich die bisweilen geradezu einseitige Herleitung der Reformation aus städtischen Voraussetzungen. Programmatisch A. G. Dickens, The German Nation and Martin Luther (London 1974) 182: „The German Reformation was an urban event at once literary, technological and oratorical." Vgl. zu dieser Frage letzthin H. C. Rublack, Forschungsbericht Stadt und Reformation, in: Stadt und Kirche im 16. Jahrhundert, hg. von $B$. Moeller (Schriften des Vereins für Reformationsgeschichte 190) (1978) 9-26. Vgl. auch Brady, Ruling Class (s.o. Anm. 71), der sich gegen ein allzu ideales Bild der damaligen Stadtgemeinde wendet.

${ }^{79}$ In dem landschaftlich gegliederten Forschungsüberblick von 0 . Herding, Ubber einige Richtungen (s.o. Anm. 14), nehmen von den 51 Seiten allein 37 der süd- und südwestdeutsche Humanismus ein.

${ }^{80} H$. Rupprich, Humanismus und Renaissance in den Städten und an den Universitäten (1935) (Deutsche Literatur in Entwicklungsreihen) 226-238. Hier wird der allgemeine Aufschwung der 
Wissenschaften wie der oben genannten Naturwissenschaften, also nicht nur der Humaniora angesprochen. Als oberste und maßgebliche Bildungskraft erscheint jedoch die in Dichtkunst und Rede vollendete Eloquenz, die erst alle "doctrina“ fruchtbar macht und zur wahren "sapientia“ führt. Grundlegend $L$ W. Spitz, Conrad Celtis the German Arch-Humanist (Cambridge, Mass., 1957). Nur am Rande sei bemerkt, daß die Übersetzung der Ingolstädter Rede von $H$. Heger, Spätmittelalter. Humanismus. Reformation. Texte und Zeugnisse, Zweiter Teilband: Blütezeit des Humanismus und Reformation (Die deutsche Literatur II/2) (1978) 3-11, undiskutabel ist. Vgl. demgegenüber die englischen Auszüge bei Spitz, Conrad Celtis 26-31.

${ }^{81}$ Der genaue Titel lautet: Cathalogus illustrium virorum Germaniam suis ingeniis et lucubrationibus omnifariam exornantium; erschienen: Mainz 1495. Spitz, Course of German Humanism (s.o. Anm. 14) 404, spricht in diesem Zusammenhang von „cultural nationalism“.

${ }_{82}$ Zusammenstellung der entsprechenden Äußerungen bei Moeller, Deutsche Humanisten (s.o. Anm.37) 52.

${ }^{83}$ Aufschlußreich hierzu auch die schöne Spezialstudie von $D$. Wuttke, Dürer und Celtis: Von der Bedeutung des Jahres 1500 für den deutschen Humanismus: Jahrhundertfeier als symbolische Form;, in: Journal of Med. and Ren. studies 10 (1980) 73-129; dass. ohne Fußnoten, aber mit instruktiven Diskussionsbeiträgen, in: Humanismus und Reformation als kulturelle Kräfte (s. o. Anm. 30) 121-150 und 200-214.

${ }^{84}$ Dazu auch noch $F . J$. Worstbrock, Über das geschichtliche Selbstverständnis des deutschen Humanismus, in: Historizităt in Sprach- und Literaturwissenschaft, hg. von W. Müller-Seidel (1974), 499-519. Aus der älteren Literatur vor allem Joachimsen, Geschichtsauffassung; s.o. Anm. 26.

${ }^{85}$ Mannigfache Aspekte hierzu treten in dem Sammelband ,Das Verhältnis der Humanisten zum Buch“ hervor (DFG Kommission für Humanismusforschung, Mitteilung IV) (1977). Ferner auch E. L. Eisenstein, The Printing Press as an Agent of Change. Communications and cultural transformations in early-modern Europe I-II (Cambridge usw. 1979), sowie $R$. Hirsch, Printing, Selling and Reading. 1450-1550 (1967). R. G. Cole, The Reformation Pamphlet and Communication Processes, in: Flugschriften als Massenmedium der Reformationszeit, hg. von H.-J. Köbler (Spätmittelalter und frühe Neuzeit 13) (1981), 155-158, gibt einen Querschnitt durch die Thematik einer Flugschriftensammlung jener Zeit. Selbst hier sind etwa im Verhältnis zu mancherlei Vulgärliteratur die Humaniora gar nicht so schlecht vertreten.

${ }^{86}$ Wobei ich mir mit der Forschung über die Problematik dieses Begriffs durchaus im klaren bin. Dazu letztens Woblfeil, Einführung (s.o. Anm. 30) 123-133 mit der Literaturliste ebd. 217-219.

${ }^{87}$ Studien, wie sie der Titel der Vortragssammlung, Die Humanisten in ihrer politischen und sozialen Umwelt' (DFG Kommission für Humanismusforschung, Mitteilung III, 1976) im allgemeinen umreißt, verdienten speziell in dieser Richtung weitergetrieben zu werden. Für unser Thema aufschlußreich ist u. a. auch der Anteil humanistischer Titel an Privatbibliotheken der frühen Neuzeit. Dazu erstmals H. Kramm, Deutsche Bibliotheken unter dem Einfluß von Humanismus und Reformation (1938, ND 1968). Weitere Literatur jetzt bei $E$. Weyrauch, Überlegungen zur Bedeutung des Buches im Jahrhundert der Reformation, in: Flugschriften als Massenmedien (s. o. Anm. 85) 243-259 (insbesondere $250 \mathrm{Anm}$. 23), wo auf eine in Vorbereitung befindliche Sozial- und Kulturgeschichte des bürgerlichen Buchbesitzes im 16./17. Jahrhundert vorverwiesen wird. Vgl. dazu auch in: Wolfenbütteler Barock-Nachrichten 8 (1981) 150-154. Bei $B$. Vogler, Le clergé protestant thénan au siècle de la Réforme (1555-1619) (Paris 1976) 282-289, finden sich Zahlen über "humanistische" Bücher in Klerikerbibliotheken; doch sind die zugrunde liegenden Angaben der Zeitgenossen offensichtlich lückenhaft, so daß ein Gesamturteil über das humanistische Interesse kaum möglich ist. Die für unsere Epoche einschlägigen ersten Kapitel bei $R$. Engelsing, Der Bürger als Leser. Lesergeschichte in Deutschland 1500-1800 (1974), sind nur wenig ergiebig.

${ }^{88}$ Seifert, Logik (s. o. Anm. 65) 23: Ruf nach „Beschneidung einer durch das Interesse an Exaktheit unerträglich kompliziert gewordenen Terminologie“.

${ }^{89}$ "Sprachbildung" hat man im weitest-einflußreichen Sinne zu verstehen. Vgl. z. B. den Einfluß der Sprache auf das Kunstwerk der Renaissance; G. Kauffmann, Zum Verhältnis von Bild und Text in der Renaissance (Rhein.-Westfäl. Akademie d. Wiss. Geisteswiss. Vorträge 249) (1980). 
90 Über die psychologischen Konsequenzen s. jetzt auch P. Laurens, Rome et la Germanie chez les poètes humanistes allemands, in: L'Humanisme allemand (s. o. Anm. 14) 339-355: Indem die deutschen Humanisten z.B. darauf hinweisen, daß die Deutschen die Klassiker-Handschriften verwahrt hatten, welche die Italiener jetzt nach Süden abschleppten, versuchten sie das kulturgeschichtliche Abhängigkeitsverhältnis krampfhaft umzukehren. Zum „mythe de la continuité“, den die deutschen Humanisten pflegten, s. Ridé, Un grand projet, unten Anm.96. Im übrigen gab es Italiener, die jene Handschriften als Raubstücke der deutschen Invasoren in Italien ansahen. Vgl. Guarino an Pizolpasso (A. Sottili, Wege des Humanismus: Lateinischer Petrarchismus und deutsche Studentenschaften italienischer Renaissance-Universitäten, in: From Wolfram and Petrarch to Goethe and Grass. Studies in Literature in Honour of Leonard Forster, 1982, $136 \mathrm{f}$.): „In istis Germanie Gallieque latebris infinita quedam librorum copia iacet, superiorum etatum spolia Ytalie civitatibus, ut certis signis et testimoniis adducor, abacta, ... quos tua ... diligencia et humanitas ex tenebris in lucem, ab exilio in patriam revocare possit.“

91 . Amelung, Das Bild des Deutschen in der Literatur der italienischen Renaissance (1400-1559) (1964).

${ }^{92}$ Vgl. ebd. 66-73 den aufschlußreichen „Exkurs: Die Reaktion der deutschen Humanisten auf das Barbaren-Verdikt der Italiener." Wie sich im Laufe der Zeit der deutsche Humanismus eigenes Profil gab, zeigt am Beispiel des Beatus Rhenanus D'Amico, Beatus Rhenanus and Italian humanism (s.o. Anm. 56). Auch Erasmus bemühte sich, seine frühere italienische Beeinflussung vergessen zu machen; dazu $R$. Marcel, Les dettes d'Érasme envers Italie, in: Actes du Congrès Erasmien (Amsterdam 1971) 159-173.

${ }^{93}$ Zum Grundbestand deutscher Humanistenideale gehörte der Freiheitsgedanke; s. L. W. Spitz, Ideas of Liberty in German Humanism, in: Church History 31 (1962) 336-349. In ihm verband sich Persönliches mit dem Wunsch, von fremder Bevormundung frei zu sein.

${ }^{94}$ Ein schönes Beispiel ist die „Germanisierung“ des Herkules (nach Tacitus) und die dementsprechende Nutzung für deutsche Tagespolitik und Nationalpatriotismus; s. W. C. McDonald, Maximilian I of Habsburg and the veneration of Hercules: on the revival of myth and the German Renaissance, in: Journal of Med. and Ren. studies 6 (1976) 139-154, mit Übersicht über die umfangreiche Literatur zum Herkules-Thema. - Dem Überblick von S. Dresden, The Profile of the Reception of the Italian Renaissance in France, in: Itinerarium Italicum (s.o. Anm. 14) 119-189, zufolge spielte das nationale Moment im französischen Humanismus dagegen keine Rolle. In Frankreich ist die „nationale“ Entwicklung ganz und gar „politisch“ verlaufen und war damals schon weitgehend ausgereift; vgl. dazu neuerdings viel Material und Literatur bei $J$. Krynen, Idéal du prince et pouvoir royale en France à la fin du moyen âge (1380-1440) (Paris 1981). So auch das Ergebnis von $H$. Böhm, „Gallica Gloria“. Untersuchungen zum kulturellen Nationalgefühl in der älteren französischen Neuzeit, Diss. phil. Freiburg (1977) 400, „daß das kulturelle Nationalgefühl kaum eine zentrale Stellung“ im Denken der „französischen Humanisten einnahm“ (z.B. recht gezwungener Rückgriff auf die Kelten!).

${ }^{95}$ Grundlegend jetzt $J$. Ridé, L'image du Germain dans la pensée et la littérature allemandes de la redécouverte de Tacite à la fin du XVI $\mathrm{XV}^{\mathrm{e}}$ siècle. Contribution à l'étude de la genèse d'un mythe I-III (Thèse Paris IV) (Paris 1977). Vgl. auch L. Krapf, Germanenmythus und Reichsideologie. Frühhumanistische Rezeptionsweisen der taciteischen "Germania“ (1979).

${ }^{96} \mathrm{~J}$. Ridé, Un grand projet patriotique: „Germania illustrata“, in: L'Humanisme allemand (s.o. Anm. 14) 99-111. Vorbild war die „Italia illustrata“ des Flavio Biondo, die erste geographisch-historische Landesbeschreibung überhaupt. Vgl. auch oben Anm. 27.

${ }^{97}$ Moeller, Deutsche Humanisten (s. o. Anm. 37), hebt „Dynamik“ (57), „Begeisterung“ (58), „Optimismus“ (60) usw. wiederholt hervor. Hat es bei Moeller zunächst den Anschein, dies seien Kennzeichen des Humanismus überhaupt (46f.), so schränkt er später, wo er von der Aufnahme Luthers durch Humanisten in den romanischen Ländern spricht, doch ein (und, wie ich meine, sachgerecht): „Allerdings ist hier die erste Begeisterung, naturgemäß, nicht so allgemein wie in Deutschland" (59 Anm. 47).

${ }^{98}$ M. Schmidt, Luthers Schau der Geschichte, in: Luther-Jahrbuch 30 (1963) 17-69; H.-G. Hofak$k e r$, „Vom alten und nüen Gott, Glauben und Ler“. Untersuchungen zum Geschichtsverständnis 
und Epochenbewußtsein einer anonymen reformatorischen Flugschrift, in: Kontinuität und Umbruch (s. o. Anm. 35) 145-177.

${ }^{99}$ Uber das gleichwohl historische Interesse im evangelischen Bereich (auch Luthers selbst) vgl. etwa Strauss, Course of German History (s.o. Anm. 14) 678-686, sowie in aller Kürze Spitz, Humanism in the Reformation (s.o. Anm.30) 654f. Uber die göttliche Sendung Deutschlands als damaliges „stereotype in historical literature“ im Zusammenhang mit dem gottgewollten Erfolg der deutschen Reformation s. Strauss, Course of German History 684. Zu Luther s. noch J. Headley, Luther's View of Church History (New Haven 1963): Gott realisiert seine Möglichkeiten in der geschichtlichen Zeit. Ähnlich schon $H$. W. Krumwiede, Glaube und Geschichte in der Theologie Luthers. Untersuchung zum Entstehen des geschichtlichen Denkens in Deutschland (1952). Zu Melanchthon s. P. Fraenkel, Testimonia Patrum. The Function of the Patristic Argument in the Theology of Philip Melanchthon (Travaux d'Humanisme et Renaissance 46) (Genf 1961).

${ }^{100}$ Rüdiger, Wesen und Wandlung des Humanismus (s.o. Anm. 2), stellt zwei aufeinanderfolgende Kapitel seines Buches mit Recht gegenüber: „Ulrich von Hutten und der deutsche Humanismus" und: „Desiderius Erasmus und der europäische Humanismus“.

${ }^{101}$ Vgl. etwa das Resümee: „Gesamtgesellschaftliche Krise“?, in: Moeller, Deutschland im Zeitalter der Reformation (s.o. Anm. 37) 46f.; H. Boockmann, Zu den geistigen und religiösen Voraussetzungen des Bauernkrieges, in: Bauernkriegs-Studien, hg. von B. Moeller (1975) 9-27. Einen (von den fehlenden theologischen Quellen abgesehen) repräsentativen Querschnitt durch „Manifestations of Discontent in Germany on the Eve of the Reformation“ bietet die so betitelte Quellensammlung von der „Reformatio Sigismundi“ bis zur Judenvertreibung aus Regensburg 1519, die G. Strauss (Bloomington und London 1971) herausgegeben hat.

${ }^{102}$ Den Komplex Humanismus und (Bildende) Kunst lasse ich im folgenden ganz beiseite. Die Forschung entwickelt hier z.Zt. ganz neue Ansātze. Vgl. G. Kauffmann, Humanitas und Rhetorik in der deutschen Kunst um 1500, in: L'Humanisme allemand (s.o. Anm. 14) 493-504, sowie die ebd. 505-592 folgenden Artikel über Einzelthemen. Vgl. auch Wuttke, Dürer und Celtis (s. o. Anm. 83).

103 Über die damalige Deutung der Gegenwart als „goldenes Zeitalter" s. D. Wuttke, Wunderdeutung und Politik. Zu den Deutungen der sog. Wormser Zwillinge des Jahres 1495, in: Landesgeschichte und Geistesgeschichte. Festschrift O. Herding (1977) 233 und 241, mit weiterer Literatur; Wuttke, Dürer und Celtis (s.o. Anm.83) 112-115.

${ }^{104} \mathrm{Daß}$ dies aber nicht so eng und von einer sich von Valla über Erasmus ziehenden Linie aus allein zu sehen ist, sondern ein breiterer Traditionsstrom wirkt, machen die verschiedenen Beiträge in der Vortragssammlung: Histoire de l'exégèse au XVI ${ }^{\mathrm{e}}$ siècle. Textes du Colloque international tenu à Genève en 1976, hg. von O. Fatio und P. Fraenkel (Genf 1978), offenkundig. Vgl. auch die unten in Anm. 181 genannte Literatur.

${ }^{105} \mathrm{Vgl}$. etwa den Forschungsbericht von $R$. Stupperich, Humanismus und Reformation in ihren gegenseitigen Beziehungen, in: Kommission für Humanismusforschung, Mitteilung II (s.o. Anm. 14) 41-57. Wesentlich kritischer und dem heutigen Forschungsstand entsprechend zurückhaltender zu diesen Beziehungen: G. Müller, Reformationsgeschichte, innerhalb des Forschungsüberblicks: Die Renaissance im Selbstverständnis der heutigen Wissenschaft, in: Wolfenbütteler Renaissance Mitteilungen 1 (1977) 43-47. Vgl. jetzt auch die Beiträge in der IV. Section: „Humanisme et Réformes“, in: L'Humanisme allemand (s. o. Anm. 14) 357-491 (zu den einzelnen Beiträgen s. weiter unten).

106 Vgl. in diesem Sinne auch die beiden Beiträge von Laurens, Rome et la Germanie (s.o. Anm.90), sowie von M. Greschat, Humanistisches Selbstbewußtsein und reformatorische Theologie, in dem oben (Anm. 14) genannten Sammelwerk: L'Humanisme allemand 371-386.

${ }_{107} \mathrm{~J}$. Beumer, Erasmus von Rotterdam und sein Verhältnis zu dem deutschen Humanismus mit besonderer Rücksicht auf die konfessionellen Gegensātze, in: Scrinium Erasmianum I (Leiden 1969) 165-201; P. Bietenbola, Érasme et le public allemand, 1518-1520: Examen de sa correspondance selon les critères de la publicité intentionelle ou involontaire, in: L'Humanisme allemand (s.o. Anm. 14) 81-98. Ein Gesamtbild der Beurteilung des Erasmus im 16. und 17. Jh. gibt A. Flitner, Erasmus im Urteil seiner Nachwelt. Das literarische Erasmusbild von Beatus Rhena- 
nus bis zu Jean Le Clerc (1952). Dort heißt es zu unserer Frage (20): „Die erasmusfreundlichen Elemente der Reformation, das melanchthonsche und das zwinglische, sind nicht die bestimmenden für die nächste Zukunft und werden zurückgedrāngt im Zeitalter der Religionskāmpfe und der konfessionellen Verhärtungen.“

${ }_{108} E .-W . K o b l s$, Erasmus und die werdende evangelische Bewegung des 16. Jahrhunderts, in: Scrinium Erasmianum (s.o. Anm. 107) 203-219; Spitz, Humanism in the Reformation (s.o. Anm. 30) 647 f.; J.-C. Margolin, Mutianus Rufus et son modèle érasmien, in: L'Humanisme allemand (s. o. Anm. 14) 169-202; dort über den ,esprit irénique“, den der erasmianische Humanismus den Reformatoren vermittelte. Im gleichen Sinne $R$. Stupperich, Erasmus und Melanchthon in ihren gemeinsamen Bestrebungen, ebd. 405-426: ungebrochenes Ziel Melanchthons, pietas und eruditio zu versöhnen. Doch vgl. dazu unbedingt auch unten Anm. 168.

${ }^{109}$ Die Haltung war oft schwankend, anfänglicher Zustimmung folgte oft spätere Distanzierung. Vgl. etwa Holzberg, Willibald Pirckheimer (s. o. Anm. 72) 263-371 („Der Publizist und Úbersetzer in seiner Auseinandersetzung mit der Reformation 1521-1530").

${ }^{110}$ Forschungsgeschichtlich aktuell gemacht von H. Schöffler, Die Reformation (1936) $37 \mathrm{f}$. Vgl. auch Augustijn, Stellung der Humanisten (s. o. Anm.30), sowie unten Anm.113.

${ }^{111}$ Das „Selbstbewußtsein“ der Humanisten als Verständnisbrücke für ihren Zuschlag zu Luther ist ausdrücklich thematisiert und ausführlich abgehandelt von Greschat, Humanistisches Selbstbewußtsein (s. o. Anm. 106), der sich einerseits von dem „Uberbau“verdacht salvieren zu müssen glaubt (was unter Zugrundelegung sozial-psychologischer Kategorien aber gar nicht nötig ist), andererseits die „nationale“ Komponente dabei zu kurz kommen läßt. Vgl. dazu vor allem auch oben Anm. 99.

${ }_{112}$ Wahrscheinlich wird der Historiker dem psychologischen Moment überhaupt viel größere Bedeutung beizumessen haben, als es geschieht, wenn Geschichte zu sehr aus einem Kräftespiel "objektiver“, „struktureller“ Faktoren syllogistisch deduziert wird.

${ }^{113}$ Moeller, Deutsche Humanisten (s.o. Anm. 37) 56 f. Die Universität Wittenberg hatte den jüngsten Lehrkörper in Deutschland. $H$. Schöffler, Wirkungen der Reformation. Religionssoziologische Folgerungen für England und Deutschland (1960) 126-132: „Die jugendlichste Fakultät“. Die katholisch bleibenden Humanisten waren in der Regel älter. S. auch Spitz, Religious Renaissance (s.o. Anm. 32) $291 \mathrm{f}$.

${ }^{114}$ Grundlegend W. Maurer, Der junge Melanchthon zwischen Humanismus und Reformation I: Der Humanist, II: Der Theologe (1967-1969). Ferner A. Sperl, Melanchthon zwischen Humanismus und Reformation (1979). Zur älteren Literatur vgl. im übrigen $M$. Greschat, Zwanzig Jahre Melanchthonstudium. Sechs Literaturberichte (1945-1965) (Genf 1967) 72-77 und 150-158. Für die nāchste Generation sei hier lediglich auf Joachim Camerarius hingewiesen. F. Baron $(\mathrm{Hg}$.), Joachim Camerarius (1500-1574). Beiträge zur Geschichte des Humanismus im Zeitalter der Reformation (Humanistische Bibliothek I, 24) (1978) (Sammelband mit Einzelbeiträgen).

${ }^{115}$ Moeller, Deutsche Humanisten (s. o. Anm. 37) 54.

${ }^{116}$ Vgl. etwa E. Iserlob, Geschichte und Theologie der Reformation im Grundriß $\left(1980,{ }^{2} 1982\right)$ 48: ,Jedenfalls ist es Melanchthon zu verdanken, daß die Reformation nicht gegen, sondern mit der Bildung der Zeit ging." Neuerdings $H_{\text {. }}$ A. Stempel, Melanchthons pädagogisches Wirken (1979) (nicht ganz befriedigend). Neuss, Melanchthons Einfluß auf das Gymnasialschulwesen (s. u. Anm.125) 134, resümiert, ,daß Melanchthon nach dem verhängnisvollen Bruch zwischen Humanismus und Reformation auch in Schuldingen die Mittlerrolle und die Mittelstellung einnahm, die Luther, der innerlich mit den letzten Zielen des Humanismus niemals in Berührung gekommen war, weder behaupten konnte noch wollte.“

${ }_{117}$ M. Brecht, Martin Luther. Sein Weg zur Reformation 1483-1521 (1981); dort die Kapitel „Der Erfurter Humanismus und Luther“ 48-53 (52: „Der Theologe und Bibelausleger Luther hat manche seiner Wurzeln auch im Humanismus seiner Studienzeit; später erhielt er weitere Impulse aus dieser Richtung. Das Angebot des Humanismus hat er freilich auf eigene Weise verwendet. Letzte Autorität wurden ihm die klassischen Autoren nie. Auch sein religiöser Weg erscheint kaum durch den Humanismus beeinflußt. Es war später vielmehr so, daß nicht zuletzt die Tiefe seines Ansatzes weithin die Oberflächlichkeit der humanistischen Auffassung erkennen und sie überholt sein ließ.") und „Distanzierung vom Humanismus" 160-164 mit Vorausverweis 
auf Luthers Gegensatz zu Erasmus als „bis in die Grundfragen des Menschseins reichender Konflikt Luthers mit dem ,Humanismus'." Doch im gleichen Sinne bereits Moeller, Deutsche Humanisten (s.o. Anm. 37) 49. Auch Spitz, Religious Renaissance (s.o. Anm. 32) 293, sehr eindeutig: "Luther rejected the Renaissance synthesist solution of the problem of religion and culture." Ders., Headwaters of the Reformation: Studia Humanitatis, Luther Senior, et Initia Reformationis, in: Oberman (Hg.), Luther (s. o. Anm. 34) 89-116: Trotz persönlicher Freundschaft zu evangelischen Humanisten in der Sache (115) ,clear distinctions and sharp contrasts between Luther's conception of God and the evaluation of man and those predominant in Renaissance humanism and Platonism." Vgl. auch das Kapitel: Luthers Absage an den Humanismus (von E. Iserlob), in: Handbuch der Kirchengeschichte, hg. von H. Jedin, IV (1967) 146-157. Der Versuch von H. $O$. Burger, Martin Luther und der Humanismus, in: L'Humanisme allemand (s. o. Anm. 14) 357-369, eine innigere Verbindung herzustellen, scheitert, weil er zu eng und in diesem Zusammenhang auch zu ăußerlich auf der humanistischen Affektenlehre aufbaut. Zur Entwicklung des Problems "Luther und der Humanismus" in der jüngeren Forschung s. H. Jungbans, Der Einfluß des Humanismus auf Luthers Entwicklung bis 1518, in: Luther-Jahrbuch 37 (1970) 37-45.

${ }^{118}$ Es dürfte kaum bekannt sein, daß auf die ,Introductiones Latinae (1481/1495) des Antonio de Nebrija (Lebrija), eines Hauptmitarbeiters an der Polyglotte, das Gerundium und Supinum unserer Schulgrammatik zurückgehen. Zur Polyglotte immer noch grundlegend Bataillon, Erasmo y España 10-43 (s.u. Anm. 164). Vgl. jetzt auch $J$. H. Bentley, New Light on the Editing of the Complutensian New Testament, in: BHR 42 (1980) 145-156.

${ }^{119}$ Zur gerade gegensätzlichen, sich gegen Luther wendenden Entwicklung bei Clichtove s. Massaut, Josse Clichtove (s.o. Anm. 52).

${ }^{120}$ Daß dieser Begriff allerdings sehr differenziert zu verwerten ist, wurde neuerdings gerade im Zusammenhang mit der Verwendung von Kirchengut für neue Bildungseinrichtungen betont; $P$. Baumgart, Die deutsche Universität des 16. Jahrhunderts. Das Beispiel Marburg, in: Hess. Jb. f. Landesgesch. 28 (1978) 68 f.; A. Schindling, Die Universitāt Gießen als Typus einer Hochschulgründung, in: Academia Gissensis, hg. von P. Moraw und V. Press (1982) $89 \mathrm{f}$.

${ }^{121}$ Beispiele: J. Rauscher, Die Prädikaturen in Württemberg vor der Reformation, in: Württ. Jbb. f. Statistik und Landeskunde 2 (1908) 152-211;H. Tüchle, Kirchengeschichte Schwabens II (1954) 364-378; T. Freudenberger, Der Würzburger Domprediger Dr. Johann Reyss. Ein Beitrag zur Geschichte der Seelsorge im Bistum Würzburg am Vorabend der Reformation (1954); $E$. Lengwiler, Die vorreformatorischen Prädikaturen der deutschen Schweiz von ihrer Entstehung bis 1530 (Fribourg 1955); P. Mai, Predigtstiftungen des späten Mittelalters im Bistum Regensburg, in: Beitr. zur Gesch. d. Bist. Regensburg 2 (1968) 7-33; R. Kießling, Bürgerliche Gesellschaft und Kirche in Augsburg im Spätmittelalter (1971) 301-305; G. Geiger, Die Reichsstadt Ulm vor der Reformation. Städtisches und kirchliches Leben am Ausgang des Mittelalters (1971) 150-152; S. E. Ozment, The Reformation in the Cities. The Appeal of Protestantism to SixteenthCentury Germany and Switzerland (New Haven und London 1975) 38-42 (zu dem Buche insgesamt vgl. jedoch die Rezension von B. Moeller, in: ARG 68 (1977) 317-319). Im Protestantismus drängte die Kanzel dann den Altar in seiner Bedeutung sichtlich zurück; $H$. Mai, Der evangelische Kanzelaltar. Geschichte und Bedeutung (1969). Diese Entwicklung der Predigt bildete eine wesentliche Voraussetzung für die zur Begründung der reformierten Kirchen wichtige Glaubensdisputation; B. Moeller, Zwinglis Disputationen. Studien zu den Anfängen der Kirchenbildung und des Synodalwesens im Protestantismus, in: ZRG KA 56 (1970) 275-324 und 60 (1974) 213-364. G. W. Locher, Die Zwinglische Reformation im Rahmen der europäischen Kirchengeschichte (Göttingen und Zürich 1979) 267-282; E. Walder, Reformation und moderner Staat, in: 450 Jahre Berner Reformation (Arch. d. Hist. Ver. des Kantons Bern 64/65, 1980/81) 445-583.

${ }^{122}$ Das schloß Warnungen vor damit verbundener „Verweltlichung“ natürlich nicht aus. Vgl. bei D. Hay, The Church in Italy in the Fifteenth Century (Cambridge 1977) 91-109, das Kapitel "The Italian Renaissance and the Clergy of Italy in the Fifteenth Century" mit dem entsprechenden Ergebnis (108): „Few would have followed the argument over, poetry" or ,paganism “. Generell: „As for the effects of the Renaissance on the clergy in the end they had no alternative but to conform to the new manner... In any case the leader of the clergy, the cardinals and above all 
the pope, if they gave no lead worth the name in church reform, did give a lead in the literary, moral and artistic developments."

${ }^{123}$ So etwa schon in Wittenberg; dazu Grossmann, Humanismus in Wittenberg (s. o. Anm. 73), mit der eindeutigen Feststellung (134): „It is a dubious supposition to regard humanism as a natural ally of Protestantism". Weiteres bei Spitz, in: Itinerarium (s. o. Anm. 14) 415-420.

${ }^{124} \mathrm{Zu}$ Luthers Unterstützung des Humanismus in Wittenberg s.u.a. einzelne Beiträge im Sammelband „450 Jahre Martin-Luther-Universität Halle-Wittenberg I. 1502-1816“ (1952). Moeller, Deutschland im Zeitalter der Reformation (s.o. Anm. 37) 122: „Luther selbst hat diese geschichtliche Begegnung und Vereinigung (von Reformation und Humanismus) immer wieder als ein Werk der Vorsehung gedeutet.“ Die Unterscheidung von Nützlichkeit und theologischer Relativierung im Verhältnis Luthers zum Humanismus tritt im Luther-Kapitel bei Spitz, Religious Renaissance 237-266, heraus. Maßgeblich wohl jetzt vor allem das Kapitel „Universitāts- und Wissenschaftsreform im Bund mit dem Humanismus“ bei Brecbt, Martin Luther (s.o. Anm. 117) 264-284. Dazu H.-B. Kaufmann, Grundfragen der Erziehung bei Luther, in: Luther. Mitteilungen der Luthergesellschaft 25 (1954) 60-76. Vgl. auch W. Maurer, Über den Zusammenhang zwischen kirchlicher Ordnung und christlicher Erziehung in den Anfängen lutherischer Reformation, in: Praxis Ecclesiae. K. Frör zum 65. Geburtstag (1970) 60-85, sowie Weyrauch, Überlegungen zur Bedeutung des Buches (s.o. Anm.87). Auf die „praktische“ Bedeutung der Humanisten für die "politische" Seite der Reformation weist hin: J. M. Kittelson, Humanism and the Reformation in Germany, in: Central European History 9 (1976) 303-322.

${ }^{125} \mathrm{Vgl}$. etwa $M$. Brecht, Luthertum als politische und soziale Kraft in den Stādten, in: Kirche und gesellschaftlicher Wandel in deutschen und niederländischen Stādten der werdenden Neuzeit, hg. von F. Petri (1980), $12 \mathrm{f}$. Zur Bedeutung Melanchthons in diesem Zusammenhang: F. Hofmann, Philipp Melanchthon und die zentralen Bildungsprobleme des Reformationsjahrhunderts. Ein Beitrag zur erziehungsgeschichtlichen Wertung des 16. Jahrhunderts, in: Philipp Melanchthon. Humanist, Reformator, Praeceptor Germaniae (1963) 83-109, und ebd. 110-137: E. Neuss, Melanchthons Einfluß auf das Gymnasialschulwesen der mitteldeutschen Städte im Reformationszeitalter; hier 122 der "philippische" Grundsatz: „Die Grammatik wirkt in der Schule, der Katechismus in der Kirche Wunder".

${ }^{126}$ In dem kürzlich erschienenen Buch von $G$. Strauss, Luther's House of Learning: Indoctrination of the Young in the German Reformation (Baltimore und London 1978), taucht der Begriff "Humanismus“ nirgendwo auf. Gleichwohl erscheint auch hier im Kapitel „Techniques of Indoctrination: Schooling“" $188 \mathrm{f}$. die Lektüre der Klassiker. Doch fällt weitaus deutlicher die völlige Dominanz der religiösen Erziehungsziele und -praxis auf; vgl. programmatisch Kapitel 11: „The making of a Christian: Religion and discipline“. Vgl. auch die beiden Beiträge von G. Strauss, Reformation and Pedagogy: Educational Thought and Practice in the Lutheran Reformation, und von L.W. Spitz, Further Lines of Inquiry for the Study of „Reformation and Pedagogy“, in: Pursuit (s.o. Anm. 41) 272-306.

${ }_{127} R$. Stauffer, L'influence et la critique de l'humanisme dans le, De vera et falsa religione' de Zwingli, in: L'Humanisme allemand (s.o. Anm. 14) 427-439. Dort die einschlägige Literatur, vor allem: $E$ - $W$. Kobls, Die theologische Lebensaufgabe des Erasmus und die oberrheinischen Reformatoren (s.o. Anm. 56). Ferner: G. W. Locher, Zwingli und Erasmus, in: Zwingliana XIII/I (1969) 37-61. H, Liebing, Die Ausgänge des europäischen Humanismus, in: Geist und Geschichte der Reformation. Festgabe H. Rückert zum 65. Geburtstag (1966) 360, spricht von der „wohl innigsten, am schwersten auseinanderzudividierenden Synthese von Humanismus und Reformation", die uns in Zwinglis Theologie entgegentrete. Doch vgl. dagegen H. Meylan, Zwingli et Érasme, de l'Humanisme à la Réformation, in: Colloquia Erasmiana Turonensia (s. o. Anm. 55) 849-858, wiederabgedruckt in: H. M., D'Érasme à Théodore de Bèze (Genf 1976) 53-62; dort 854 (58): ,un fossé s'est creusé entre érasmiens et évangéliques, que rien ne pourra combler, entre les ,docti ${ }^{6}$ trop assurés de ce qu'ils savent et les annonciateurs du pur Évangile, les, Leser der göttlichen Geschrift', comme en dit à Zurich et à Bern.“ Das berühmte Bekenntnis des Erasmus „Ego mundi civis esse cupio" steht übrigens in einem Brief an Zwingli (1522), der ihn nach Zürich eingeladen hatte; s. ebd. 855 (59). Beispiel für einen „Bruch“: $J$. M. Kittelson, Wolfgang Capito. From Humanist to Reformer (Studies in Med. and Ref. Thought XVII (Leiden 1975). 
128 Exemplarisch dazu etwa $C$. Béné, Thomas Murner et la défense de l'humanisme, in: ACTours (s.o. Anm. 23) 359-368. Spitz, Humanism in the Reformation (s. o. Anm. 30) 660, formuliert sogar: „The various confessions, the Catholic somewhat more easily than the Protestant, gave an important place to humanist culture and gave it a positive role to perform in the worldly sphere."

129 G. Toffanin, L'Umanesimo al Concilio di Trento (Bologna 1955) 1-74; G. Alberigo, I vescovi italiani al concilio di Trento (Florenz 1959). Für die früheren Jahrzehnte des 16. Jahrhunderts s. vor allem A. Renaudet, Érasme et l'Italie (Travaux d'Humanisme et Renaissance XV) (Genf 1954). Wenn ich recht sehe, wird auf katholischer Seite der damalige Humanismus im kirchlichen Bereich etwas ängstlich kaum in seiner Eigenbedeutung und um so mehr nur in Verbindung mit der katholischen Reform gewürdigt. Vgl. z. B. die beiläufige Einbringung des Humanismus-Themas in das Kapitel "Vorstufen (nàmlich: der katholischen Reform) in Italien und Spanien" im "Handbuch der Kirchengeschichte“ (Jedin) (s.o. Anm. 117) 451-465; dazu die Nachträge im Neudruck 1975: 692 f. Vgl. auch Cantimori, Umanesimo (s.u. Anm. 164).

130 G. M. Pachtler, Ratio studiorum et institutiones scholasticae Societatis Jesu per Germaniam diu vigentes II (Monumenta Germaniae Paedagogica V) (1889). Vgl. dazu jetzt $K$. Hengst, Jesuiten an Universitāten und Jesuitenuniversitäten. Zur Geschichte der Universitäten in der Oberdeutschen und Rheinischen Provinz der Gesellschaft Jesu im Zeitalter der konfessionellen Auseinandersetzung (1981) 55-72.

${ }^{131}$ Zur fruchtbaren Entwicklung in England s. W. S. Howell, Logic and Rhetoric in England, 1500-1700 (Princeton 1956); Eighteenth-Century British Logic and Rhetoric (Princeton 1971). Eine umfassende Darstellung zum 16. und zur ersten Hälfte des 17. Jahrhunderts unter gesamteuropäischem Aspekt, wenngleich mit besonderer Berücksichtigung Frankreichs, lieferte kürzlich M. Fumaroli, L'Age de l'éloquence. Rhétorique et "res literaria“ de la Renaissance au seuil de l'époque classique (Genf 1980). Für die deutsche Literaturgeschichtsforschung wegweisend wurde das Buch von $W$. Barner, Barockrhetorik. Untersuchungen zu ihren geschichtlichen Grundlagen (1970). Es greift naturgemäß immer wieder auf das 16. Jahrhundert zurück.

${ }^{132}$ Dazu allgemein F. Charmot, La Pédagogie des Jésuites. Les principes, son actualité (Paris 1951); M. Lundberg, Jesuitische Anthropologie und Erziehungslehre in der Frühzeit des Ordens (ca. 1540-ca. 1650) (Uppsala 1966). Die weitere hauptsächliche Literatur bei Hengst, Jesuiten (s. o. Anm. 130) 566. Anm. 8. Dazu auch die unten in Anm. 135 genannte allgemeine Literatur sowie bei Barner, Barockrhetorik (s.o. Anm. 131) 322-366 das Kapitel „Rhetorik an den Jesuitengymnasien“; dort 366: „Blickt man auf das Ganze der Barockepoche, so scheint es, als habe der Jesuitenorden am klarsten erkannt, welch ungeheure Macht in der Rhetorik verborgen liegt." Vgl. auch $A$. Battistini, I manuali di retorica dei Gesuiti, in: La „Ratio studiorum“. Modelli culturali e pratiche educative dei Gesuiti in Italia tra Cinque e Seicento (Rom 1981) 77-120.

${ }_{133}$ Materialreiche Basis: B. $D u b r$, Geschichte der Jesuiten in den Ländern deutscher Zunge I (16. Jahrhundert) (1907) 237-294; exemplarisch: J. Kuckboff, Die Geschichte des Gymnasium Tricoronatum. Ein Querschnitt durch die Geschichte der Jugenderziehung in Köln vom 15. bis zum 18. Jahrhundert (1931). Neuerdings: E. Schubert, Zur Typologie gegenreformatorischer Universitätsgründungen: Jesuiten in Fulda, Würzburg, Ingolstadt und Dillingen, in: H. Rössler - G. Franz (Hg.), Universität und Gelehrtenstand 1400-1800 (1970) 85-105 (dort 98: der Straßburger Johannes Sturm lobt die Jesuitenschulen in Dillingen, Mainz und Trier, die aus freien Stücken Sprachen und Dialektik lehrten; ,innere Verbundenheit humanistischer Grundhaltung katholischer und protestantischer Observanz"). Dazu auch $A$. Seifert, Die jesuitische Reform. Geschichte der Artistenfakultät im Zeitraum 1570 bis 1650, in: Die Ludwig-Maximilians-Universität in ihren Fakultäten II: Die Philosophische Fakultät (1980) 65-90; ders., Weltlicher Staat und Kirchenreform. Die Seminarpolitik Bayerns im 16. Jahrhundert (1978); Hengst, Jesuiten (s. o. Anm. 130), die aber vor allem die organisatorische Seite behandeln, nicht die Lehrstoffe. Vgl. im übrigen die eindeutige Wertung des Jesuiten-Humanismus bei Spitz, Religious Renaissance (s. o. Anm. 32) 292 f. - En passant eine grundsätzliche Bemerkung: So verdienstvoll die derzeitige Erforschung der Bildungsorganisation ist (das gilt nicht nur für das 16. Jahrhundert), so sollten die Bildungsinhalte darüber doch nicht in der Weise vernachlässigt werden, wie es bisweilen der Fall ist. Um so begrüßenswerter, daß in dem umfassenden Werk von Fumaroli, L'Age de l'éloquence (s.o. 
Anm. 131), gerade die Jesuitenrhetorik ausführliche Darstellung erhalten hat (231-423, also 200 Seiten!), wenngleich auf Frankreich beschränkt.

${ }_{134}$ W. Hentrich, Gregor von Valencia und die Emeuerung der deutschen Scholastik im 16. Jahrhundert, in: Philosophia Perennis. Festgabe J. Geyser I (1930) 294: „Vermählung der humanistischen Form mit dem scholastischen Inhalt“. Weiteres s. Lexikon für Theologie und Kirche IV ( $\left.{ }^{2} 1960\right) 1194$ f., sowie in: $W$. Kausch, Geschichte der Theologischen Fakultät Ingolstadt im 15. bis 16. Jahrhundert (1472-1605) (Ludovico-Maximiliana. Forschungen 9) (1977) 252 s.v. Gregor de Valencia. Interessant z.B. auch, daß Ignatius von Loyola und der Straßburger Schulgründer Sturm gleiche und gleichzeitige Studienorte (Paris und Löwen) hatten.

${ }^{135}$ Neben dem als Materialbasis immer noch nützlichen Standardwerk von F. Paulsen, Geschichte des gelehrten Unterrichts auf den deutschen Schulen und Universitäten vom Ausgang des Mittelalters bis zur Gegenwart. Mit besonderer Rücksicht auf den klassischen Unterricht I ( $\left.{ }^{3} 1921\right)$ seien noch genannt: W. Moog, Geschichte der Pädagogik II. Die Pädagogik der Neuzeit von der Renaissance bis zum Ende des 17. Jahrhunderts. Neu hg. von F.J. Holtkemper, $\left.\left({ }^{8}=7\right) 1967\right)$ 122-203, sowie: T. Ballauff und $K$. Schaller, Pädagogik. Eine Geschichte der Bildung und Erziehung II. Vom 16. bis zum 19. Jahrhundert (1970) 15-101.

${ }^{136} \mathrm{Vgl}$. dazu jetzt N. Hammerstein, Humanismus und Universitäten, in: Die Rezeption der Antike (s. o. Anm. 42) 23-39; ferner J. M. Fletcher, Change and resistance to change: a consideration of the development of English and German universities during the sixteenth century, in: History of the Universities 1 (1981) 1-36.

${ }^{137}$ Für Deutschland hier nur: L. Boebm, Humanistische Bildungsbewegung und mittelalterliche Universitätsverfassung. Aspekte zur frühneuzeitlichen Reformgeschichte der deutschen Universităten, in: Grundwissenschaften und Geschichte. Festschrift P. Acht (1976) 311-333; ergänzte Fassung in: The Universities in the Late Middle Ages, hg. von J. IJsewijn und J. Paquet (Mediaevalia Lovaniensia I/VI) (Löwen 1978) 315-346; J. Bücking, Reformversuche an den deutschen Universitäten in der frühen Neuzeit, in: Festgabe für E. W. Zeeden (1976) 355-369; A. Seifert, Integrazione (s.o. Anm.65); sowie der Sammelband: Beiträge usw. wie oben Anm. 76. Nur als Einzelbeispiel aus den Veröffentlichungen der letzten Jahre sei hier genannt: H. Hradil, Der Humanismus an der Universitāt Ingolstadt (1477-1585), in: Ludwig-Maximilians-Universität II (s.o. Anm. 133) 37-63.

${ }^{138}$ A. Scbindling, Humanistische Hochschule und freie Reichsstadt. Gymnasium und Akademie in Straßsburg 1538-1621 (1977) 1-33 und 385-397 (Spitz, Humanism in the Reformation (s. o. Anm. 30) 651, bezeichnet Johannes Sturm, den Gründer und Leiter des Straßburger Gymnasiums, als ,the greatest of all Protestant educators"); Beiträge von U. Im Hof (Schweiz), A. Schindling (Straßburg) und H. E. Specker (Ulm), in: E. Mascbke und J. Sydow (Hg.), Stadt und Universität im Mittelalter und in der frühen Neuzeit (1977); U. Im Hof, Die reformierte Hohe Schule zu Bern. Vom Gründungsjahr 1528 bis in die zweite Hälfte des 16. Jahrhunderts, in: 450 Jahre Berner Reformation (Archiv Hist. Ver. Kanton Bern 64/65, 1980/81) (Bern 1981) 194-224; Schindling, Universitāt Gießen (wie oben Anm. 120) 99-101; A. Schindling, Humanistische Reform und fürstliche Schulpolitik in Hornbach und Lauingen. Die Landesgymnasien des Pfalzgrafen Wolfgang von Zweibrücken und Neuburg, in: Neuburger Kollektaneenblatt 133 (1980) 141-186. Vgl. auch den Artikel „Landesschule“ in: Handwörterbuch zur deutschen Rechtsgeschichte, 14. Lieferung (1976) 1408-1412, von A. Scbindling; ferner G. Heiss, Konfession, Politik und Erziehung. Die Landschaftsschulen in den nieder- und innerösterreichischen Ländern vor dem Dreißigjährigen Krieg, in: Bildung, Politik und Gesellschaft, hg. von G. Klingenstein usw. (1979) 13-63. Die Bestände ganzer Regionen umfassend z. B. J. Kuckboff, Der Sieg das Humanismus in den katholischen Gelehrtenschulen des Niederrheins 1525-1557 (1929); A. Hartlieb von Wallthor, Höhere Schulen in Westfalen vom Ende des 15. bis zur Mitte des 19. Jahrhunderts, in: Westfäl. Zs. 107 (1957) 18-50; C. Haase, Die Lateinschule in Niedersachsen von der Reformation bis zur napoleonischen Zeit, in: Niedersächs. Jb. 51 (1979) 137-194 (der ausdrücklich auf die Spannung hinweist, daß ,nun ,Bildung“ $z$ war nach wie vor auf humanistischer Grundlage ruht ..., aber zugleich Bildung zum rechten Glauben sein soll und ist"). Vgl. auch Anm.133 über die Jesuitenschulen. Die obersten Abteilungen des Gymnasiums nannten die Jesuiten einfach "humaniora" und „Humanität“; Lundberg, Jesuitische Anthropologie (s.o. Anm. 132) 28. Zum protestantischen 
Fürsteninteresse parallel dazu etwa: $B$. Vogler, La politique scolaire entre Rhin et Moselle. L'exemple du Duché de Deux-Ponts (1556-1619), in: Francia 3 (1975) 236-320 und 4 (1976) 287-364.

${ }^{139}$ Zur Exemplifizierung der allgemeinen Entwicklung seien genannt auf der einen Seite das berühmte und einflußreiche Löwener Collegium Trilingue, das in enger Verbindung mit der Universität stand; $H$. de Vocbt, History of the Foundation and the Rise of the Collegium Trilingue Lovaniense 1517-1550, I-IV (Löwen 1951-1955). Andererseits etwa die Gründung eines Ratsgymnasiums in Erfurt zum Nachteil der Universität, sodann die Errichtung eines Jesuitengymnasiums ebd.; E. Kleineidam, Universitas Studii Erffordensis (s.o. Anm.73), Teil III: Die Zeit der Reformation und Gegenreformation 1521-1632 (1980) 82-92.

${ }^{140}$ Zum pādagogischen Humanismus s.u. a. R. R. Bolgar, The Classical Heritage and its Beneficiaries (Cambridge 1954) 329-369. Er hält nicht Melanchthon und Johannes Sturm, sondern Mathurin Cordier (den Lateinlehrer Calvins) für den eigentlichen Repräsentanten des pädagogischen Humanismus.

${ }^{141}$ Schindling, Humanistische Hochschule (s.o. Anm. 138) 395 f., in seiner Schlußwertung. Zur ersten allgemeinen Einführung s. E. Garin, Geschichte und Dokumente der abendländischen Pädagogik II: Humanismus; III: Von der Reformation bis John Locke. Quellenauswahl für die deutsche Ausgabe: E. Keßler (1966-67). Die italienische Ausgabe: L'educazione in Europa (Bari 1957); Moog, Geschichte der Pädagogik II (s.o. Anm.135) 14-121; T. Ballauff, Pädagogik (s.o. Anm.135) I (1969) 507-631. Zur pädagogischen Grundtendenz des Humanismus: E. Garin, Il pensiero pedagogico dell'Umanesimo (Florenz 1958). Forschungen über die schulpraktische Umsetzung der humanistischen Pädagogik im italienischen Quattrocento (aber auch für die spätere Zeit) scheinen weitgehend zu fehlen. Dazu $D$. Hay, Storici e Rinascimento negli ultimi venticinque anni, in: Il Rinascimento (s.o. Anm. 1) 33: „Per una storia dell'istruzione che illustri la diffusione dei principi umanistici bisogna volgersi a coloro che hanno affrontato il problema per l'Europa settentrionale ... Non conosco alcuna opera del genere sulle scuole italiane." Aus dem Beitrag von P. Denley, Recent studies on Italian universities of the Middle Ages and Renaissance, in: History of Universities 1 (1981) 193-205, ist zu schließen, daß sich auch in den letzten Jahren daran nichts geāndert hat; doch s.u. Anm. 231. Beiträge wie C. Frova, La scuola nella città tardomedievale: un impegno pedagogico e organizzativo, in: Le città in Italia e in Germania nel Medioevo: cultura, istituzioni, vita religiosa (Bologna 1981) 119-143, oder: M. Pastore Stocchi, Scuola e cultura umanistica fra due secoli, in: Storia della cultura veneta dal primo quattrocento al concilio di Trento I (Vicenza 1980) 93-121, bestätigen indirekt die Negativmeldungen auch weiterhin. Der Vortragsband: Vittorino e la sua scuola. Umanesimo, pedagogia, arti (Florenz 1981), bleibt ganz im Umkreis des Feltresen. - Eine nützliche Einführung in den humanistischen Schulbetrieb nördlich der Alpen (exemplarisch auch für andere Gebiete über die Niederlande hinaus) gibt P. N. M. Bot, Humanisme en Onderwijs in Nederland (Utrecht und Antwerpen 1955). Auch Spitz, Humanism in the Reformation (s.o. Anm. 30) 651, weist auf den Unterschied zwischen der älteren „elitist conception“ der Humanisten und der jüngeren „universal compulsory education“ im neuen Gymnasialwesen hin. Generell gilt: „Never in history ... has so much been written on educational theory and practice as in the age of the Renaissance.“

142 Dementsprechend klafften Anspruch und Bedeutung bisweilen auseinander, so wenn der Rektor des Lüneburger Johanneum, Lorenz Rhodoman (1546-1606) als ,christlicher Homer“ bezeichnet wurde; s. Haase, Lateinschule in Niedersachsen (s. o. Anm. 138) 155.

${ }^{143}$ Dazu jetzt W. Küblmann, Gelehrtenrepublik und Fürstenstaat. Entwicklung und Kritik des deutschen Späthumanismus in der Literatur des Barockzeitalters (1982) 285-454 („,Der Gelehrte in der Gesellschaft“); ebd. 85-112 über „die todkranken Studien“: „Bilder der Spätzeitlichkeit“, Greisenalter, Kältetopos usw. Vgl. auch W. Küblmann, Apologie und Kritik des Lateins im Schrifttum des deutschen Späthumanismus. Argumentationsmuster und sozialgeschichtliche Zusammenhänge, in: Daphnis 9 (1980) 33-63.

${ }^{144}$ Mit dieser Formulierung möchte ich den Ursprung des konfessionellen Sachverhalts als solchen mit dem heutigen Forschungsstand in Ưbereinstimmung bringen, daß er nämlich zeitlich nicht schon mit dem Beginn der Reformation zusammenfällt. 
${ }^{145}$ Zur allgemeinen Charakteristik des vom religiösen Ordnungsdenken geprägten 16. Jahrhunderts s. grundlegend $W$. Reinbard, Gegenreformation als Modernisierung? Prolegomena zu einer Theorie des konfessionellen Zeitalters, in: ARG 68 (1977) 226-252.

${ }^{146}$ Bereits 1524 äußerte Vives in einem Brief aus London an Erasmus über die Entwicklung in Deutschland: „Ista vel pro Luthero vel in Lutherum excusserunt de pectoribus studiosorum omnem aliarum litterarum curam"; vgl. IJsewijn, Coming of Humanism (s. o. Anm. 53) $281 \mathrm{f}$. Für die Unterordnung des Humanismus unter die religiösen Forderungen der Reform charakteristisch ist z. B. auch Clichtove; Massaut, Josse Clichtove (s.o. Anm. 52) II 380-407 („Clichtove et l'humanisme"). Ein Beispiel von der anderen Seite: In einem Brief an Camerarius (1529) stellt Melanchthon Erasmus als Arius, Luther als „Schutzwall gegen die von Erasmus ausgehende Aufklärung“ hin; Maurer, Der junge Melanchthon II (s. o. Anm. 114) 597 Anm. 138. Im Vorwort ebd. 5 bezeichnet Maurer Melanchthons „Stellung“ zwischen Humanismus und Reformation „als eine ständige Bewegung zwischen zwei Polen“.

${ }_{147}$ Doch ergibt sich für das ganze Jahrhundert ein offensichtliches Bildungsübergewicht des protestantischen Klerus gegenüber dem katholischen; The Recruitment and the Training of the Clergy in the $16^{\text {th }}$ Century, in: Miscellanea Historiae Ecclesiasticae III (Bibliothèque de la Revue d'Hist. Eccl. 50) (Löwen 1970) 107-283.

148 Schindling, Humanistische Hochschule (s.o. Anm.138) 33, womit dem „Dazwischentreten“ ein neuer, freilich ganz entgegengesetzter Sinn zukäme. Wenn Brecht, Luthertum (s. o. Anm. 125) 12, zurecht bemerkt: „Ob der Humanismus ohne die Reformation einen derartigen Ausbau des Bildungswesens auf allen Ebenen erreicht hätte, ist mindestens fraglich“, so könnte man „Reformation“ hier ohne weiteres durch „Konfessionalisierung“ ersetzen. Vgl. die instruktiven Beispiele für das konfessionell bedingte Nebeneinander mehrerer Gymnasien am selben Orte bei Haase, Lateinschule in Niedersachsen (s.o. Anm. 138) $150 \mathrm{f}$.

${ }_{149}^{14}$ Liebing, Ausgänge des europäischen Humanismus (s. o. Anm. 127) 368 f.: „Dieser Humanismus, dem die drei Konfessionen auf Jahrhunderte eine gesicherte, unangefochtene propädeutische Funktion einräumten, hat Generationen guter Lutheraner, Reformierter und Katholiken zu Dienern der Kirche und des Staates erzogen ... Sie alle, denen die alten Sprachen geläufig, die antiken Autoren vertraut waren, bildeten bis zum Ende des ancien régime das vielleicht unauffällige, aber höchst wirksame und notwendige Fundament einer europäischen Gesellschaft, ohne das auch der Fortschritt, das „Moderne“, die Revolution und die Emanzipation nicht zu denken gewesen wären."

${ }_{150} E$. Trunz, Der deutsche Späthumanismus um 1600 als Standeskultur, in: Zeitschr. f. Gesch. der Erziehung u. des Unterrichts 21 (1931) 17-53; wiederabgedruckt in: Deutsche Barockforschung, hg. von $R$. Alewyn ('1965) 147-181. Wenngleich nicht speziell dem Humanismus gewidmet, bietet die ganze Sammlung des letztgenannten Sammelwerkes doch wesentliche retrospektive Einsichten auch für unser Thema. Im besonderen hierzu Trunz 173: „Das was den Humanismus ... um 1600 zum so wesentlichen Bestandteil der deutschen Gesamtkultur machte, war der Umstand, daß er den geistigen Besitz von Tausenden ausmachte, die als Lehrer, Pfarrer und andere Gelehrte die Hochschulen verlassen hatten und eine breite, mit allen Schichten des Volkes vielfach in Berührung stehende Masse bildeten."

${ }^{151}$ Vgl. etwa das Kapitel „Mythologie“ bei $A$. Buck, Die Rezeption der Antike in den romanischen Literaturen der Renaissance (1976) 192-227 (mit Literatur). Grundlegend war E. Panofsky, Studies in Iconology: Humanist Themes in the Art of the Renaissance (New York 1939). Anregend: $E$. Wind, Pagan Mysteries in the Renaissance (London ${ }^{2} 1968$ ); deutsche Ausgabe: Heidnische Mysterien in der Renaissance (1981). Als Quellensammlung zugleich fundamental wie monumental die von S. Orgel herausgegebene 55bändige Ikonomythographie: Renaissance and the Gods, und die daran anschließende 22bändige Textsammlung: The Philosophy of Images (New York 1979 ff.). Aus Deutschland ebd. die „Heydenweldt und ihre Götter“ (Basel 1554) des (Basilius) Johannes Herold (1511-1567) (New York 1980), des ersten großen deutschen Mythographen und Ikonographen, der im katholischen wie im evangelischen Deutschland von weitreichender, auch vulgarisierender Wirkung war. Ein Wolfenbütteler Kolloquium im Dezember 1982, dessen Vorträge in absehbarer Zeit wohl auch im Druck vorliegen, ist dem Thema „Mythographie der frühen Neuzeit“ gewidmet. 
${ }^{152}$ C. Wiedemann, Vorspiel der Anthologie, in: Die deutschsprachige Anthologie II. Studien zu ihrer Geschichte und Wirkungsform, hg. von J. Bark und D. Pforte (1969) 6. Ebd. 5: „Es war entscheidend für die Entstehung und das Gesicht der zukünftigen deutschen Literatur, daß sich in der Frage der kulturellen Erneuerung die beiden einzigen literarisch progressiven Gruppen, die bürgerlichen Humanisten und der schöngeistige Adel zusammenfanden.“ Die „humanistisch gebildeten Bürgerlichen“ erhielten „immer häufiger Ämter bei Hof“. Vgl. auch das Kapitel „Kontakte des Adels zur bürgerlichen Gelehrtenbildung" bei Barner, Barockrhetorik (s.o. Anm. 131) 384-386 („Konvergenz von Adelserziehung und modern-rhetorischer Gelehrtenschulbildung“ am Ausgang der Barockzeit).

${ }^{153}$ So Engel, in: Handbuch III (s.o. Anm. 9) 54, unter Aufnahme der Max Weberschen Beurteilung. Allerdings betont auch Trunz, Deutscher Späthumanismus (s. o. Anm. 150), daß ,auf dieser Stufe der Entwicklung der Humanismus als Gegenstand rein gelehrten Wissens der allgemeinen Volkskultur gegenüberstand“ und „als zerbröckelter Wissensstoff in die große Schicht der Gebildeten, das neu sich entwickelnde höhere Bürgertum, versickerte“. Die unterschiedlichen Beurteilungen machen jedoch aufs beste die Doppelgesichtigkeit deutlich, auf die auch unsere Analyse hinausläuft: einerseits den Verfall in mediokre Unerheblichkeit, andererseits die Integration in die maißgebliche gesellschaftliche Führungsschicht. Im Lichte der jüngeren Forschung über den stark literarischen Charakter der Bildenden Kunst und über die Bedeutung des Figuralen in der Literatur ist der Gegensatz zwischen Sprach- und Bildkunst, der seinerzeit eine wichtige Rolle gespielt hat, heute zumindest sehr abgemildert.

${ }^{154}$ V. Sinemus, Poetik und Rhetorik im frühmodernen deutschen Staat (1978) 23, der im übrigen die hier angedeuteten Linien durchzieht. Celtis erhielt für dieses Werk auch von Kaiser Friedrich III. den Dichterlorbeer. Zu der Schrift selbst s. zuletzt J. Leonhardt, Niccolò Perotti und die „Ars versificandi“ von Conrad Celtis, in: Humanistica Lovaniensia 30 (1981) 13-18. Zum Thema insgesamt s. auch das Kapitel "Rhetorik in der Adelserziehung“ bei Barner, Barockrhetorik (s.o. Anm. 131) 367-386.

${ }^{155}$ Heer, Die dritte Kraft (s. u. Anm. 164) 461: „Mit der heidnischen Antike zieht etwas von der Weite, Schönheit und Lebenslust der archaischen Gesellschaft und der offenen Katholizităt Alteuropas in die Bildungswelt der Gegenreformation ein." Vgl. auch den Sammelband: Classical Influences on European Culture. 1500-1700, hg. von $R$. R. Bolgar (Cambridge 1976). Daß man das Problem "mythologischer" Dichtung allerseits erkannte, zeigt die frühe Auseinandersetzung Vadians mit dieser Frage in seiner Poetik von 1518; J. Lefebure, Le poète, la poésie et la poétique. Élements pour une définition et pour une datation de l'humanisme allemand, in: L'Humanisme allemand (s. o. Anm. 14) 285-301; dort 295-297. Wie man es trotz großer Schwierigkeiten, etwa durch (,mittelalterliche") typologische Mythenallegorese löste, zeigt eindrucksvoll $F$. Obly, Skizzen zur Typologie im späteren Mittelalter, in: Medium aevum deutsch. Festschrift für K. Ruh (1979) 251-310 (zum Begriff „Mittelalter“ ebd. 251: „manche Bahnen des Mittelalters enden erst mit dem 18. Jahrhundert"). Im weiteren Rahmen dazu ders., Schriften zur mittelalterlichen Bedeutungsforschung (1977) 312-400, und: Typologische Figuren aus Natur und Mythus, in: Formen und Funktionen der Allegorie. Symposion Wolfenbüttel 1978 (1979) 126-166.

156 Spitz, Humanism in the Reformation (s. o. Anm. 30) 661: „The balance achieved between religious concern as such and the cultivation of classical learning in ,confessional humanism" resulted in a strength and stability which lasted into modern times, no small achievement for so fragile a thing as higher culture."

${ }^{157}$ Kennzeichnende Konsequenz: das Schäferspiel. Vgl. dazu neuerdings: Le Genre pastoral en Europe du XV au XVII ${ }^{e}$ siècle. Actes du Colloque international tenu à Saint-Étienne ... 1978 (Saint-Etienne 1980). Eine andere Gelegenheit zum Außergewöhnlichen bot das im besonderen „höfische“ Fest. Aus der zahlreichen hier einschlägigen Literatur nenne ich lediglich die ălteren Sammelbände: Les fêtes de la Renaissance I-III, hg. von J. Jacquot und E. Konigson (Paris 1956-1975) (der zweite unter dem Titel: Fêtes et cérémonies au temps de Charles Quint). Beiträge über mittelalterliche Traditionen in diesen Festen der Renaissance führen Möglichkeiten der Adaptation vor, die zu einem wichtigen Anliegen der „christlichen“ Literatur wurde; s.u. Anm. 158. 
${ }^{158} \mathrm{Vgl}$. etwa die grundlegende jüngste Arbeit über das deutsche Jesuitentheater von J.-M. Valentin, Le théâtre des Jésuites dans les pays de langue allemande (1554-1680). Salut des âmes et ordre des cités I-III (Bern usw. 1978). Der darin etwas verdeckte Gesichtspunkt der Verchristlichung der Antike ist deutlicher herausgearbeitet von dems., Das Jesuitendrama und die literarische Tradition, in: Deutsche Barockliteratur und europäische Kultur (Dokumente des Internationalen Arbeitskreises für deutsche Barockliteratur 3) (1977) 116-140. Neuerdings noch R. Wimmer, Jesuitentheater. Didaktik und Fest. Das Exemplum des ägyptischen Joseph auf den deutschen Bühnen der Gesellschaft Jesu (1982) (trotz des biblischen Themas hier einschlägig). Über den Lütticher Dramatiker Holonius, dessen Stücke für die Entwicklung des Jesuitendramas „Modellcharakter" bekamen, s. J. A. Parente Jr., Counter-Reformation Polemic und Senecan Tragedy: The Dramas of Gregorius Holonius (1531?-1594), in: Humanistica Lovaniensia 30 (1981) 156-180; sein Ziel (160): „to christianize pagan theater“, und zwar speziell: den heidnischen Heroen durch den christlichen Märtyrer als „Held“ zu ersetzen. Instruktiv und im besten Sinne zugleich vergnüglich ist die kommentierte Faksimilesammlung von $E . M$. Szarota, Das Jesuitendrama im deutschen Sprachgebiet. Eine Periochen-Edition. Texte und Kommentare I/II (1979/80). Zur protestantischen Seite: H. Hommel, Antikes Erbgut im evangelischen Kirchenlied, in: Theologia Viatorum. Jb. d. kirchl. Hochschule Berlin 1948/49, 122-139; J. Lebeau, Aux origines du théâtre biblique Luthérien, in: L'Humanisme allemand (s. o. Anm. 14) 477-491 (maßgeblicher Einfluß des von Gulielmus Gnapheus 1529 verfaßten „Acolastus“). Regional: E. Weber, Musique et thêâtre dans les pays rhénans II. Le thêâtre humaniste et scolaire dans les pays rhénans (Paris 1974). Ein instruktives Beispiel für die „Intention, antike Tradition und christlich-moralisches Engagement zu verschmelzen" s. bei H.-G. Roloff, Thomas Naogeorg und das Problem von Humanismus und Reformation, in: L'Humanisme allemand (s. o. Anm. 14) 455-475. Zur Interpretatio christiana ferner noch $E$. Schäfer, Horatius Christianus. Zur Rezeption der Horazischen Dichtung bei den deutschen Neulateinern des 16. Jahrhunderts, in: Acta Conventus NeoLatini Lovaniensis 1971 (Löwen und München 1973) 509-515. S. auch oben Anm. 157: Les fêtes de la Renaissance.

${ }^{159}$ Moeller, Deutsche Humanisten (s.o. Anm. 37) 47 f., über „zwei Tendenzen innerhalb der humanistischen Bewegung“, wo das religiöse Element und das „literarisch-wissenschaftliche Interesse" auf derselben Seite erscheinen. Vgl. im übrigen oben Anm. 41-43.

$160 \mathrm{Vgl}$. den Artikel "Vermittlungstheologie“ von R. Bäumer, in: Lexikon für Theologie und Kirche X $\left({ }^{2} 1966\right) 719$, und das Kapitel „Vermittlungstheologen“ bei E. Iserlob, Geschichte und Theologie der Reformation (s.o. Anm. 116) 101-103. Im übrigen die oben Anm. 108 genannten Studien zum erasmianischen Irenismus.

${ }^{161}$ In diesem zweiten Sinne etwa H.A. Enno van Gelder, The Two Reformations in the $16^{\text {th }}$ Century. A Study of the Religious Aspects and Consequences of Renaissance and Humanism (Haag ${ }^{2}$ 1964) 7: ,We have to distinguish side by side with Catholicism and Protestantism a third religious movement, parallel to both but not between them, and having a more modern aspect ... I shall call it humanistic religion." Ihr Weg führt nach Enno van Gelder über die Aufklärung zum heutigen sog. „Humanismus“. Vgl. auch Renaudet, Erasme et l'Italie (s.o. Anm. 129) 200-242 („Le problème de la troisième église“); ebd. 201: „Il souhaitait une simplification du dogme, réduit aux exigences indispensables d'un spiritualisme évangelique“, und wünschte, daß die Lehren Christi „pouvaient s'accorder avec les plus hautes leçons des philosophes antiques.“ Im gleichen Sinne ders, Études érasmiens (1521-1529) (Paris 1939) 122-189 („Le modernisme érasmien“).

${ }^{162}$ Hengst, Jesuiten (s.o. Anm. 130) $58 \mathrm{f}$.

${ }^{163} \mathrm{Daß}$ es auch betrāchtliche Weiterwirkung gab, darf allerdings nicht ganz übersehen werden. Vgl. etwa H. R. Guggisberg, Sebastian Castellio im Urteil seiner Nachwelt vom Spāthumanismus bis zur Aufklärung (Basel und Stuttgart 1956).

${ }^{164}$ F. Heer, Die dritte Kraft. Der europäische Humanismus zwischen den Fronten des konfessionellen Zeitalters (1959). A. Franzen, Die Kelchbewegung am Niederrhein im 16. Jahrhundert. Ein Beitrag zum Problem der Konfessionsbildung im Reformationszeitalter (1955). Zu Frankreich s. P. Imbart de la Tour, Les origines de la Réforme III. L'Évangelisme (Paris 1914). Zu Italien: Reformation and Counter Reformation, in: Cocbrane $(\mathrm{Hg}$.), The Late Italian Renaissance (s.o. Anm. 21) 209-284; ferner: Eresia e Riforma nell'Italia del Cinquecento. Miscellanea I (Florenz- 
Chicago 1974); D. Cantimori, Umanesimo e religione nel Rinascimento (Turin 1975) (Aufsätze zum Gesamtwerk Cantimoris s. G. Miccoli, Delio Cantimori. La ricerca di una nuova critica storiografia, Turin 1970); M. P. Gilmore, Italian Reactions to Erasmian Humanism, in: Itinerarium Italicum (s.o. Anm. 14) 61-115. Materialreich jetzt auch das dieses Thema an und für sich weit überschreitende Werk von M. Petroccbi, Storia della spiritualità italiana I: Il Duecento, il Trecento e il Quattrocento; II: Il Cinquecento e il Seicento (Rom 1978). Vgl. auch Anm. 51 und 165. Zu Spanien: M. Bataillon, Érasme et l'Espagne. Recherches sur l'histoire spirituelle du XVI ${ }^{\mathrm{e}}$ siècle (Paris 1937); zu benutzen in der erweiterten spanischen Übersetzung: Erasmo y España. Estudios sobre la historia espiritual del siglo XVI (Mexico und Buenos Aires 1966). Zumindest in wenigen repräsentativen Beispielen ist diese Literatur im Zusammenhang mit unserem Thema zu erwähnen, da in ihr der europäische Rückstoß des nördlichen christlichen Humanismus zur Sprache kommt. Umgekehrt erscheint es mir problematisch, in die deutsche Politik Gattinaras (Tolerierung Luthers) das Humanismusthema einzuführen, wie dies kürzlich J. M. Headley, Gattinara, Erasmus, and the Imperial Configurations of Humanism, in: ARG 71 (1980) 64-98, getan hat.

${ }_{165}$ Charakteristisch das Schicksal des als päpstlicher Nuntius in Deutschland wirkenden Humanisten und Reformers Pier Paolo Vergerio, der sich nach seinem Scheitern gegen den Papst wandte; s. jetzt $A$. Jacobson Schutte, Pier Paolo Vergerio. The Making of an Italian Reformer (Gent 1977). Über den der Häresie beschuldigten Kardinal Pole: D. Fenlon, Heresy and Obedience in Tridentine Italy: Cardinal Pole and the Counter-Reformation (Cambridge 1973); J. I. Tellechea Idígoras, Fray Bartolomé Carranza y el Cardenal Pole (Pamplona 1977). Des weiteren zu Carranza, der Melanchthon schätzte, von dems.: Melanchthon y Carranza. Préstamos y afinidades (Salamanca 1979); sowie die Aufsatzsammlung: Tiempos recios. Inquisición y heterodoxias (Salamanca 1977).

${ }_{166}$ Während sich der Humanismus als konfessionell eingebundener Schulhumanismus eben erfolgreich halten und weiterwirken konnte, wie Liebing, Ausgänge des europäischen Humanismus (s.o. Anm. 127) 373 f., mit Recht betont.

${ }^{167}$ Daß Erasmus trotz der Indizierung gerade im katholischen Bildungsraum weiterbenutzt wurde, zeigt I. Brezzel, Erasmusdrucke des 16. Jahrhunderts in bayerischen Jesuitenbibliotheken, in: Das Verhältnis der Humanisten zum Buch (s. o. Anm. 85) 145-162. Dasselbe gilt im übrigen für den durch die jesuitische Schulordnung verbotenen Melanchthon; ebd. 162. Ähnlich aufschlußreich für die Niederlande: S. W. Bijl, Erasmus in het Nederlands tot 1617 (Nieuwkoop 1978) (unter den mehr als 100 Ubersetzungen auch zahlreiche im katholischen Bereich). Dazu früher schon $R$. Crabay, Les censeurs louvanistes d'Érasme, in: Scrinium Erasmianum I (Leiden 1969) 221 -249. Über italienische Erasmusleser nach seiner Indizierung: J. Tedeschi, A SixteenthCentury Italian Erasmian and the „Index“, in: Essays presented to M. P. Gilmore (Florenz 1978) 305-315.

${ }^{168}$ Flitner, Erasmus (s.o. Anm. 107); vgl. auch das dort schon angeführte Zitat. Zur Verurteilung des Erasmus auf dem Tridentinum ebd. 33-46. Sehr bestimmt auch Liebing, Ausgänge des europäischen Humanismus (s. o. Anm. 127) 361: „Diese ganze Reihe (Bucer, Melanchthon, Calvin) weiß sich vom Erasmischen Humanismus durch eine äußerste, im einzelnen Fall freilich verschieden angesetzte Grenze geschieden, die nicht überschritten werden darf, ohne daß damit die Reformation überhaupt preisgegeben wird. Jenseits der Grenze, spätestens aber jenseits der Position $Z$ winglis, stehen diejenigen Humanisten, die vom ganzen Protestantismus als nicht-reformatorisch abgelehnt werden." Zur Ablehnung des Erasmus durch beide Seiten s. auch Bierlaire, Les Colloques d'Érasme (s.o. Anm. 55) 201-203. Neuere Literatur aufarbeitend und auch zeitlich über Flitner hinausführend neuerdings B. Mansfield, Phoenix of His Age. Interpretations of Erasmus ca. 1550-1750 (Toronto 1979).

169 So auch erklärt sich Joachimsens Urteil (Der Humanismus und die Entwicklung des deutschen Geistes $476=$ Gesammelte Aufsätze II 382; s.o. Anm. 33): „Um 1550 ist die humanistische Bewegung zu Ende“. Aus der prinzipiell gleichen Fesselung durch die Reformationsgeschichte heraus aber auch Paulsen, Geschichte des gelehrten Unterrichts (s.o. Anm. 135) 249: „Seit dem Anfang der zwanziger Jahre entzieht ihm (dem Humanismus) der Ausbruch der großen kirchlichen Bewegung rasch die Teilnahme". 
${ }^{170}$ So trotz der Kritik, die H. Baron, Secularization of Wisdom and Political Humanism in the Renaissance, in: Journal Hist. Ideas 21 (1960) 131-150, an dem Buch von E. F. Rice Jr. , The Renaissance Idea of Wisdom (Cambridge, Mass., 1958), geübt hat, dem er vorhält, er beurteile den Renaissance-Humanismus wie ,in Dilthey's days“. Seine eigene Position umreißt Rice (IX) wie folgt: „The process by which „sapientia“, traditionally one of the central ideas of metaphysics and theology, became a term with primarily ethical meanings is both a secularizing one - as wisdom is drained of its specifically Christian meanings - and a humanizing one - as wisdom comes to concern itself with human things."

${ }^{171}$ Nur zu nennen sind des weiteren etwa die vom Humanismus erzeugten Spannungen und Konflikte in der Jurisprudenz; Burmeister, Studium der Rechte (s. u. Anm. 183) 256: Hinweis auf die Parallelität zum theologischen Bereich.

${ }_{172} W$. Risse, Die Logik der Neuzeit I (1500-1640) (1964) 14-200; C. Vasoli, La dialettica e la retorica dell'Umanesimo. „Invenzione“ e „Metodo“ nella cultura del XV e XVI secolo (Mailand 1968); E. J. Ashworth, Language and Logic in the Post-Medieval Period (Dordrecht 1974); Seifert, Logik zwischen Scholastik und Humanismus (s. o. Anm. 65). Als erster Uberblick nützlich die Abschnitte 42 ("The eclipse of medieval logic") und 43 („Humanism and the teaching of logic") von $E$.J. Asbworth bzw. L. Jardine in der "Cambridge History of Later Medieval Philosophy“ (Cambridge usw. 1982) 787-807. Unter dem allgemeineren Aspekt der Methodengeschichte geht auch Gilbert, Renaissance Concepts of Method (s.o. Anm. 18) 119-163, auf die rhetorische Dialektik ein.

${ }^{173}$ Als erster international anerkannter Repräsentant der neuen deutschen Wissenschaftlichkeit wurde er von seinen deutschen Zeitgenossen über alle Maßen gefeiert und erhielt in kürzester Zeit sechs Biographien; J. M. Weiss, The Six Lives of Rudolph Agricola: Forms and Functions of the Humanist Biography, in: Humanistica Lovaniensia 30 (1981) 19-39. Zu Agricola vgl. im allgemeinen Spitz, Religious Renaissance (s. o. Anm. 32) 20-40;M. A. N. Nawwelaerts, Rudolphus Agricola (Haag 1963); sowie den Artikel, Agricola Rudolf' von F.J. Worstbrock, in: Die deutsche Literatur des Mittelalters. Verfasserlexikon I (1978) 84-93. Ein interessanter, wenngleich lediglich zur Diskussion gestellter Neuansatz (s. u. Anm. 178) von E. Kessler, Humanismus und Naturwissenschaft bei Rudolf Agricola, in: L'Humanisme allemand (s. o. Anm. 14) 141-157. Zur Dialektik s. die einschlägigen Abschnitte in den in Anm. 172 genannten Werken; dort weiterführende Literatur. Vgl. auch T. Cave, The Cornucopian Text. Problems of Writing in the French Renaissance (Oxford 1979) 12-34, sowie Totok, Handbuch III (s.o. Anm. 2) $280 \mathrm{f}$.

${ }^{174}$ L. Jardine, Lorenzo Valla and the Intellectual Origins of Humanist Dialectic, in: Journal of the History of Philosophy 15 (1977) 143-164; H. B. Gerl, Rhetorik als Philosophie. Lorenzo Valla (1974).

${ }^{175}$ Zur Begriffsklärung s. Lang, Loci theologici (s. u. Anm. 196) 57: Topoi sind bei Aristoteles „Propositionen von allgemeinem Inhalt und allgemeiner Geltung, die geeignet sind, als Prāmissen für dialektische Syllogismen zu dienen".

${ }^{176}$ Eigenartigerweise gibt es keine größere Gesamtdarstellung der humanistischen Rhetorik. Die Fülle der damaligen Rhetorik-Traktate (867 Autoren, darunter recht viele Deutsche) zeigt die von J.J. Murphy herausgegebene Bibliographie: Renaissance Rhetoric. A Short-Title Catalogue of Works on Rhetorical Theory from the Beginning of Printing to A. D. 1700, with Special Attention to the Holdings of the Bodleian Library, Oxford (New York und London 1981); ebd. in der Einleitung IX: „There is no comprehensive work on Renaissance rhetoric“. Das in seiner Materialfülle imponierende Buch von Fumaroli, L'Age de l'éloquence (s.o. Anm. 131), gibt zwar einen gesamteuropäischen Überblick (Bibliographie mit 1722 Titeln), legt seinen Schwerpunkt aber auf Frankreich sowie zeitlich auf die zweite Hälfte des 16. und die erste Hälfte des 17. Jahrhunderts. Ein Úberblick über die Rhetorikforschung der letzten Zeit ebd. 1-6. 1977 ist eine „Société internationale pour l'histoire de la rhétorique“ gegründet worden, die jährlich Kongresse abhält und ein Publikationsorgan (Rhetoric Newsletter) herausgibt.

177 Vasoli, Dialettica e retorica (s. o. Anm. 172) 263, betont, daß die topische Dialektik in starkem Maße evolutionär orientiert war; die hypothetischen, offenen Schlüsse spielten die entscheidende Rolle. Eine kritische und nützliche Diskussion der Begriffe „probabilitas“, „opinio“, „inventio“ usw. bei Seifert, Logik (s. o. Anm. 65) 77-98. Zur Logik als „Wahrscheinlichkeitslehre“" bei Caesarius (s.u.) vgl. Risse, Logik der Neuzeit I (s.o. Anm. 172) $26 \mathrm{f}$. 
${ }^{178}$ Kessler, Humanismus (s.o. Anm. 173) 151, versucht von hier aus, ,indirekt“ Agricola in die Nähe eines „Weges von der humanistischen Rhetorik zur naturwissenschaftlichen Methodik“ gelangen zu lassen.

${ }^{179}$ Die "Gemeinplätzigkeit“ der humanistischen Topik zeigt zugleich die enge Beziehung zur Literatur an, in der die Loci communes als Ordnungsschema für die Griffbereitschaft von Zitaten grundlegende Bedeutung hatten; J. M. Lechner, Renaissance Concepts of the Commonplaces. An Historical Investigation of the General and Universal Ideas Used in All Argumentation and Persuasion. With Special Emphasis on the Educational and Literary Tradition of the Sixteenth and Seventeenth Centuries (New York 1962; Reprint: Westport 1974). In diese weiteren Zusammenhänge gut hineinleuchtend auch Buck, Die „studia humanitatis" (s. o. Anm. 3) 280 ff.; ders.: Die Kompilationsliteratur, in: Buck, Rezeption der Antike (s. o. Anm. 151) 83-89. Uber den Gemeinplatz als Sachverhalt oraler Kultur s. W.J. Ong, The Presence of the Word (New Haven und London 1967); ders., Commonplace Rhapsody: Ravisius Textor, Zwinger and Shakespeare, in: Classical Influences (s. o. Anm. 155) 91-126. In dem bahnbrechenden Werk von E. R. Curtius, Europäische Literatur und lateinisches Mittelalter $\left({ }^{1} 1947\right)$, wird die Rhetorik unter dem Gesichtswinkel der Topik als Lebensprinzip humanistischer Kultur gesehen. Vgl. die Zusammenstellung einschlägiger Äußerungen von Curtius zur Topik bei P. Jehn $(\mathrm{Hg}$.), Toposforschung. Eine Dokumentation (Respublica literaria 10) (1972) 3-19, und ebd. in der Einleitung VII-LXIV eine engagierte Auseinandersetzung mit den Begriffskontaminationen bei Curtius. Wie die Doppelgesichtigkeit der topischen Dialektik der Humanisten zeigt, liegt bei ihnen eine ähnliche Kontamination vor.

${ }^{180}$ Risse, Logik der Neuzeit I (s.o. Anm. 172) 150: „Nach dieser Dispositionstheorie hat die Methode Lehrstücke zu ordnen, nicht unmittelbar zu beweisen. Wohl aber bestimmt sie dianoetisch die Zugehörigkeit eines Lehrstücks zu einem System“. Es bleibt „die systematische Gliederung der Lehrstücke“. Diese „Methode entspricht eher dem ,ordo“ als der ,methodus" der Aristoteliker“. Vgl. dazu auch Buck, Die "studia humanitatis“ (s.o. Anm. 3) 288, mit einem Zitat Montaignes (Essais I 25), der „nos pédants“ (s. dazu oben bei Anm. 143) vor der Loci-Methode warnt. Ähnlich wie Risse urteilt auch Troje, Wissenschaftlichkeit (s. u. Anm. 183) 78, über die Jurisprudenz: „Den von Ramus bzw. seiner Schule beeinflußten Juristen liegt vor allem an Gliederungen."

${ }_{181}$ Bahnbrechend, historisch aber noch nicht breit genug, P. Joachimsen, Loci communes. Eine Untersuchung zur Geschichte des Humanismus und der Reformation, zuerst erschienen im Luther-Jahrbuch 8 (1926) 27-87, wiederabgedruckt in: Gesammelte Aufsätze (s.o. Anm. 33) 387-442. Besser das wissenschaftsgeschichtliche Gesamtfeld berücksichtigend sodann W. Maurer, Melanchthons Loci communes von 1521 als wissenschaftliche Programmschrift. Ein Beitrag zur Hermeneutik der Reformationszeit, in: Luther-Jahrbuch 27 (1960) 1-50; ders., Der junge Melanchthon (s.o. Anm. 114) I 192-214 und 243-247, mit recht präzisen Formulierungen, etwa $213 \mathrm{f}$.: „Die biblische Exegese gewinnt ihre formale Methode aus den Regeln der Rhetorik ... Jede Gestalt, jeder Gegenstand, jedes Ereignis repräsentiert einen locus communis: Kain die Sünde, die Posaunen von Jericho oder das Manna das Wort Gottes ... Die geschichtlichen Beispiele ... haben ihren locus communis in der fides ... Dabei wird deutlich, daß es sich bei den Loci niemals um abstrakte Begriffe, sondern immer um die Bezeichnung geschichtlicher Entscheidungen handelt. Der Redner wählt bezeichnende Geschichten aus, stellt deren locus communis fest und wendet diesen auf seine Zuhörer an, um bestimmte Gefühle oder Entschlüsse in ihnen zu wecken." Zum ganzen Problem mancherlei Bedenkenswertes auch in dem Sammelband: Logique et théologie au XVI $\mathrm{X}^{\mathrm{e}}$ siècle: aux sources de l'argumentation de Martin Bucer (Cahiers de la Revue de théologie et de philosophie 5) (Genf usw. 1980).

${ }_{182}$ G. Kisch, Melanchthon und die Rechtswissenschaft, in: Festschrift für Hans Liermann (1964) 87-95. Vgl. auch G. Kisch, Melanchthons Rechts- und Soziallehre (1967). Uber Juristen, die sich von den Loci communes Melanchthons inspirieren ließen, s. Troje, Wissenschaftlichkeit (s.u. Anm. 183) $76 \mathrm{f}$.

${ }^{183}$ H. E. Troje, Wissenschaftlichkeit und System in der Jurisprudenz des 16. Jahrhunderts, in: Philosophie und Rechtswissenschaft. Zum Problem ihrer Beziehung im 19. Jahrhundert, hg. von J. Blübdorn und J. Ritter (1969) 63-97; T. Viebweg, Topik und Jurisprudenz. Ein Beitrag zur rechtswissenschaftlichen Grundlagenforschung ( $\left.{ }^{5} 1974\right) ; H$. E. Troje, Kapitel "Juristische Argu- 
mentationslehre“, in: Handbuch der Quellen und Literatur der neueren europäischen Privatrechtsgeschichte II/1 (1977) 731-741. Vgl. auch Schindling, Humanistische Hochschule (s.o. Anm. 138) 162-235, sowie $M$. Reulos, Quelques aspects de l'humanisme juridique allemand, in: L'Humanisme allemand (s.o. Anm. 14) 221-230, der als die zwei maßgeblichen Tendenzen in der humanistischen deutschen Jurisprudenz des 16. Jahrhunderts das philologisch orientierte Textstudium und die von Agricola und Melanchthon beeinflußte Bemühung um die Methode nennt. Zur Entwicklung der humanistischen Jurisprudenz insgesamt, auf die hier nicht im einzelnen eingegangen werden kann, s. $H$. E. Troje, Die Literatur des gemeinen Rechts unter dem Einfluß des Humanismus, in: Handbuch usw. wie oben 615-795 (vgl. u.a. auch H. E. Troje, Zur humanistischen Jurisprudenz, in: Festschrift H. Heimpel II (1972) 110-139); speziell zu Deutschland: $A$. Mazzacane, Scienza, logica e ideologia nella giurisprudenza tedesca del sec. XVI (Ius nostrum 16) (Rom 1971); K. H. Burmeister, Das Studium der Rechte im Zeitalter des Humanismus im deutschen Rechtsbereich (1974) (vor allem 251-261 § 24: „Die humanistische Reform“; $230 \mathrm{f}$. über die Loci communes). Verdienstvoll: G. Kisch, Humanismus und Jurisprudenz (Basel 1955), sowie: Studien zur humanistischen Jurisprudenz (Berlin und New York 1972). Allgemein grundlegend war D. Maffei, Gli inizi dell'Umanesimo giuridico (Mailand 1956, Neudruck 1972).

${ }^{184} \mathrm{Vgl}$. dazu auch V. Piano Mortari, Considerazioni sugli scritti programmatici dei giuristi del secolo XVI, in: Studia et documenta Historiae et Iuris 21 (1955) 276-302; Dialettica e giurisprudenza. Studio sui trattati di dialettica legale del secolo XVI, in: Annali di Storia del diritto 1 (1957) 293-401; Ricerche sulla teoria dell'interpretazione del diritto nel secolo XVI (Mailand 1956). In diesen Arbeiten werden auch die deutschen Juristen ausführlich behandelt. Der Autor mißt der humanistischen Logik große Bedeutung für die rechtswissenschaftliche Begriffs- und Systembildung zu. Dagegen Troje, Wissenschaftlichkeit (s. o. Anm. 183) 96, mit Nachdruck für „die autochthone Entwicklung der modernen Systematik aus dem antiken, griechisch-römischen ordo juris".

${ }^{185}$ Daneben wäre noch zu nennen der ebenfalls einige Zeit in Köln lehrende „professor bonarum literarum" (s. H. Keussen, Matrikel der Universität Köln Il (1919) 884) Bartholomäus Latomus, der hier 1533 eine ,Epitome commentariorum dialecticae inventionis Rodolphi Agricolae herausgab. Ủber die weiteren (auch Pariser) Drucke s. W.J. Ong, Ramus and Talon Inventory. A Short-Title Inventory of the Published Works of Peter Ramus (1515-1572) and of Omer Talon (ca. 1510-1562) in Their Original and in Their Altered Forms (Cambridge, Mass., 1958) 543-554. Älteres zur Person s. in: Lexikon für Theologie und Kirche VI ('21961) 822. Dazu noch Vasoli, Dialettica e retorica (s.o. Anm. 172) 255-260, innerhalb des Kapitels „L'influenza di Rodolfo Agricola“ usw. 249-277.

${ }^{186}$ Risse, Logik der Neuzeit I (s.o. Anm. 172) 25-32; Vasoli, Dialettica e retorica (s.o. Anm. 172) 260-277. Vgl. auch W.J. Ong, Ramus, Method, and the Decay of Dialogue. From the Art of Discourse to the Art of Reason (Cambridge, Mass., 1958) 234-245. Risse bezeichnet Caesarius im übrigen als „Eklektiker“.

${ }_{187}$ Symptomatisch für den Einfluß des Caesarius: Anfang der 60er Jahre las in Ingolstadt nur ein Professor die Logik, und zwar nach Caesarius; Seifert, Logik (s.o. Anm. 65) 150 Anm. 20. In seiner $1533 \mathrm{zu} \mathrm{Köln}$ erschienenen ,Rhetorica in septem libros sive tractatus digesta, universam fere eius artis vim compendio complectens', zitiert Caesarius unter den Zeitgenossen übrigens nur Melanchthon; Maurer, Der junge Melanchthon (s.o. Anm. 114) I 245 Anm. 68.

${ }^{188}$ Zur großen Verbreitung und Wirkung Agricolas s. W. Risse, Bibliographia logica. Verzeichnis der Druckschriften zur Logik mit Angabe ihrer Fundorte I. 1472-1800 (1965) 237 und 279 s. v. Agricola: 27 Editionen und 6 Kommentatoren, darunter Frissemius mit 15 Ausgaben. Caesarius bringt es bei Risse 243 und $281 \mathrm{~s}$. v. Caesarius gar auf 34 Belege für ihn selbst und auf $4 \mathrm{Kom}$ mentatoren, Latomus im übrigen auf 11 Belege (256 s. v. Latomus). Vgl. auch P. Aquilon, La réception de l'humanisme allemand à Paris à travers la production imprimée: 1480-1540, in: L'Humanisme allemand (s.o. Anm. 14) 45-79, mit einer Liste der in Paris von den Werken Agricolas, Melanchthons und des Caesarius veranstalteten Drucke. Noch einige Hinweise zur Bedeutung, die Agricola damals erlangte: 1530 Klage der Universität Paris, daß man Agricola eifriger als Aristoteles studiere (Ong, Ramus, Method, s.o. Anm. 186, 95); 1535 königliche Anordnung, daß 
in Cambridge Agricola zusammen mit Aristoteles, Georg von Trapezunt und Melanchthon gelesen werde (ebd. 94).

${ }^{189}$ Grundlegend: Ong, Ramus, Method (s.o. Anm. 186), und: Ramus and Talon Inventory (s.o. Anm. 185). Ferner: Gilbert, Renaissance Concepts of Method (s.o. Anm. 18) 129-163; Risse, Logik der Neuzeit I (s.o. Anm. 172) 122-200 ; Vasoli, Dialettica (s.o. Anm. 172) 333-589; Ashworth, Language (s. o. Anm. 172) 15-17; Lobr, in: RenQ (s. u. Anm. 208) 33 (1980) 676-682.

${ }^{190}$ Jardine, in: Cambridge History of Late Medieval Philosophy (s. o. Anm. 172) 803: „His manuals were designed for the humblest members of the intellectual community“; 805: Das dialektische Handbuch hatte nicht mehr zu sein als ,a pocket blueprint for successful performance in set disputations“. Dem entspricht die Anlegung von „loci-communes-Heften“ als Gedächtnisstütze für Schüler im Unterricht, um Dichterzitate rasch bei der Hand zu haben; vgl. dazu Buck, Kompilationsliteratur (wie oben Anm. 179) 83, mit weiterer Literatur. Doch sei auch das (vorläufige) Schlußurteil von Jardine (807) nicht unerwähnt: Solange es keine grundlegendere Studie gibt, "we shall not be in a position to decide whether the humanist intervention in the history of logic represents a decisive impoverishment or a possible enrichment of the tradition“. Seifert, Logik (s. o. Anm. 65) 98, spricht von den „weit überspannten Erwartungen, die die Humanisten dieser Dialektik und ihrem topicum artificium entgegenbrachten." Vgl. ebd. 169 Anm. 150 die kritischen Äußerungen von Bacon und der Logik von Port Royal zur rhetorischen Dialektik.

${ }^{191}$ Auf die Spannungen, die das dialektische Wissenschaftsverständnis eines Agricola bei dem Reformator Melanchthon erzeugte, hat bereits Joachimsen, Loci communes (s. o. Anm. 181), mit Nachdruck hingewiesen. Zur Wirkung Melanchthons s. im übrigen das Kapitel „Die Melanchthonschule“ bei Risse, Logik der Neuzeit I (s.o. Anm. 172) 79-121.

${ }^{192}$ Sehr erhellend G. Müller, Die Aristoteles-Rezeption im deutschen Protestantismus, in: Die Rezeption der Antike (s. o. Anm. 42) 55-70: Melanchthon propagierte als Pädagoge die peripatetische Philosophie als solche, lehnte aber die scholastische Interpretation ab. Vgl. auch Strauss, Luther's House of Learning (s.o. Anm. 126) $72 \mathrm{f}$ : ,Melanchthon's orthodox Aristotelian treatment was probably the most influential psychology book of the century ... From Melanchthon in 1540 to Giacomo Zabarella and Robert Burton's ,Anatomy of Melancholy' in the early seventeenth century, Aristotle dominated all discussions and controversies on the vital principle ... In the middle of the sixteenth century the best key to Aristotelian psychology was Philip Melanchthon's, On the Soul', written in 1540, a handy summary of received ideas and, coming from the leading academic theologian of Wittenberg, a work accepted nearly everywhere in Lutheran circles as an authoritative statement of classical psychology for the modern readers."

${ }^{193}$ Ein abschreckendes Beispiel bildet etwa das 1550 in Frankfurt (Oder) herausgekommene Werk des Iodocus Willichius, De methodo omnium artium et disciplinarum. Seifert, Logik (s.o. Anm. 65) 169, bezeichnet die darin für die einzelnen Disziplinen gebotene Aufstellung von „loci“ als „ein krauses Durcheinander von Termini technici, Lehrsätzen und allgemeinen Obertiteln“. Zu Willich s. Risse, Logik der Neuzeit I (s. o. Anm. 172) 108-110, sowie neuerdings Lobr, in: RenQ (s. u. Anm. 208) 35 (1982) 231. Einen nicht minder unangenehmen Exzeß formalisierter, in Dichotomie aufgelöster Inhaltsleere stellt die 1576 in Basel erschienene ,Professio regia des dortigen ramistischen Rhetorikprofessors Thomas Freige dar; Ong, Ramus, Method (s.o. Anm. 186) 298-301; Risse, Logik der Neuzeit I 173f.; allerdings recht günstige Beurteilung durch Mazzacane, Scienza (s.o. Anm. 183) 3-30, 49-93 und passim.

${ }^{193 a}$ Vgl. auch W. Sparn, Einige Fragen zur Entwicklung des theologischen Interesses an der Logik im 16. Jahrhundert, in: Logique et théologie (s.o. Anm. 181) 79: das „eigentümlich theologische Interesse“ des 16. Jahrhunderts habe von selbst zu der Frage geführt: „Welches Verhältnis entwickelt die Logik zu ihren metaphysischen Rahmenbedingungen?“

${ }^{194}$ Vgl. etwa Risse, Logik der Neuzeit I (s. o. Anm. 172) 177-196; Dreitzel, Protestantischer Aristotelismus (s. u. Anm. 212) 84f. Beispiele aus Niedersachsen bei Haase, Lateinschule in Niedersachsen (s.o. Anm. 138) 153: Hannover (1577), Braunschweig, Hildesheim, Stade. Freilich sind die Fronten nicht so glatt. Vgl. Risse I 179 ff. über vermittelnde Philippo-Ramisten, sowie $193 \mathrm{f}$. über „innerramistische Streitigkeiten“ und des weiteren I $440 \mathrm{ff}$. zu dem sich schon Ende des 16. Jahrhunderts abzeichnenden und dann im 17. Jahrhundert entfaltenden ,aristotelisch-scholastisch-ramistischen Synkretismus“. Über die offensichtlich stärkere Position des Ramismus im 
Calvinismus (und bei den Zwinglianern, zu denen Ramus selber gehörte) s. J. Moltmann, Zur Bedeutung des Petrus Ramus für Philosophie und Theologie im Calvinismus, in: ZKG 68 (1957) 295-318: Gegen Bezas Aristotelisierung wurde der Ramismus „zur Grundlage für den calvinistischen Humanismus ..., für den calvinistischen Empirismus ... und für den calvinistischen Pietismus". Deutsche Vertreter z. B. Olevian und Tremellio in Heidelberg, Th. Zwinger und Polanus in Basel, Bullinger und Gualter in Zürich, Sturm in Straßburg, Molanus in Bremen, Nathan Chytraeus in Rostock (von dort verdrängt nach Bremen), Freige, Gyphanus und Donellus in Altdorf, Piscator, Alsted und Alting in Herborn. In der bei Risse, Bibliographia logica I (s. o. Anm. 188) 283 , s. v. Ramus gebotenen Liste von Ramus-Kommentatoren fällt die große Zahl deutscher Logiker auf. Der Index auctorum ebendort 237-276 zeigt insgesamt eine überraschend hohe deutsche Präsenz. Zur europäischen Reaktion gegen Ramus s. auch Gilbert, Renaissance Concepts of Method (s. o. Anm. 18) 145-163 und 197-220 (hier 213 ff.: „The Clash of Aristotelian and Ramist Methodology in Germany").

${ }^{195}$ Petrus Ramus gehörte in Paris zu den Schülern des Johannes Sturm, als dieser dort im neu gegründeten Collège Royal über Agricolas,De inventione dialectica' dozierte. 1568 suchte Ramus bei seinem Lehrer in Straßburg vorübergehend Zuflucht, ehe er sich nach Basel wandte; vgl. dazu Mazzacane, Scienza (s. o. Anm. 183) 63-93. Über die Rolle Sturms bei der Entwicklung der Dialektik s. Risse, Logik der Neuzeit I (s. o. Anm. 172) 41-46 (er brachte als erster die Lehre Agricolas nach Paris). Zu Sturms starkem Nachwirken: J. Rott, Bibliographie des œuvres imprimées du recteur strasbourgeois Jean Sturm (1507-1589), in: Actes du $95^{\mathrm{e}}$ Congrès National des Sociétés Savantes. Section de Philosophie et d'Histoire jusqu'à 1610, I (Paris 1975) 319-404.

${ }^{196}$ Grundlegend dazu A. Lang, Die Loci theologici des Melchior Cano und die Methode des dogmatischen Beweises (1925). Neuerdings: J. Belda Plans, Los lugares teológicos de Melchor Cano en los comentarios a la suma (Colección Teológica 33) (1982, noch nicht gesehen).

197 J. IJsewijn (vgl. zu dem oben in Anm. 53 genannten Großbeitrag kürzer auch noch: Niederländischer Humanismus, in: Wolfenbütteler Renaissance Mitteilungen 1 (1977) 29-33) sieht 1575 mit der Gründung der Universität Leiden eine scharfe Zäsur; seitdem „begann die Zeit der umfangreichen Editionen, Kommentare und Sammelwerke, wie sie das 16. Jahrhundert vorher fast nicht gekannt hatte“. Ich weiß nicht, ob man das so absolut sagen kann.

${ }^{198}$ Zur ersten Einführung s. bei R. Pfeiffer, A History of Classical Scholarship. From 1300 to 1850 (Oxford 1976) das Kapitel: „Humanists and Scholars of the French Renaissance“ 99-123; jetzt auch in deutscher Übersetzung: Die Klassische Philologie von Petrarca bis Mommsen, (1982) 127-155 („Humanisten und Philologen der französischen Renaissance“).

199 Pfeiffer, Klassische Philologie $121 \mathrm{f}$. und 174-178.

${ }^{200}$ Schon U. von Wilamowitz-Moellendorf hat in seiner "Geschichte der Philologie“ (1921, $\left.{ }^{3} 1927\right) 23 \mathrm{f}$. Scaliger als „Fürsten“ in der Entwicklung der Philologie als Fachwissenschaft bezeichnet. Vgl. auch Pfeiffer, Klassische Philologie 143-151, in seinem Werk seien die französischen und italienischen Vorgänger und Zeitgenossen vereinigt und weit übertroffen worden (143). Das Buch von U. Mublack-A. Hentschke, Einführung in die Geschichte der klassischen Philologie (1972), enttäuscht, insofern es sich bis zum 18. Jahrhundert fast ausschließlich mit Beatus Rhenanus befaßt. Natürlich soll damit die Bedeutung der älteren Humanisten für die Geschichte der Philologie, beginnend schon mit Petrarca, nicht verkannt werden.

${ }^{201}$ Vgl. etwa Dreitzel, Protestantischer Aristotelismus (s. u. Anm. 212) 45, über den aus einer niederländischen Adelsfamilie stammenden Caselius (1533-1613): „Seine geistige Haltung ist am besten als eine Fortentwicklung des humanistischen Luthertums Melanchthons zu einem Humanismus ohne konfessionelle Prägung zu charakterisieren.“

${ }^{202}$ Mublack-Hentschke (s. o. Anm. 200) 60 f. nach J. Bernays, Joseph Justus Scaliger (1855) 59. S. auch Wilamowitz, Geschichte (s.o. Anm. 200) 23.

${ }^{203}$ Zur begrifflichen Abgrenzung gegenüber dem Mittellateinischen s. IJsewijn, Companion (s. u. Anm. 205) VII : „By ,Neo-Latin“ I mean all writings in Latin since the beginnings of Italian Humanism in about 1300 A. D.: this definition was adopted by the Second International Congress of Neo-Latin Studies (Amsterdam, 1973) and the statutes of the International Association for Neo-Latin Studies.“ 
${ }^{204}$ Die Poetik des älteren Julius Cäsar Scaliger war bis ins 18. Jahrhundert das maßgebliche Lehrbuch der Dichtkunst; $M$. Costanzo, Introduzione alla poetica di Giulio Cesare Scaligero, in: Giornale Storico della Letteratura Italiana 138 (1961) 1-37; dort: 35-37.

${ }^{205}$ Eine gute Einführung bietet der von J. IJsewijn, dem Gründer des neulateinischen Studienzentrums "Seminarium Philologiae Humanisticae" in Löwen herausgegebene „Companion to Neo-Latin Studies" (Amsterdam usw. 1977); dazu die wichtigen Addenda von J. IJsewijn, in: Humanistica Lovaniensia 28 (1979) 328-335. Recht informativ auch: Ryan, Neo-Latin Literature (s. o. Anm. 14). Die bis 1961 (Band XVI) von H. de Vocht als Buchreihe herausgegebenen „Humanistica Lovaniensia“ erscheinen seit 1968 (Band XVII) unter der Leitung von J. IJsewijn jährlich als Zeitschrift des Löwener Seminarium als ,Journal of Neo-Latin Studies". Ein weiteres Informationsorgan sind die von der Pennsylvania State University seit 1952 herausgegebenen „NeoLatin News“. Vgl. auch die Akten der in den letzten Jahren an verschiedenen Orten abgehaltenen neulateinischen Studientagungen: Acta Conventus Neo-Latini Lovaniensis 1971 (München und Löwen 1973); Acta Conventus Neo-Latini Amstelodamensis 1973 (1979); Acta Conventus NeoLatini Turonensis 1976 (Paris 1980). Eine weitere Tagung fand 1979 in Bologna statt. Bahnbrechend für die deutsche Literaturgeschichte wurde G. Ellinger, Geschichte der neulateinischen Literatur Deutschlands im sechzehnten Jahrhundert I-III (1929-1933, Neudruck 1969). Vgl. auch den Literaturbericht von $K$. O. Conrady, Die Erforschung der neulateinischen Literatur. Probleme und Aufgaben, in: Euphorion 49 (1955) 413-445. Aus letzter Zeit nenne ich exemplarisch nur $E$, Schäfer, Deutscher Horaz, Conrad Celtis, Georg Fabricius, Paul Melissus, Jakob Balde. Die Nachwirkung des Horaz in der neulateinischen Dichtung Deutschlands (1976). Mit souveräner Selbstverständlichkeit ist hier in gesamteuropäischer Weite und Offenheit die verhängnisvolle Spaltung irrelevant, die in der deutschen Literaturgeschichtsforschung zwischen "humanistischer" und "neulateinischer" Dichtung vorgenommen wurde. Vgl. dazu (recht vehement) Roloff, Thomas Naogeorg (s.o. Anm. 158), wo die entsprechenden prominenten Germanisten mit ihren jeweiligen Handbüchern zusammengestellt sind. Im gleichen Sinne G. Hess, Deutsche Literaturgeschichte und neulateinische Literatur. Aspekte einer gestörten Rezeption, in: Acta Conventus Neo-Latini Amstelodamensis (s. o.) 493-538.

${ }^{206}$ Grundlegend E. Lewalter, Spanisch-jesuitische und deutsch-lutherische Metaphysik des 17. Jahrhunderts (1935). Zuletzt: J. de Vries, Zur Geschichte und Problematik der Barockscholastik in Deutschland, in: Theologie und Philosophie 57 (1982) 1-20.

${ }^{207} \mathrm{Vgl}$. die Beiträge des XVI. Colloque International de Tours: Platon et Aristote à la Renaissance (De Pétrarque à Descartes XXXII) (Paris 1976); Fazit von $R$. Weil (549): „que vous avez uni ici Platon et Aristote, comme le faisaient les humanistes de la Renaissance." $P$. O. Kristeller, La tradizione aristotelica nel Rinascimento (Padua 1962).

${ }^{208} \mathrm{Vgl}$. z. B. die zahlreichen Aristoteles-Kommentare der Renaissance, die C. H. Labr in den Studies in the Renaissance 21 (1974) 228-289 und in RenQ 28 (1975) 689-741, 29 (1976) 714-745, 30 (1977) 681-741, 31 (1978) 532-603, 32 (1979) 529-580, 33 (1980) 623-734 und 35 (1982) 164-256 (Abschluß) zusammengestellt hat. Zu den Editionen s. F. E. Cranz, A Bibliography of Aristotle Editions 1501-1600 (1971). Zu den Übersetzungen: E. Garin, Le traduzioni umanistiche di Aristotele nel secolo XV, in: Atti e memorie dell'Accademia Fiorentina di Scienze Morali „La Colombaria“ 16 (n.s. 2) (1947-50) 55-104. Allerdings verzeichnet Worstbrock, Antikerezeption (s.o. Anm. 10) 24 f., für Deutschland lediglich Ps. Aristoteles, Oeconomica (nach Leonardo Bruni) und die ,Secreta Secretorum'. Zur Forschung: Schmitt, A Critical Survey (s.o. Anm. 39); ders., Philosophy and Sciences in Sixteenth-Century Universities: Some Preliminary Comments, in: The Cultural Context of Medieval Learning, hg. von J. E. Murdoch und E. D. Sylla (Dordrecht 1975) 485-537. S. auch oben Anm. 11 zu Aristoteles.

${ }^{209} \mathrm{Vgl}$. etwa noch E. F. Rice Jr., Humanist Aristotelianism in France: Jacques Lefèvre d'Étaples and his circle, in: Humanism in France usw., hg. von A. H. T. Levi (Manchester 1970) 132-149; Bedouelle, Lefèvre d'Étaples (s.o. Anm. 54) 28-36 (,A la recherche du véritable Aristote“); C. B. Schmitt, Aristotle's Ethics in the Sixteenth Century: Some Preliminary Considerations, in: Ethik im Humanismus (s. o. Anm. 12) 87-112 (mit neuerer Literatur über das hier behandelte Spezialthema hinaus). Gerade deutsche Humanisten waren vom Aristotelismus Lefèvres beeindruckt. So schrieb der Nürnberger Johannes Cuno (s.o. Anm. 56) an Reuchlin: „Quid enim te non vel bea- 
tum dixerim, qui in hoc foelix aevum incideris, quo non solum inter cetera ingenii et fortunae praeclara dona defecata illa et pura philosophia Peripatetica a diserto illo et celeberrimo philosopho Iacobo Fabro apud Parisios sis initiatus et eruditus ..., qui ut alter Daedalus faber carpento ornato affabre fabrefacto philosophiam Aristotelicam eleganti stola et phrasi decoratam cunctis aspiciendam invexit“. Ähnlich der Humanist Heinrich Stromer. Nachweise bei Rice (s.o.) 132 und 144. Die traditionelle aristotelische Logik hielt sich in der ersten Hälfte des 16. Jahrhunderts jedoch im wesentlichen nur in Italien (Risse, Logik der Neuzeit I, s.o. Anm. 172, $201 \mathrm{ff}$.), ,erneuertes Aristoteles-Studium“ in der Logik gab es in Deutschland erst wieder „nach der Jahrhundertmitte“ (256); vgl. bei Risse das ganze Kapitel „Altaristoteliker und Averroisten“ 201-301. S. auch Gilbert, Renaissance Concepts of Method (s.o. Anm. 18) 145-212.

${ }^{210}$ So letztens etwa Seifert, L'integrazione (s. o. Anm. 65) 30-32.

${ }^{211}$ Darüber ist am Beispiel des Lehrbetriebs an der Universität Köln demnächst eine Studie von E. Höbn zu erwarten.

${ }^{212}$ Zunächst in Parallelentwicklung (dabei u. a. paduanischer Einfluß), jedoch dann unter starkem Einfluß der spanischen Scholastik: P. Petersen, Geschichte der aristotelischen Philosophie im protestantischen Deutschland (1921; Neudruck 1964 und 1975); K. Eschweiler, Die Philosophie der spanischen Spätscholastik auf den deutschen Universitäten des 17. Jahrhunderts, in: Gesammelte Aufsätze zur Kulturgeschichte Spaniens 1 (1928) 251-325; M. Wundt, Die deutsche Schulmetaphysik des 17. Jahrhunderts (1939); H. Robbers, De spaans-scholastieke wijsbegeerte op de Noord-Nederlandse Universiteiten in de eerste helft der 17e eeuw, in: Bijdragen. Tijdschrift voor Philosophie en Theologie 17 (1956) 26-55 (Einfluß von Deutschland her); H. Dreitzel, Protestantischer Aristotelismus und absoluter Staat. Die „Politica“ des Henning Arnisaeus (ca. 1575-1636) (1970). Neuerdings W. Sparn, Wiederkehr der Metaphysik. Die ontologische Frage in der lutherischen Theologie des frühen 17. Jahrhunderts (1976). Dort 204 das aufschlußreiche Resümee: „Die erneuerte metaphysische Arbeit der Theologie folgt der Einsicht, daß gerade das ,praktische Christentum, das sich durch die Reformation im Gegensatz zur ,spekulativen' Scholastik neue Geltung verschafft hatte, der Theorie bedurfte." Zum ganzen Fragenkreis zuletzt: Müller, Aristoteles-Rezeption (wie oben Anm. 192). Ein wichtiges Datum: 1605 werden in Wittenberg die Lehrbücher Melanchthons für den akademischen Unterricht abgeschafft; W. Friedensburg, Geschichte der Universität Wittenberg (1917) 504.

${ }^{213}$ Dreitzel, Protestantischer Aristotelismus (s.o. Anm. 212) 64. Im übrigen äußerst informativ dort das ganze Kapitel „Aristotelische Philosophie“ 53-86. Vgl. auch Lewalter, Metaphysik des 17. Jahrhunderts (s. o Anm. 206) 37-44, sowie Liebing, Ausgänge des europäischen Humanismus (s. o. Anm. 127) 369-371. Von den 13 Drucken der ,Disputationes', die 1600-1636 nach der Erstausgabe von 1597 (Salamanca) erschienen, gehören allein 6 nach Deutschland (4 Mainzer, 2 Kölner); s. Lobr, in: RenQ 35 (1982) 185.

${ }^{214}$ D. Gerbard, Old Europe. A Study of Continuity, 1000-1800 (New York usw. 1981) 84: „Until the turn from the seventeenth to the eighteenth century, though, the curricula of schools and universities were to offer a combination of scholastic and humanist studies, of intellectual and linguistic training under the old predominance of religion and logic."

${ }_{215}$ W. J. Bouwsma, The Two Faces of Humanism. Stoicism and Augustinianism in Renaissance Thought, in: Itinerarium Italicum (s. o. Anm. 14) 3-60.

${ }^{216}$ So bei dem ersten großen humanistischen Pädagogen Pier Paolo Vergerio (1370-1444); $D$. Robey, Humanism and Education in the Early Quattrocento: The ,De ingenuis moribus' of P. P. Vergerio, in: BHR 42 (1980) 27-58.

${ }^{217}$ So schon L. Zanta, La Renaissance du Stoïcisme au XVI ${ }^{\mathrm{e}}$ siècle (Paris 1914). Vgl. auch J. $L$. Saunders, Justus Lipsius. The Philosophy of Renaissance Stoicism (New York 1955). Neuerdings G. Abel, Stoizismus und frühe Neuzeit. Zur Entstehungsgeschichte modernen Denkens im Felde von Ethik und Politik (1978), der insbesondere herausarbeitet, daß der Neo-Stoizismus nicht, wie die antike Stoa, vom Logos in der Naturordnung ausging, sondern von der durch menschliche Vernunft begründeten moralischen und politischen Ordnung. Er wendet sich u. a. gegen H. Blumenberg, daß der Neo-Stoizismus keine tiefergehenden Wirkungen auf das moderne Denken gehabt hätte. Leider kommt auch in diesem Buch die ältere, seit dem Quattrocento im italienischen Renaissance-Humanismus sehr präsente stoische Ưberlieferung völlig zu kurz. Vgl. dazu recht in- 
formativ Buck, Rezeption der Antike (s. o. Anm. 151) 104-124, wo der Stoizismus in den größeren Rahmen der "Weisheitsethik“ eingebaut ist. Dem unergiebigen Versuch, Ramismus und Neo-Stoizismus miteinander in Verbindung zu bringen (228-246), scheint Abel wohl auch selbst keine größere Chance beigemessen zu haben.

${ }^{218} \mathrm{Vgl}$. bei Abel, Stoizismus, die ausführlichen Kapitel über Guillaume Du Vair und Pierre Charron.

219 Weltanschauung und Analyse des Menschen (s.o. Anm. 31) $439 \mathrm{ff}$.

220 G. Oestreich, Antiker Geist und moderner Staat bei Justus Lipsius (1546-1606). Der Neostoizismus als politische Bewegung, Hab.-Schrift Berlin 1954; ders., Politischer Neustoizismus und Niederländische Bewegung in Europa und besonders in Brandenburg-Preußen, in: Geist und Gestalt des frühmodernen Staates. Ausgewählte Aufsätze (1969) 101-156; ders., Das politische Anliegen von Justus Lipsius' De constantia ... in publicis malis (1584), in: Festschrift H. Heimpel I (1971) 618-638. Zur Kritik an Oestreich s. diesen selbst, Die Bedeutung des niederländischen Späthumanismus für Brandenburg-Preußen, in: Humanismus und Naturrecht in Berlin - Brandenburg - Preußen. Ein Tagungsbericht, hg. von H. Tbieme (Berlin und New York 1979), 16-27 und Diskussionsbeitrag 50-54. Jüngste (unvollständige) Literaturübersicht zu Lipsius: Totok, Handbuch III (s. o. Anm. 2) 352-355.

${ }^{221}$ Zanta, Renaissance 333-344; 337: „En résumé, le néo-stoïcisme reste tout proche d'un christianisme moyen, fait pour des gens raisonnables, pour des intellectuels qui raisonnent tout, leur foi et les actes qu'elle leur dicte ... Le néo-stoïcisme est en définitive un rationalisme chrétien, dans lequel le christianisme n'apparaît pas toujours comme essentiel, mais plutôt comme surajouté." Exemplarisch etwa das Verhältnis des Franz von Sales zum Stoizismus: $A$. Jagu, L'utilisation du stoïcisme par saint François de Sales, in: Revue des sciences religieuses 38 (1964) 42-59; R. Murpby, Saint François de Sales et la civilité chrétienne (Paris 1964). Vgl. kurz, aber treffend $A$ bel, Stoizismus (s.o. Anm. 217) 301 f., und ebd. 362 f. die zahlreichen Studien von J.-E. d'Angers. Sie sind inzwischen aber von $L$. Antoine gesammelt herausgegeben worden: J.E. d'Angers, Recherches sur le stoïcisme au XVII ${ }^{\mathrm{e}}$ siècle (Hildesheim-New York 1976).

${ }^{222}$ Infolgedessen okkupieren die Titel mancher gesamtgeschichtlicher Darstellungen doch zu ausschließlich den Begriff „Humanismus“ für diese frühere Zeit; etwa $M$. P. Gilmore, Le Monde de l'Humanisme, 1453-1517 (1952; Paperback: New York 1962); A. Chastel-R. Klein, L'Europe de la Renaissance: L'Age de l'Humanisme (Paris 1963); deutsche Ausgabe: Die Welt des Humanismus. Europa 1480-1530 (1963). Zum Epochenproblem jetzt das informative Buch von $S$. Skalweit, Der Beginn der Neuzeit (Erträge der Forschung 178) (1982).

${ }^{223}$ Nach C. H. Lobr, Die Entwicklung des mittelalterlichen Denkens. Gedanken zu einigen neuen Texteditionen, in: Theologie und Philosophie 55 (1980) 361-383, fallen Editionen von Hoch- und Spätscholastikern schwergewichtig zunächst in die Zeit 1470-1520; eine zweite Phase, die neues Interesse an der Hochscholastik anzeigt, liegt 1575-1675. Das Datum 1520 indiziert sicher auch die in diesem Zusammenhang unverkennbare Auswirkung der Reformation; doch könnte es nicht minder andeuten, daß der Humanismus, europäisch gesehen, doch erst um 1520 allgemein dominierend geworden ist. Petersen, Geschichte der aristotelischen Philosophie (s.o. Anm. 212), dürfte die von ihm beschriebene aristotelische Vorherrschaft im deutschen Protestantismus mit 1530 zu früh ansetzen.

${ }^{224}$ Ein dafür typisches jüngstes Beispiel ist Kölmel, Aspekte des Humanismus (s. o. Anm. 63). Er erweist sich damit als Spätling jener Sichtweise, die E. Cochrane in der Einleitung zu dem von ihm herausgegebenen Sammelband: „The Late Italian Renaissance 1525-1630“ (s.o. Anm. 21) 7-20 in ihren repräsentativen Vertretern vorgestellt und zugleich zurückgewiesen hat. Vgl. ebd. 77-208 die in Teil II unter dem Titel „Continuation and Change in the Humanistic Disciplines“ zusammengestellten Aufsätze.

${ }^{225}$ Liebing, Ausgänge des europäischen Humanismus (s.o. Anm. 127) 358: Ganz „aus dem Blickfeld der Kirchenhistorie gerückt" sei, ,was nach und neben seiner" (nämlich: des Humanismus) „Berührung mit der Reformation aus ihm geworden sei. Selbst das Schicksal der deutschen Humanisten verliert in dem Augenblick an Interesse, in dem sie ihren Beitrag zur Geschichte der Reformation und Gegenreformation geleistet haben." So auch kritisch Scbindling, Humanistische 
Hochschule (s.o. Anm. 138) 395f., und: Universitāt Gießen (s.o. Anm. 120) 101 f. Anm. 46. Auf die humanistische Kontinuität im Reformationszeitalter verweist programmatisch u. a. Spitz, Humanism in the Reformation (s. o. Anm. 30) 641-662. Vor allem jetzt Roloff, Thomas Naogeorg (wie oben Anm. 158). Von einem Hiatus Mitte des 16.-Mitte des 18. Jahrhunderts in der Geschichte des deutschen Humanismus spricht $P$. Grappin, L'humanisme en Allemagne après la réforme luthérienne, in: L'Humanisme allemand (s. o. Anm. 14) 593-605. Die Gründe für diese Fehleinschätzung werden hier besonders deutlich, nämlich ein sowohl $z u$ allgemeiner als auch $z \mathfrak{u}$ undifferenzierter Humanismusbegriff, der den Schulhumanismus nicht zur Kenntnis nimmt.

226 Liebing, Ausgänge des europäischen Humanismus 375: „Die bedeutenderen Humanisten werden von zwingenden Erfahrungen zu Sachproblemen geführt, die sie nicht mehr, moralphilosophisch', sondern nur noch wissenschaftlich, rational, empirisch, traditions- und autoritätskritisch bewältigen können."

227 A. Levi, French Moralists. The Theory of the Passions, 1585 to 1649 (Oxford 1964).

${ }^{228} H$. Plessner, Die verspätete Nation. Über die politische Verführbarkeit bürgerlichen Geistes ( $\left.{ }^{4} 1966\right) 36 \mathrm{f}$. (wenngleich ausschließlich in Funktionalisierung des ebd. nicht weiter substantiierten Sachverhaltes als solchen). (Ungewollt) exemplarisch für diese Absenz: Q. Skinner, The foundations of modern political thought I-II (Cambridge 1978) (der wesentliche deutsche Beitrag darin: Luther). Zu Erasmus s. jetzt $: J . D$. Tracy, The Politics of Erasmus. A Pacifist Intellectual and his Political Milieu (Toronto 1978).

${ }^{229}$ Zum gesamteuropäischen Vergleich s. Jones (Hg.), Present State (s. o. Anm. 4); dort über den Stand der deutschen Literaturgeschichtsforschung: E. Sobel, German Literature (169-196). Er führt alle einschlägigen Publikationen der letzten Zeit auf, die von allgemeinerer Bedeutung sind, so daß auf deren Einzelnennung hier verzichtet werden kann.

${ }^{230}$ Die derzeitige Tendenz der Forschung geht dahin, die vielfältigen Unterschiede des sich von Land zu Land anders ausprägenden Humanismus zu ermitteln. Daß die Bemühung um ständigen Vergleich auch die Übereinstimmung erfaßt, ist darin wohl als selbstverständlich eingeschlossen.

${ }^{231}$ Wie das z.B. ansatzweise für die Bildungsorganisation in der oben in Anm. 137 genannten Studie von Boebm, Bildungsbewegung und Universitätsverfassung, geschehen ist. So wären die deutschen Schulen beispielsweise mit den Seminaria nobilium in Italien zu vergleichen; dazu $G$. P. Brizzi, La formazione della classe dirigente nel Sei-Settecento. I seminari nobilium nell'Italia centro-settentrionale (Bologna 1976).

\section{Diskussion zum Referat Meuthen}

Scblosser: Herr Kollege Meuthen, ich habe eine ganz einfache und schlichte Frage, für die ich vorweg Ihr Verständnis erbitte, daß ich sie paradigmatisch aus dem juristischen Verständnis entwickle. Sie haben die Spätscholastik angesprochen, und ich frage Sie, wie würden Sie folgendes aus Ihrer Sicht sehen? Meiner Meinung nach hat die Spätscholastik, insbesondere in ihrer spanischen Ausprägung, eine nicht wegzudenkende Bedeutung für den Humanismus überhaupt und zwar deswegen, weil durch sie eine erste Hinwendung zur Säkularisierung des Weltbildes und damit auch des Rechtsdenkens stattfand. Die nächste Folge war dann natürlich das Naturrecht, und ich nehme jetzt Ihre Frage auf, als Sie nach dem System und nach der Ordnung gefragt haben. Ich meine: Systemdenken, Ordnungsdenken ist nicht das primäre Ergebnis des Humanismus, sondern erst des Naturrechts. Würden Sie jetzt, konkret gefragt, die Spätscholastik sozusagen als unerläßliches Verbindungsglied zwischen dem $\mathrm{Hu}$ - 
manismus sehen können? Vor diesem Hintergrund würde ich dann allerdings die Spätscholastik im Vorfeld des Naturrechts sehen und weniger als den Rivalen des Humanismus.

Meuthen: Ich muß, glaube ich, etwas definitorisch richtigstellen. Ich verstehe unter "Spätscholastik“ die spätmittelalterliche Scholastik. Die spanische Scholastik bezeichne ich als Neuscholastik. Gerade als ich den Ramismus kurz skizzierte, habe ich an einer bestimmten Stelle betont, daß dieses Ordnungsdenken als solches nicht mehr humanistisch ist. Das Humanistische in den loci communes ist das, was aus der Rhetorik stammt, das Gemeinplätzige, etwas sehr Literarisches, das heißt, eine typisch humanistische Angelegenheit. Es kommt in der rhetorischen Dialektik zweierlei zusammen, nämlich durch die loci communes etwas finden und es ordnen können; und die Ordnung dient wieder dazu, im Gedankengang argumentativ wirksam weiterschließen zu können. Was hier zusammenkommt, entspricht der Gesamtentwicklung, in der Humanismus und Scholastik nun eine Ehe eingehen. Man kann sich das konkret vor Augen führen: Wer in der Jesuitenschule war, lernte zunächst die loci communes in der Literatur usw. Studiert er dann z. B. noch Jura, dann lernte er sie auch dort kennen. Es handelt sich um eine phantastische Ehe, die Sie angedeutet haben, und die sich auf solche Weise zwanglos erklärt.

Reinhard: Nur eine Bemerkung, Sie haben an einer Stelle gesagt, daß die kirchliche Indienstnahme des Humanismus in Italien schon im 15.Jahrhundert einsetzte. Ich glaube, daß das nach den Forschungen von Denys Hay und nach verschiedenen neueren Arbeiten zur Papstgeschichte so nicht zu halten ist. Auch dort ist das ein Prozeß des 16.Jahrhunderts, und die berühmten Humanistenpäpste sind eher Episoden geblieben. Man weiß heute, daß es sich etwa bei Sixtus IV. um ein recht oberflächliches Mäzenatentum handelt, das mit einem tieferen Kontakt mit dem Humanismus eigentlich nichts zu tun hat.

Meuthen: „Indienstnahme“, das Wort habe ich in diesem Zusammenhang, glaube ich, nicht gebraucht, weil ich derselben Meinung bin, daß in solcher Weise von einer Indienstnahme nicht gesprochen werden kann; denn sie ist tatsächlich erst eine Sache des konfessionellen Zeitalters. Aber es findet eine selbstverständlichere, organische Einwandlung statt. So habe ich das verstanden wissen wollen. Wenn Sie die gewisse Reserve, die bei Denis Hay zum Vorschein kommt, sehr stark in den Vordergrund stellen, so könnte ich z. B. die Arbeiten von O'Malley entgegenhalten, der ja die Belege bringt, wo der Humanismus gerade gegenüber den Päpsten benutzt wurde, etwa in den Predigten an der Kurie. Die Humanistenpäpste, die Sie genannt haben, sind Sonderfälle. Doch darum geht es nicht. Vielmehr dürfte Pomponius Laetus eine Ausnahme sein, eine Episode. Maßgeblicher ist der normale Alltag, die ganz problemlose Übernahme des Humanismus. Darum ging es mir. Im Unterschied dazu dann die gezielte Einvernehmung im konfessionellen Zeitalter; denn jetzt wird der Humanismus erst zum echten Problem, wo alles nun auch theologisch „hinter"fragt wird. Wir sind sicher einer Meinung, daß dieses recht Selbstverständliche der Christlichkeit des italie- 
nischen Quattrocento etwas anderes war, ganz und gar und untheologisch, ich denke z.B. an Traversari. Den Konflikt der späteren Zeit gibt es dort nicht.

Reinhard: Das ist alles richtig, was Sie sagen, aber das fehlende massenweise Auftreten eines humanistisch gebildeten Klerus, darauf kommt es mir an, daß hier kein Mißverständnis entsteht.

Meutben: Der italienische Klerus ist im Quattrocento sicher nicht mehr und nicht weniger humanistisch gebildet als der deutsche. Weil ich merkte, daß hier ein Mißverständnis entstehen könnte, habe ich an einer Stelle ausdrücklich von einer Intellektuellenschicht gesprochen, damit ich nicht so verstanden würde, als seien hier $25 \%$ eines Jahrgangs (wie heute, nicht wahr?) Intellektuelle gewesen. Kristeller hat aber in einem Aufsatz einmal zahlreiche Kleriker zusammengestellt, die Humanisten waren; und da ergibt sich doch eine ganze Kolonne von Ordensmitgliedern, die nicht nur aus religiösem, sondern aus wirklich humanistischem Antrieb heraus, z. B. mit Abhandlungen und Editionen, die studia gefördert haben, eine lange Liste italienischer Ordensangehöriger, die Humanisten waren.

Wuttke: Ich glaube, man müßte jetzt sehr lange Zeit haben zu diskutieren, aber die Zeit haben wir nicht, und so möchte ich nur zwei Punkte herausgreifen, die mich ganz besonders interessieren. Das eine ist, daß Sie, wenn ich Sie richtig verstanden habe, eine geradezu prinzipielle Trennung zwischen Humanismus und Christentum vornehmen. In dem Zusammenhang wollte ich fragen: Wie kann ich es verstehen, daß mitten im christlichen Europa zunächst einzelne, dann immer mehr Gelehrte, Künstler und Dichter nach den Schätzen der Antike greifen und sich deren Gehalte aneignen? Wie kann ich diesen erstaunlichen Vorgang verstehen? Geschieht es deshalb, weil sie sich als Heiden entdecken und nun diese Seite durch die Berührung mit der Antike verstärkt hervorbringen wollen, oder ist es etwas ganz anderes, das sie bewegt? Ist es möglicherweise so wie das ganze sogenannte Mittelalter hindurch, das außer von der christlichen Lehre im eigentlichen Sinne ja auch von einem immer wieder neuen und sehr starken ethischen Impuls getragen war als etwas, das der christlichen Lehre zuarbeitet, das sozusagen die Vorarbeit für das Eigentliche leistet? Ob möglicherweise jetzt in Anlehnung an die antiken Schätze eine neue Welle ethischer Neubesinnung aufkommt und man sich sozusagen der alten Wahrheiten neu vergewissern möchte dadurch, daß man zu neuen Formen greift, aber auch dadurch, daß man zu neuen Inhalten greift? Wie soll ich mir die im Anfang des Renaissance-Humanismus bestehende Verbindung von Humanismus und Christentum bei Petrarca erklären? Wie soll ich mir erklären, daß es später um 1500 bei Raffael die enge Verbindung von Humanismus und Christentum gibt - übrigens auch bei Dürer? Zu Raffael vergleiche man das Buch von Heinrich Pfeiffer S.J. „Zur Ikonographie von Raffaels Disputà,, Rom 1975, in dem er die Versöhnung von Antike und Christentum bei Raffael aufzeigt. Wie soll ich mir einen Mann wie Baptista Mantuanus erklären, wie einen Erasmus, mit ihrem unermeßlichen Erfolg bei den zeitgenössischen Lesern, wenn nicht bei ihnen der Impuls fortwirkte, die besten Kräfte der Antike für das Christentum zu gewinnen? Und 
andererseits: Sind denn die paganen Kräfte der Renaissance, die ich nicht leugne, wirklich stärker als die, die es das ganze sogenannte Mittelalter hindurch gab? In einem Satz gesagt, ich komme immer mehr dazu festzustellen, christlicher Humanismus zu sagen ist eigentlich überflüssig, Humanismus ist von Anfang an ganz wesentlich eine christliche Erneuerungsbewegung. Und das Heidentum, die Gestaltungen der heidnischen Antike werden für diese Erneuerungsbewegung benutzt.

Dies ist der eine Punkt, der andere betrifft das Verhältnis von Humanismus und Naturwissenschaft. Die Oratio des Celtis haben Sie mit Recht als eine sehr wesentliche deutsche humanistische Programmschrift hingestellt. Sie gipfelt darin, daß Celtis die Philosophia als dasjenige hinstellt, wonach es zu streben gilt. Was ist die Philosophia bei Celtis? Sie ist eine Universalwissenschaft, die alle Bereiche der Wissenschaften umfaßt, also auch die Naturwissenschaften. Das Programm findet man haargenau wieder in dem von Dürer geschaffenen Holzschnitt der Philosophia, der zuerst in den „Amores" des Celtis 1502 publiziert worden ist und später von Celtis noch mehrfach benutzt wurde. Und von da her ergibt sich für mich, daß bis um 1500 in Deutschland, aber auch in Italien, der Humanismus eine integrale Bewegung geworden ist, die auch die Naturwissenschaften mit umfaßt, wobei ich Ihnen, Herr Meuthen, Recht gebe, wenn Sie formulieren, daß auch die Naturwissenschaften zur Menschenbildung als notwendig erachtet wurden. Aber sie wurden deshalb zur Menschenbildung notwendig erachtet, weil man meinte, auch über sie Gott näher kommen zu können, eben auf naturwissenschaftliche Weise. Ob das nun naiv oder töricht gewesen ist, ich meine, darüber brauchte man jetzt nicht zu diskutieren. Jedenfalls scheint es mir so, daß es so gewesen ist, und von daher gesehen ist die Naturwissenschaft ein Bildungskomplex, der bald zum ursprünglichen sprachlich-ethischen Programm des Humanismus hinzutrat. Es ist ein Jammer, daß diese Einheit spätestens im 19. Jahrhundert zerbrochen ist, so daß wir heute immer noch darüber streiten, ob die Naturwissenschaften eine humanistische Dimension haben oder nicht. Wir hätten es leichter in der gegenwärtigen Situation, hätten wir die alte Sicht der Renaissance-Humanisten. Wir wären dann vielleicht auch mit den ethischen Problemen, vor die uns die modernen Naturwissenschaften stellen, weiter.

Meutben: Ihre Fragen erfordern ein neues halbstündiges Referat. Ich möchte versuchen, mich kurz zu fassen. Zur ersten Frage. Ich habe nicht prinzipiell zwischen $\mathrm{Hu}-$ manismus und Christentum getrennt. Ich habe vielmehr gesagt, der Humanismus ist zunächst religiös irrelevant; er ist im speziellen ambivalent, weil er sowohl die heidnische als auch die christlich-antike Tradition aufnimmt, und was Sie gesagt haben, bestätigt das ja. Man braucht nur den Augustinismus als ein wesentliches Element innerhalb des Humanismus zu nennen. Ich glaube, ich bin mißverstanden worden; denn der christliche Humanismus ist ja zur Sprache gekommen, er ist von mir aber auch klar definiert worden, damit man nicht in uferlose Verständnisweisen hineinkommt. Daß Religion, christliche Religion und christlicher Humanismus so ungefähr dasselbe seien, davor wollte ich warnen. Wenn Sie von der Erneuerungsbewegung sprechen, so hoffe ich nicht, daß Sie zu stark zu Toffanin hin tendieren, daß nämlich das ganze von Anfang an als christliche Reaktion gegen die allmählich gottlos werdende Scholastik 
angelegt gewesen sei. Es handelt sich zwar auch um eine christliche Erneuerungsbewegung, aber insofern man die christlichen Elemente eben aus der Antike herauszieht. Ich hoffe, diese Ambivalenz doch ziemlich deutlich gemacht zu haben, die einen christlichen Humanismus überhaupt nur möglich macht, eine Ambivalenz, in der man das Heidnische nicht vergessen darf. Man könnte z. B. lange diskutieren, ob Erasmus für Europa, für unsere Kultur wichtiger geworden ist als Förderer der antiken Tradition insgesamt oder der christlichen Tradition.

Nun das Zweite, die Naturwissenschaften in ihrem Verhältnis zum Humanismus. Gadol ist nicht die einzige, es gibt noch andere, die „ganzheitlich“ denken, so würde ich es einmal nennen. Doch an dieser Stelle habe ich auch auf die Schwierigkeiten des Humanismusbegriffs hingewiesen. Man kann sich definitorisch in dem Sinne einigen, wie $\mathrm{Sie}$ es vorgeschlagen haben. Ich halte mich indessen stärker an Kristeller. Sie meinen, man solle den Humanismusbegriff nicht so eng definieren, und es wäre für die Entwicklung der europäischen Kultur besser gewesen, wenn es nicht so gewesen wäre. Doch ich glaube, die Zweikulturenlehre ist nicht erst Sache unseres Jahrhunderts. Sperone Speroni hat ja bereits im 16.Jahrhundert erkannt, was sich hier anbahnte, nämlich ein Zweierlei. Das ist demnach nicht aufgepfropft, sondern bildet sich im Bewußtsein des italienischen Renaissancetums selbst. Wir müssen uns in diesem Zusammenhang klar verständigen, was Naturwissenschaft ist. Das, was Celtis hier anspricht und was hier betrieben wird, ist sicher etwas ganz anderes, als in Padua gemacht wird, glauben Sie nicht?

Wuttke: Das glaube ich auch.

Meutben: Und wenn wir uns hier definitorisch einigten, was wir unter Humanismus verstehen, dann könnten wir das von Celtis Angesprochene hinzunehmen und sagen: Das ist nicht die Naturwissenschaft als solche, sondern das ist die Integration von naturphilosophischen Überlegungen in das Menschenbild hinein, das dem Humanisten vorschwebt. Das ist eine Ausweitung, die man vornehmen kann. Um aber durch unser Thema hindurchzukommen, den europäischen Humanismus, halte ich es für besser und deutlicher, wenn wir den Humanismus nicht allzu „weit“ definieren, weil man dann nicht mehr weiß, worum es geht. Wenn Sie sagen, das, was Celtis meint, rechne ich dazu, dann wissen wir das, haben aber auch deutlich gemacht, daß der Paduaner Humanismus nichts damit zu tun hat, daß Kopernikus nichts damit zu tun hat. Dann hätten wir klare Grenzen gezogen, die ich sofort akzeptieren würde.

Kreutzer: Ich möchte nur zwei kleine Bemerkungen machen, die vielleicht mehr auf die Verfahrensweise zielen. Wenn man vom Humanismus spricht, Herr Meuthen, ist es dann in vollem Maße befriedigend, wenn man von den Humanisten spricht, indem man ihre schriftstellerischen Charaktere alleine betrachtet, also ihre Schriftstellerpersönlichkeit mit der geschichtlichen Figur im ganzen gleichsetzt? Ergibt sich nicht zumindest eine wesentliche Anreicherung, wenn man auch die geschichtliche Rolle, d.h. den Beruf, die soziale Rolle dieser Figuren mitbedenkt, nicht zuletzt deswegen, weil da höchst verschiedenartige, zum Teil in sich gespannte Verhältnisse bestehen, die dann 
auch ihre Rückwirkungen haben bei vollständiger Interpretation, ihre Rückwirkungen auf das Verständnis der Schriftstellerpersönlichkeit. - Dazu eine andere Frage, die vielleicht auch mehr verfahrensmäßiger Natur ist. Sie haben und Herr Wuttke hat soeben auch die Ingolstädter Rede des Conrad Celtis herangezogen. Wir haben sie immer als Signum einer Epoche interpretiert. Gehen Sie damit nicht sehr stark, fast einseitig auf das Selbstverständnis der Frühhumanisten, Sie nannten sie Hochhumanisten, ein? Herr Wuttke hat die Rede ja zu Recht als eine Programmschrift bezeichnet; damit sind Ideal und Wirklichkeit hinlänglich unterschieden. Ich würde gerne noch einen Schritt weitergehen und das doch geradezu als eine Bildungsutopie ansprechen. Die Epoche ist damit nicht wirklich beschrieben, es steckt in der Rede viel zu viel Postulatcharakter.

Vielleicht zuletzt noch eine dankbare Bekundung des Einverständnisses mit Ihrer „Unendlichkeitsdefinition“ für die Dauer des Humanismus. Ich habe zu Hause auf dem Schreibtisch gerade das verbindliche Lehrbuch der österreichischen Gymnasien für das 19. Jahrhundert liegen, die ,Institutio ad Eloquentiam‘. Das ist ein allgemeines lateinisches Lehrbuch für Sprache, Stil, literarische Gattungen usw. Es ist besonders interessant wegen seiner Listen von Musterautoren, antiken Autoren, auch deutschen. Der meistzitierte Autor ist dabei Klopstock. Ich glaube, ein aus unserem Gesichtswinkel zu vermutender Gegensatz von Christentum und heidnisch-antikem Geist hat die Humanisten nie sonderlich aufgeregt. Die haben sich für bestimmte Autoren interessiert, weil sie ausgezeichnet, weil sie musterhaft, weil sie die besten waren, aber letztlich weniger wegen ihrer Inhalte unter weltanschaulichem Aspekt.

Meuthen: Vielen Dank, das ist eine Bestätigung dessen, was ich gesagt habe. $\mathrm{Zu}$ nächst die zweite Frage. Genau das meinte ich mit dem Selbstbewußtsein der Humanisten. Ich habe gerade vom Selbstbewußtsein der Humanisten aus argumentiert, um verständlich zu machen, wie sie in jenen Jahrzehnten ihre eigene Rolle sahen. Aber Sie bringen mich noch auf etwas, was in Antwort auf Herrn Wuttke zu ergänzen wäre. Wenn Celtis die Naturforschung dort einbezieht, dann nimmt er den ganzen Kreis von Wissenschaften, den ich berührt habe, mit hinein. Aber indem er das tut, ist er noch nicht selber Naturforscher usw. Das ist, so glaube ich, der große Unterschied: Celtis versucht, das, was hier als Bildungsziel aufgestellt wird, von der nationalen, von der historischen Situation aus als das große Wünschbare zu sehen, und immerhin hatte man ja schon einen Agricola, gab es konkrete Anknüpfungspunkte an deutsche Naturforschung, an deutsche Philosophie. Etwas anderes ist: Philosophie jetzt wieder zum Leben erwecken. Ob man solcherlei als allgemein indizierendes Bildungsphänomen in die Nationalgeschichte oder in sein Verständnis der Geschichte insgesamt miteinbezieht, oder ob man selber praktischer Naturforscher ist, das ist sicher ein großer Unterschied.

Nun zur ersten Frage, zur Persönlichkeit. Dieses ganze Problemfeld Humanismus und Gesellschaft habe ich aus Zeitgründen leider ausklammern müssen. Vielleicht bringe ich in den Fußnoten zum Druck dieses Vortrages noch einiges dazu. Man muß diese Fragen natürlich in starkem Maße berücksichtigen, z. B. wie es mit der ständischen Bindung steht. Ich muß aber auch ehrlicherweise sagen: Die Forschung scheint 
mir hier noch sehr im Fluß. Man liest vom Bürgerhumanismus, und andere weisen mit Nachdruck auf den Hofhumanismus hin. Nach dem jetzigen Forschungsstand müßte ich, wenn ich recht sehe, bei einer Zusammenfassung ganz windelweiche Formulierungen benutzen. Auch deshalb habe ich diesen Komplex ausgeklammert, nicht weil ich dem Problem Humanismus und Gesellschaft keine Bedeutung beimesse.

Repgen: Herr Meuthen, Sie haben von der kleinen Intellektuellenschicht gesprochen und dann sehr dezidiert gesagt in Ihrem dritten Teil, das 16.Jahrhundert wurde ein religiöses, theologisch bestimmtes Zeitalter. Das ist ja evident. Ich glaube, man könnte aber, wenn man von den Intellektuellen jetzt weiter geht, breitere Kreise sich anschaut, selbst bei einem Kolloquium, bei dem es nicht um das Reformatorische und Religiöse, sondern das Säkulare geht, ruhig festhalten, daß das 16. Jahrhundert auch für andere Schichten ein religiöses war. Ganz schlicht, das hat eigentlich Klemens Maria Hofbauer schon gesagt, die Reformation konnte sich in Deutschland nur durchsetzen, weil die deutschen fromm bzw. frommer sein wollten. Das widerspricht hier dem gar nicht. Es ist nur nicht von dem ableitbar.

Meutben: Da möchte ich sagen: Ja! Und ich glaube, das habe ich in meinem Vortrag auch sehr deutlich gemacht: Das ganze Jahrhundert, die ganze Gesellschaft ist in dieser Weise religiös. Im 15.Jahrhundert bereitet sich im übrigen vieles schon allmählich vor, was dann im 16.Jahrhundert zum Durchbruch kommt. Die Äußerung von Hofbauer kenne ich nicht; ich nehme sie dankbar in mein Repertoire derartiger Zitate auf. Genauso war es gemeint, in der Durchtränkung bis unten hin.

Baumgart: Ich bin Ihnen dankbar, daß Sie den pädagogischen Charakter der humanistischen Bewegung, ihre Bedeutung als Schulbewegung so stark betont haben. Sie haben sie auch abgehoben, wenn ich das recht sehe, von einer elitären Anfangsphase des deutschen Frühhumanismus oder, wie Sie sagen würden, des europäischen Hochhumanismus in deutscher Ausprägung. Es stellt sich nun, bezogen auf die Thematik unseres Kolloquiums, die Frage, ob diese Zäsur oder Wende zu einer breiten Bildungsbewegung hin in dem Ansatz der Wittenberger Reformatoren, insbesondere Melanchthons enthalten ist oder nicht. Sie haben mit Recht Einzelheiten hier nicht näher diskutiert. Aber ich wollte auf Melanchthon als Universitätsgründer, als Universitätsreformer wenigstens hinweisen. Sie haben außerdem die neuen Schultypen erwähnt. Man kann dabei auch die neuen Gymnasia Illustria vom Typ Straßburgs oder Altdorfs erwähnen; man sollte auch an die neuen humanistisch-pädagogischen Theorien erinnern, etwa Johann Sturm, der wiederum aus Paris kommt, oder David Chryträus nennen. Jedenfalls gibt es da einen sehr breiten Zusammenhang. Mich würde nun interessieren, und das berührt auch das Generalthema dieses Kolloquiums, inwiefern tatsächlich die Reformation als auslösende Kraft gewirkt oder welchen „Stellenwert“, wie man zu sagen pflegt, sie gehabt haben könnte. Ich muß schon sehr vorsichtig ausdrücken, wenn ich den Begriff Reformation hier überhaupt noch einzuführen wage. Ein anderer diskussionswürdiger Gesichtspunkt wäre der, daß Sie sehr stark herausgehoben haben, wie ambivalent die humanistische Bewegung in ihrer religiösen 
Einstellung gewesen sei. Ich würde sagen: Gerade diese Ambivalenz hat sie befähigt, als ein so grundlegendes pädagogisches Element über die sich bildenden Konfessionen hinweg wirksam zu werden. Tatsächlich finden wir dieselben Bildungspläne formaler Art, primär bezogen auf die Dialektik und Rhetorik, sowohl in den neuen protestantischen Fürstenschulen wie in den neuen Jesuitengymnasien; wir finden sie in den humanistischen Grundkursen der Universitätsgründungen des späteren 16. Jahrhunderts und ebenso im reformierten Schulwesen. Dies ist doch wohl gerade die Folge der Ambivalenz, dieses Zurücktreten des religiösen Elements. Wären Sie nun einverstanden, wenn ich behauptete, es handele sich im Grunde um formale Bildungselemente. Inhaltliche Aussagen zu den brennenden Problemen eines Zeitalters, das Sie und andere zu Recht als religiöses Zeitalter charakterisieren, gäbe es hingegen nicht. Der humanistische Charakter der Bildung erlaubt keine Antworten auf die spezifischen Fragen des religiösen 16.Jahrhunderts. Eben deswegen aber war die Wirksamkeit, überspitzt formuliert, der humanistischen Bildungsbewegung so groß.

Meutben: Vielen Dank. Man ist als Referent immer erfreut, wenn die eigenen Gedanken anregend weiterwirken, und das ist in diesem Falle wohl geschehen. Die genannte Ambivalenz ist sicher eine maßgebliche Voraussetzung dafür, daß der Humanismus gemeineuropäisch hat weiterleben und sich in dieser ungeheuren Bedeutung hat entfalten können. Was im einzelnen das Formale und das Inhaltliche angeht, da würde ich allerdings etwas vorsichtiger sein. Ich habe dezidiert auf die Inhalte hingewiesen, die in diese humanistische Bildung eingegangen sind, die antiken Inhalte, nicht nur die Formen; denn ich glaube, daß auch diese Inhalte für die Bildung des Europäers von großer Bedeutung geblieben sind. Zum Formalen gehört die sprachliche Schulung, die sich an den klassischen Vorbildern ausrichtet. Aber es handelt sich nicht um irgendwelche Gedichte, sondern es sind eben klassische Autoren mit klassischen Inhalten. Formales wird hier dem Europäer nicht ohne gleichzeitige Inhalte vermittelt. Man muß das doch wohl zusammensehen. Für die Konfessionen, für die christliche Schule liegt das Problem nicht im Formalen, sondern ohne Zweifel in den Inhalten, und um diese Inhalte macht man sich seine Gedanken, etwa bei der Themenwahl im Theater (Jesuitendrama) und dergleichen. Hier stellt man z. B. alte christliche Märtyrerfiguren vor; aber sie sind eben „alt“, wenn sie den Löwen vorgeworfen werden und sie sich heroisch aufführen. Man nimmt gezielt die Inhalte in starkem Maße aus der Antike, offensichtlich, um die anderen „antiken“ Inhalte zurückzudrängen. Da liegt das eigentliche Spannungsfeld. Im formalen Bereich gilt das nicht so.

Zum ersten, und damit kehren wir zum Gesamtthema zurück. „Dank Luther“, habe ich gesagt, gibt es das konfessionelle Zeitalter. Ich habe nicht formuliert: „mit“ Luther, oder gar: ohne Luther oder einen anderen gäbe es das konfessionelle Zeitalter nicht, habe also auch nicht Stellung bezogen zu der Frage, ob Luther als alleiniger Begründer des konfessionellen Zeitalters anzusehen sei oder ob Luther nicht erst durch das religiöse Interesse seiner Zeit hervorgebracht worden sei. Das sind jedoch zum Teil geschichtsphilosophische Überlegungen, in die wir dann hineinkommen, und ich bitte, mich dort zu dispensieren. Ich halte es lieber mit der handfesten Geschichte, ob hic et nunc jemand Geschichte macht, so interessant die Frage ist, ob er latent konfessionell 
aktualisiert war oder an irgendeiner Stelle geradezu hat aktualisiert werden müssen. $\mathrm{Da}$ der Konfessionalismus sich in diesem starken Maße entwickelte, wurde der $\mathrm{Hu}$ manismus vor ein Problem gestellt, das ihm bis dahin weitgehend unbekannt war. Ihm tritt nun von anderer Seite ein Absolutheitsanspruch entgegen, der in dieser Schärfe und Stärke vorher nicht erhoben werden konnte, weil das Christentum bis dahin in seiner konkreten Darstellung viel selbstverständlicher war. Nun muß es genauer definiert werden und wird darum auch schärfer ausgedrückt. Dadurch wird auch der Humanismus zu genauerem „Bekenntnis“ gezwungen, wozu er vorher nicht veranlaßt war. Nun treiben manche in "Richtungen“ ab, die im konfessionellen Zeitalter nicht mehr vertretbar sind. Auf der anderen Seite nimmt der Humanismus erst jetzt, im konfessionellen Zeitalter, in der Weise Bildungsfunktionen wahr, wie wir sie eben abgehandelt haben, und mit denen er dann eine enorme Bedeutung für die weitere europäische Geschichte erhält.

Boehm: Ich darf kurz zwei Aspekte aufgreifen. Zunächst einen institutionellen. Sie haben, Herr Meuthen, meines Erachtens sehr zu Recht die Bedeutung der Pädagogisierung und Verschulung des Humanismus betont. Hier liegt sicherlich ein gewichtiges Phänomen für die Begegnung zwischen der religiösen und der Bildungs-Bewegung schon vor der Reformation. Wir wissen ja, daß das Kollegienwesen des Spätmittelalters in Deutschland weder vor noch nach der Reformation solch autochthone Formen wie in Westeuropa entwickelt hat, wohl aber im 16.Jahrhundert von Frankreich und den Niederlanden her beeinflußt wurde. Eine bedeutsame Wurzel für die Verbindung von religiöser und humanistischer Reform mit institutioneller Auswirkung war die Devotio moderna: man denkt an das von Hieronymus Busleyden unter Mitwirkung von Erasmus in Löwen gestiftete (oder als Vermächtnis begründete) Collegium Trilinguae. Ein anderer, stärker humanistisch getragener Kollegien-Typ war das Collège Royal in Paris.

Interessant erscheint es mir, daß in der religiösen Bewegung das Internatsprinzip, das Prinzip geschlossener Erziehung zumindest in den unteren Unterrichtsstufen eine Renaissance erlebte, die sich aus westeuropäischen Vorformen beleben konnte. Auf deutschem Boden fand die durch Reformation und Humanismus geförderte Institutionsform des Kollegs westeuropäischer Prägung (Internatsform) Realisation in den Jesuitenkollegien sowie in den protestantischen Pädagogien. Die Regulierung der „Humaniora" in den Jesuiten-Gymnasien, auch ihre Verkürzung, jedoch endgültige Etablierung, hat im katholisch-süddeutschen Raum bis weit in die Neuzeit hinein nachgewirkt im Kanon der „allgemeinen Wissenschaften“, der allgemeinen Bildungsfächer der ehemaligen „artes liberales“, der z. B. an der altbayerischen Universität (IngolstadtLandshut-)München erst seit 1848 abgeschafft wurde.

Ein zweiter, inhaltlicher Aspekt zum Humanismus. Sie haben die Rhetorik stark betont. Es gäbe Ansatzpunkte für eine noch weitergehende Diskussion im Hinblick auf die Erneuerung des Staatsdenkens und des Fürstenideals seit dem Spätmittelalter aus rezeptionsgeschichtlichen Ursachen. Das läßt sich vielleicht nicht so sehr an der Rezeption Ciceros nachweisen, den man ja im Mittelalter ebenso wie im Humanismus gekannt hat, jedoch an Aristoteles: seit dem 13./14. Jahrhundert wird spürbar (etwa bei 
Engelbert von Admont oder Marsilius von Padua), daß die Auswertung der aristotelischen Rhetorik und Politik in der Fürstenspiegel-Literatur in bezug auf die BildungsPostulate für den Herrscher und auch für seine Räte wirksam wird.

Meuthen: Vielen Dank. Das zweite ist ebenfalls den schon genannten Zeitgrenzen zum Opfer gefallen. Es handelt sich um den großen geschichtlichen Hintergrund der Kristellerschen Neuwertung. Von der Rhetorik aus ist uns der italienische Humanismus ganz neu verstehbar gemacht worden. Ich pflichte Ihnen da vollkommen bei. Auch beim ersten bin ich Ihrer Meinung. Ich habe die Gymnasien und Kollegien genannt. Allerdings sind sie in den zweiten Teil des Referats gelangt, und so konnte der Eindruck entstehen, sie seien erst durch die Konfessionalisierung hervorgerufen worden. Das ist natürlich nicht der Fall. Auch hier liegt eine ältere pädagogische Tradition vor. Ich habe darauf hingewiesen, daß sie von Anfang an im Humanismus deutlich ist. Wir können etwa bei Vittorino da Feltre beginnen. Man muß jedoch die Pädagogisierung nicht nur in der Zielsetzung, sondern auch in der institutionellen Verwirklichung sehen. Ist sie dem Humanismus von Anfang an eigen? Neben den von Ihnen genannten vorkonfessionellen Kollegien, wie in Löwen und Paris, haben wir auch in Italien solche Kollegien. Im übrigen leiten die pädagogischen Theoretiker eigene Schulen. Sie haben auf die Monasteria hingewiesen. Hierzu noch der Hinweis auf eine andere Wurzel. An italienischen Universitäten, anderswo ist es wohl auch so gewesen, hatten die Professoren Häuser, in denen Studenten wohnten, die bei ihnen dann auch promovierten. So wissen wir aufgrund neuer Entdeckungen, daß Nikolaus von Kues zusammen mit anderen Studenten im Hause des Professors wohnte, bei dem er sein Examen ablegte. Das war kein besonderer Vorzug, sondern offenbar gang und gäbe. Ich weiß nicht, ob von universitätspraktischen Voraussetzungen her auch hier Vorstufen vorhanden sind, daß der Lehrer direkt auf seine Schüler einwirkte, wieweit wir hier aus dem Bereich des Humanismus auf allgemeine institutionelle Sachverhalte stoßen, die dem Humanismus vorangingen.

Schwarz: Nur ganz kurz, großen Dank Ihnen, Herr Meuthen, dafür, daß Sie für den Humanismus in Deutschland eine Kontinuität gezeigt haben und eine große Gemeinsamkeit trotz der konfessionellen Spaltung und das Ganze auch noch in den europäischen Rahmen eingeordnet haben. Für die Stellung der Reformation zum Humanismus muß man ganz gewiß die besonderen Konstellationen berücksichtigen, in Wittenberg z. B. die junge Universität, die in der Konkurrenz zu Leipzig ein Studium trilingue aufbauen kann. Aber tatsächlich ist es nicht bloß eine Formfrage, sondern auch eine Frage der Inhalte, daß man nun die mit dem Drei-Sprachen-Studium sich erschließenden biblischen Inhalte kritisch gegen die Tradition wendet. Und ich frage mich auch: Welchen Begriff kann man dafür verwenden? Denn der Begriff „biblischer Humanismus" befriedigt mich auch nicht. Aber eben die Bibel wird nun analog zu anderen Texten der Antike gelesen, wobei sich dann auch noch wieder in der Wertung der Bibel Differenzen zeigen zwischen einem Basler oder Züricher Humanismus und dem Wittenberger. Aber die biblischen Inhalte schließen nicht aus, daß man die Beschäftigung der Humanisten mit der antiken Tradition aufgreift, aus Interesse an den 
Dingen, die die antiken Geschichtsschreiber und die Poeten vermitteln, nämlich eine andere Wirklichkeitserfahrung als sie bei Aristoteles, abgesehen von seiner Ethik, vermittelt wird. Die Autoren der Geschichtsschreibung und der Poesie wurden neben der Bibel studiert, so daß es selbst im lutherischen Humanismus nicht bloß zu einer Formalisierung der außerbiblischen Stoffe kommt. Wie die Dinge sich dann ausgeweitet haben, zeigt sich, wenn in Augsburg bei der Durchführung der Reformation auf dem öffentlichen Platz die Figur des Stadtheiligen Ulrich durch eine Neptun-Figur ersetzt wird. Offenbar wurden die humanistischen Bildungselemente eher für geeignet gehalten, im öffentlichen Leben Wirklichkeitsvorstellungen und ethische Ansprüche zu vermitteln, als die mittelalterlich traditionellen, kirchlichen Vorstellungen.

Meuthen: Es gibt eine umfangreiche zeitgenössische Literatur, die das allegorische Erbe der Antike festhält. Wir haben jetzt eine Serie von Nachdrucken dieser Mythographien. Diese Werke wurden natürlich nur gedruckt, weil sie von den Leuten auch gekauft wurden. Das heißt im Fall Augsburg: Alle Mitglieder des Rates usw. wußten schon recht gut, was mit dem Dargestellten gemeint war. 